\title{
Balanced Design Concepts Workshop
}

Richard W. Bukowski, editor

Building and Fire Research Laboratory

Gaithersburg, Maryland 20899

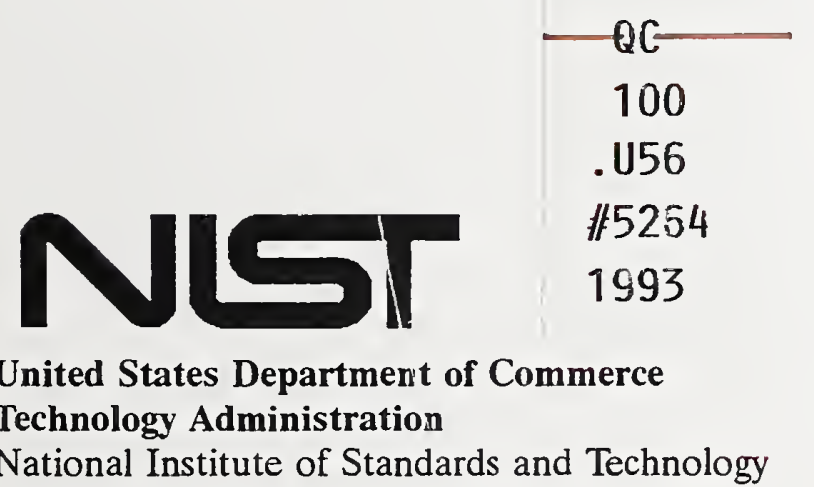

National Institute of Standards and Technology 

NISTIR 5264

\section{Balanced Design Concepts Workshop}

Richard W. Bukowski, editor

September 1993

Building and Fire Research Laboratory

National Institute of Standards and Technology

Gaithersburg, MD 20899

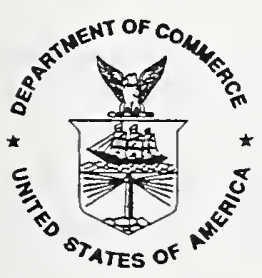

U.S. Department of Commerce

Ronald H. Brown, Secretary

Technology Administration

Mary L. Good, Under Secretary for Technology

National Institute of Standards and Technology

Arati Prabhakar, Director 


\section{Workshop on Balanced Design Concepts}

\section{Preface}

The Fire Administration Authorization Act of 1992 (PL 102-522) assigns the NIST Building and Fire Research Laboratory to conduct a study of the use, in combination, of fire detection systems, fire suppression systems, and compartmentation. The objectives of the study can be separated into three principal tasks. First, to quantify the performance and reliability of detection systems, suppression systems, and compartmentation including the field assessment of performance. Second, determination of the conditions under which reduction or elimination of one or more of these results in unacceptable risk of loss. Third, conduct a comparative analysis of compartmentation using fire resistive and noncombustible construction.

The study is to be conducted and a report thereon submitted to Congress within 30 months after enactment of the law. NIST is required to solicit non-Federal funds to support this effort in the amount of $25 \%$ of the cost, with the remaining $75 \%$ to be obtained from Federal sources and its own appropriated funds. The total cost of the study shall not exceed $\$ 1,000,000$ with the scope of work determined by the level of funding achieved. The study does not commence until receipt on all matching funds from non-Federal sources.

Since this study requires a partnership between public and private organizations for both funding and the development of technical and data resources, NIST organized a workshop to solicit ideas and support, and to assist in coordinating the effort across a broad range of interests. This document contains materials presented at that workshop and notes of the breakout sessions held. Since formal papers were not solicited in order not to limit participation, this proceedings may not be sufficiently explanatory to those who did not attend; but should help those have to organize and operate the project to take full advantage of the wisdom shared by the participants.

At the outset of the workshop, it was unclear that the required level of resources could or would be available to conduct a meaningful study. At the end, the consensus was that the benefits of such a study were sufficient to warrant the investment for most of the organizations present. Thus, the workshop concluded that the project will go forward, officially beginning with the new (federal) fiscal year on October 1, 1993.

The staff of NIST who put on this workshop are grateful for the hard work and willing contributions of the participants in sharing their thoughts and ideas freely with the group. If this same level of cooperation can be maintained throughout the next 24 months of the study, the goals and objectives will surely be met or exceeded. 


\section{Attendees - Workshop on Balanced Design Concepts \\ June 30, July 1-2, 1993 \\ National Institute of Standards and Technology \\ Building and Fire Research Laboratory \\ Gaithersburg, MD 20899}

Gene C. Abbate

New York State Concrete Masonry

Association

Kathleen Almand

American Iron \& Steel Institute

Vytenis Babrauskas

Fire Science \& Technology, Inc.

Don Bathurst

General Services Administration

John R. Battles

Southern Building Code Congress

International

Raymond Bizal

International Conference of Building

Officials

Kenneth E. Bland

American Forest \& Paper Association

Richard W. Bukowski

National Institute of Standards and Technology

Mike Caldwell

American Forest and Paper Association

Jerry Cordasco

Cerberus Pyrotronics

Scot Deal

National Institute of Standards and Technology

Irv Ellner

Cerberus Pyrotronics

Gene Endthoff

National Fire Sprinkler Association

Robert A. Garbini

National Ready Mixed Concrete Association

Richard D. Gaynor

National Ready Mixed Concrete Association
John Gross

National Institute of Standards and Technology

John R. Hall

National Fire Protection Association

Lyle Hamre

Canadian Portland Cement Association

Raymond N. Hansen

U.S. Air Force

John Heslip

National Concrete Masonry Association

Karl D. Houser

Gypsum Association

Ken Isman

National Fire Sprinkler Association

T.T. Lie

National Research Council Canada

Kenneth W. Linder

Industrial Risk Insurers

Robert E. Lister

American Insurance Services Group, Inc.

Dan Madrzykowski

National Institute of Standards and Technology

Irv Mande

Edwards Company

Larry Maruskin

U.S. Fire Administration

Robert Massey

National Concrete Masonry Association

Ronald Mengel

System Sensor

Joseph Messersmith

Portland Cement Association 


\author{
Wayne D. Moore \\ Consultant \\ Frederick W. Mowrer \\ University of Maryland \\ John F. Mueller \\ New York State Office of Fire Prevention \\ and Control \\ Larry Neibauer \\ Automatic Fire Alarm Association \\ Leon Pryzbyla \\ Underwriters Laboratories, Inc. \\ James G. Quintiere \\ University of Maryland \\ Leslie R. Richardson \\ Forintek Canada Corporation \\ Richard Roux \\ Simplex Time Recorder Company \\ Sonny Scarff \\ Marriott Corporation \\ Stephen Skalko \\ Portland Cement Association \\ Jack E. Snell \\ National Institute of Standards and Technology \\ Dave Stroup \\ General Services Administration \\ Mohamed Sultan \\ National Research Council Canada \\ Richard Walke \\ Underwriters Laboratories, Inc.
}

Alex B. Wenzel

Southwest Research Institute

Robert H. White

U.S. Department of Agriculture, Forest Service

Richard N. Wright

National Institute of Standards and Technology 

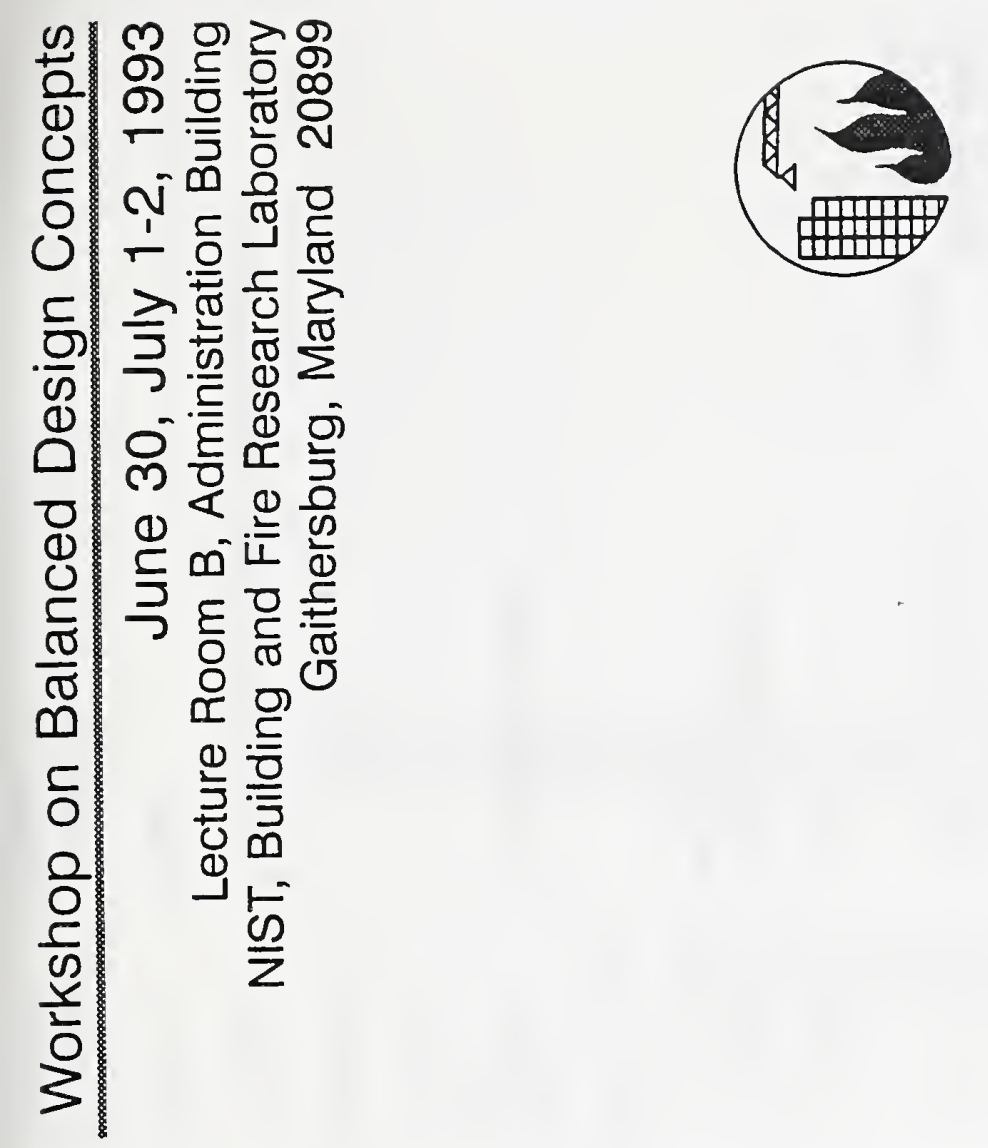

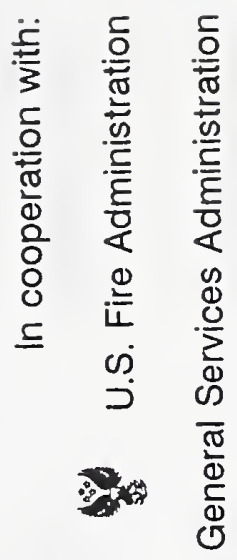

تृن

등 조

0 क

은 논

ธั ธิ

迈

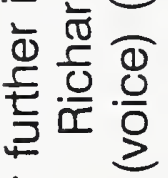

(4)

니 ह

$\infty$

ก่

o

ज़
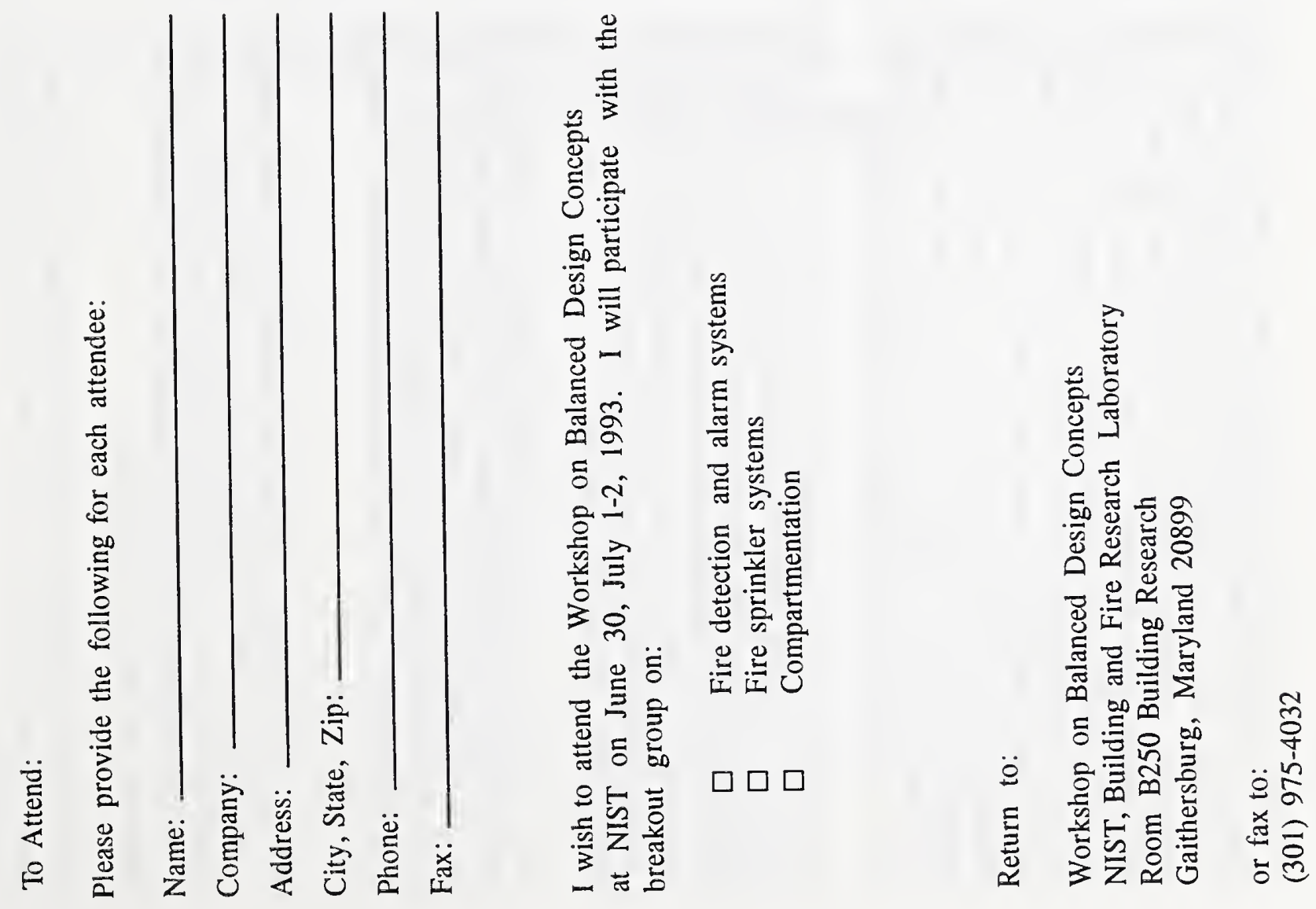


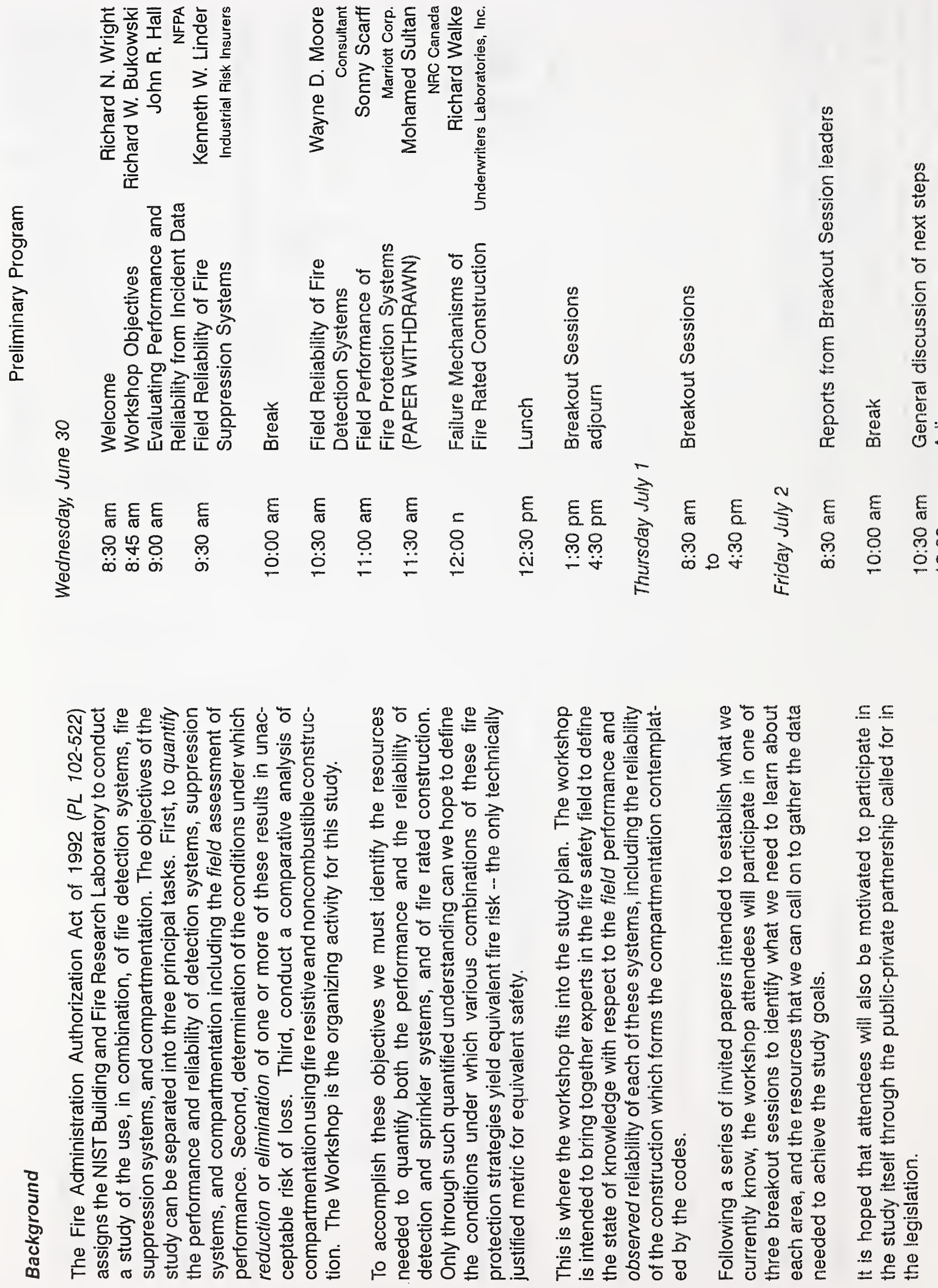




\title{
WORKSHOP OBJECTIVES
}

\author{
Presented by
}

\section{RICHARD W. BUKOWSKI \\ National Institute of Standards and Technology}




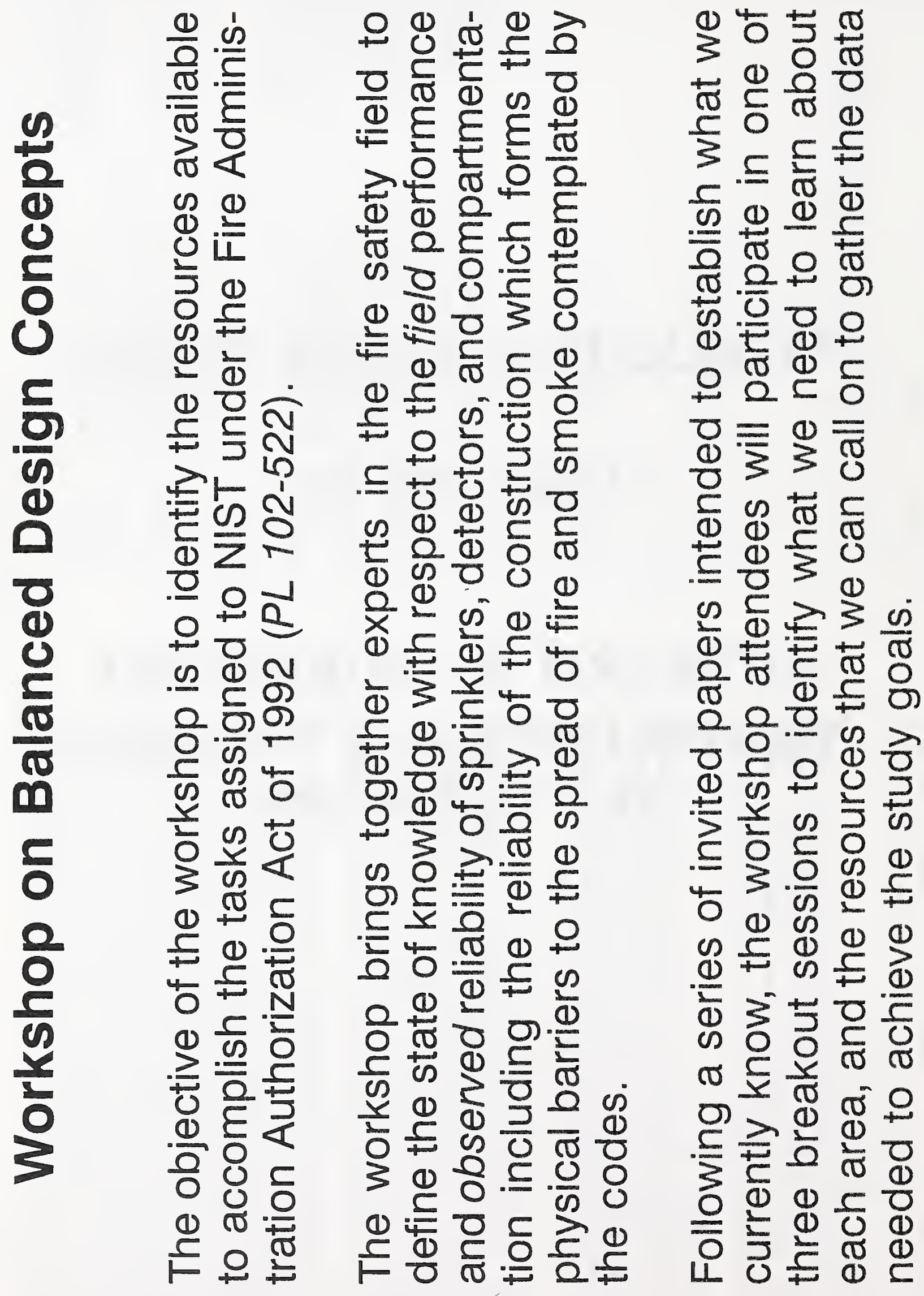




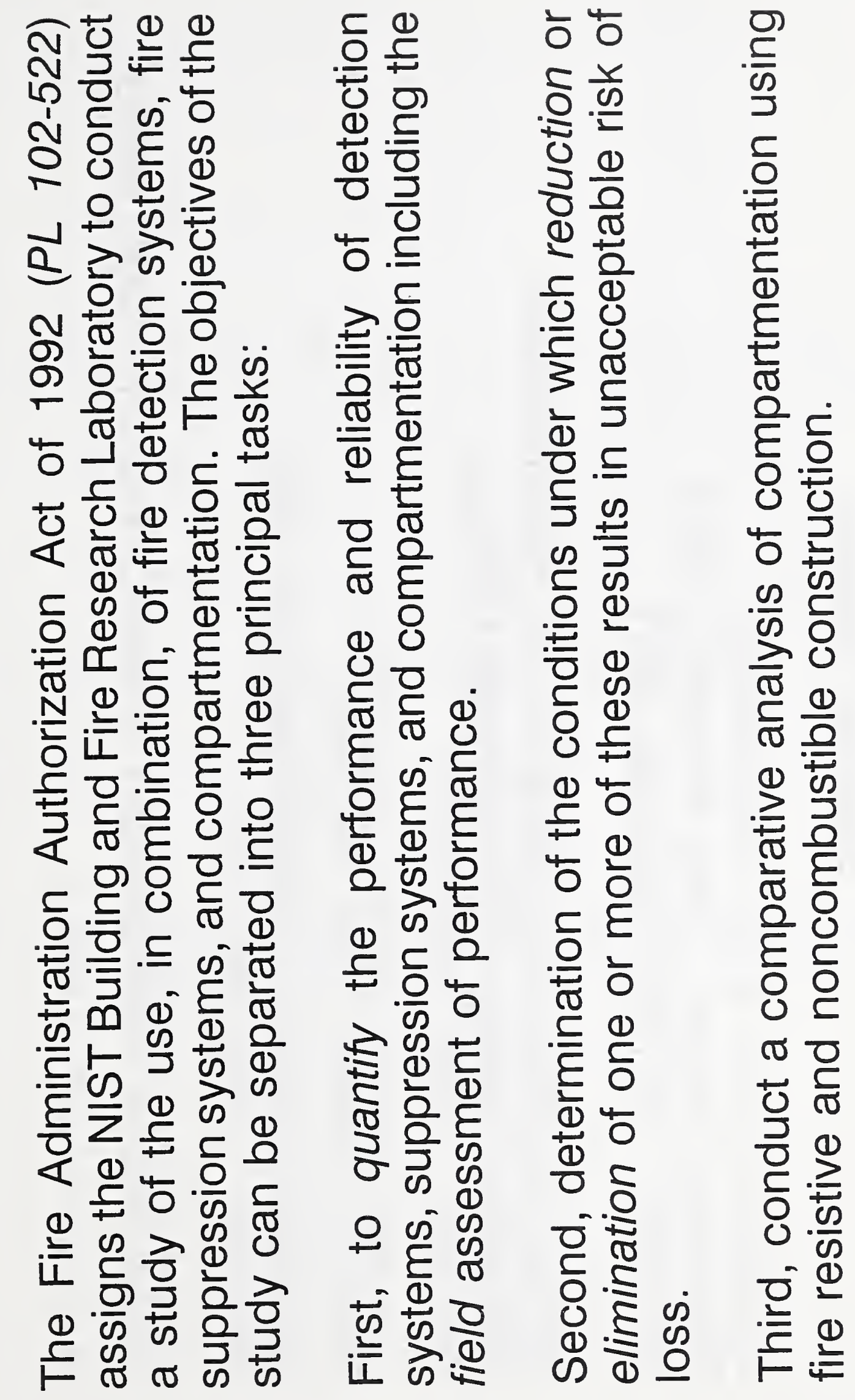




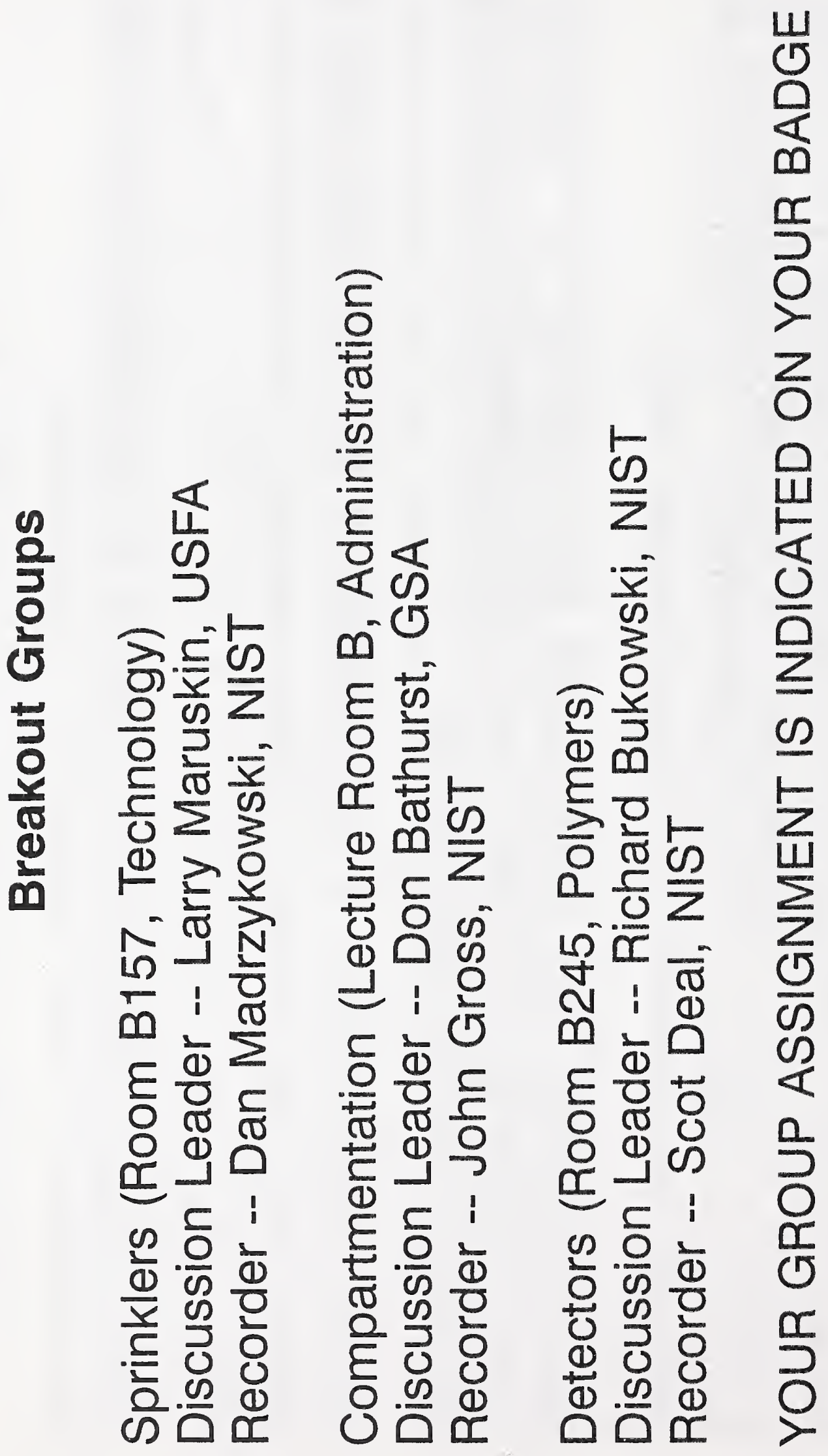




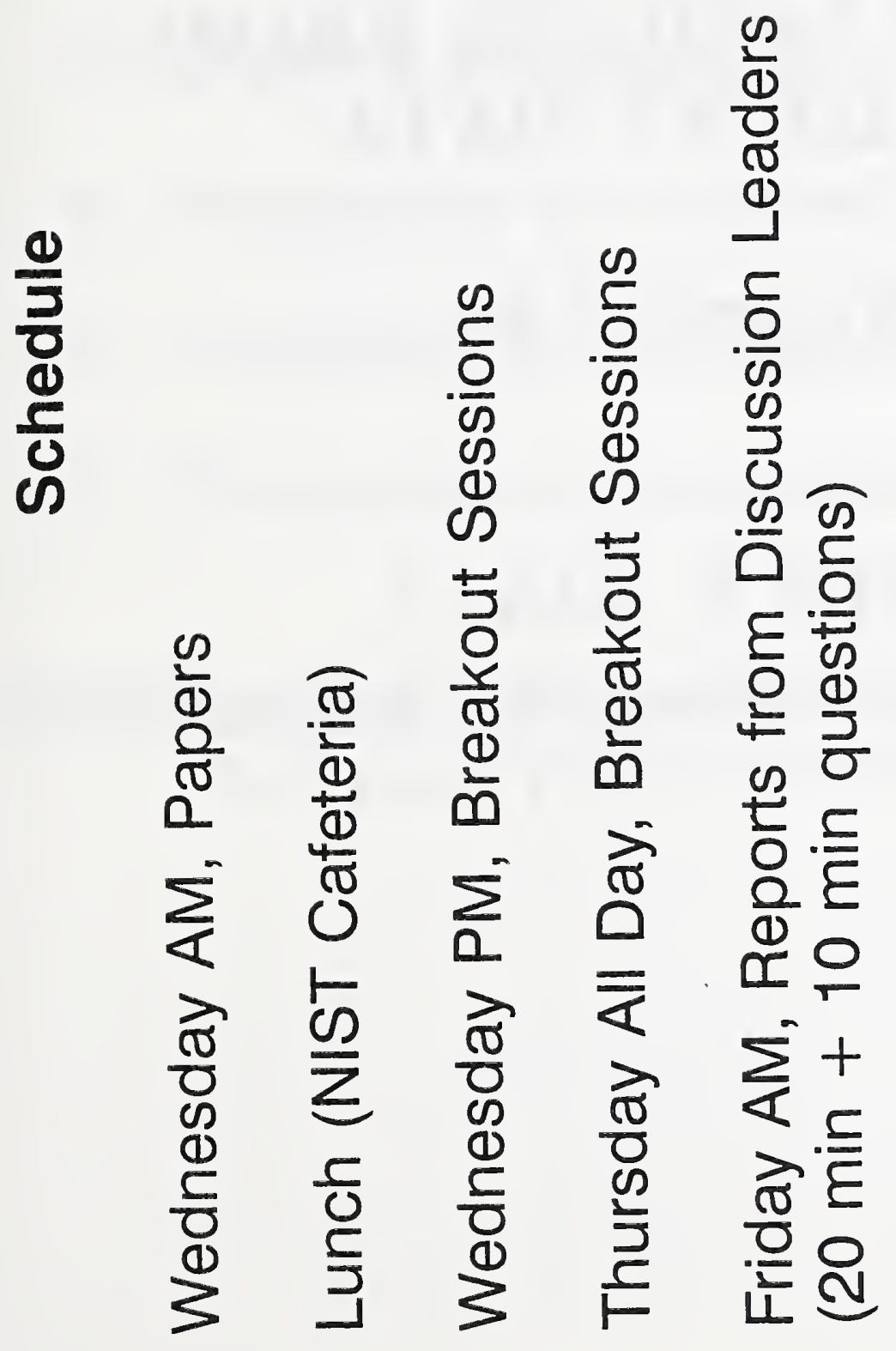




\section{EVALUATING PERFORMANCE AND RELIABILITY FROM INCIDENT DATA}

Presented by

JOHN R. HALL

National Fire Protection Association 
What are the elements of fire safety?

1. Fire prevention

2. Slow growth and spread of fire (contents and furnishings)

3. Detect fires early*

4. Suppress or control fires early*

5. Confine fire in space*

6. Evacuate occupants

* Included in scope definition of "balanced fire protection" 
What are the relevant measures for any element of fire protection?

\section{Probability of use}

Use by all properties, by type

Use, given fire occurs

Degree/type of use

2. Impact of use on fire size

Extent of flame or smoke damage Square feet of damage Time to reach a specified fire stage

3. Impact of use on fire loss

Deaths per 1,000 fires Injuries per 1,000 fires

Property damage per fire

\section{Reliability probabilities}

Performance as designed

Performance but less than designed

Failure to perform at all

Problems or reasons for no performance or less than design performance 
What are the relevant measures for any element of fire protection? (continued)

\section{System effects?}

e.g., Compartmentation support/undercuts sprinkler performance. Design of one has to reflect the other. 


\section{Pros and cons of different data sources}

1. National fire incident data

a. Pros

Best representativeness (given fire)

Good end-measures

Large sample size

b. Cons

Lack of detail

Questions on coding accuracy

2. Special fire incident data bases

a. Pros

Greater detail

More accurate coding

Good end-measures

b. Cons

Questionable representativeness

Small sample size 


\section{Pros and cons of different data sources (continued)}

\section{Special property surveys}

a. Pros

Greater detail

More accurate coding

Adequate sample size

b. Cons

Questionable representativeness

Questionable end-measures

4. Laboratory tests

a. Pros

Greatest detail

Most accurate coding

Adequate sample size

b. Cons

Most questionable representativeness

Farthest from end-measures 


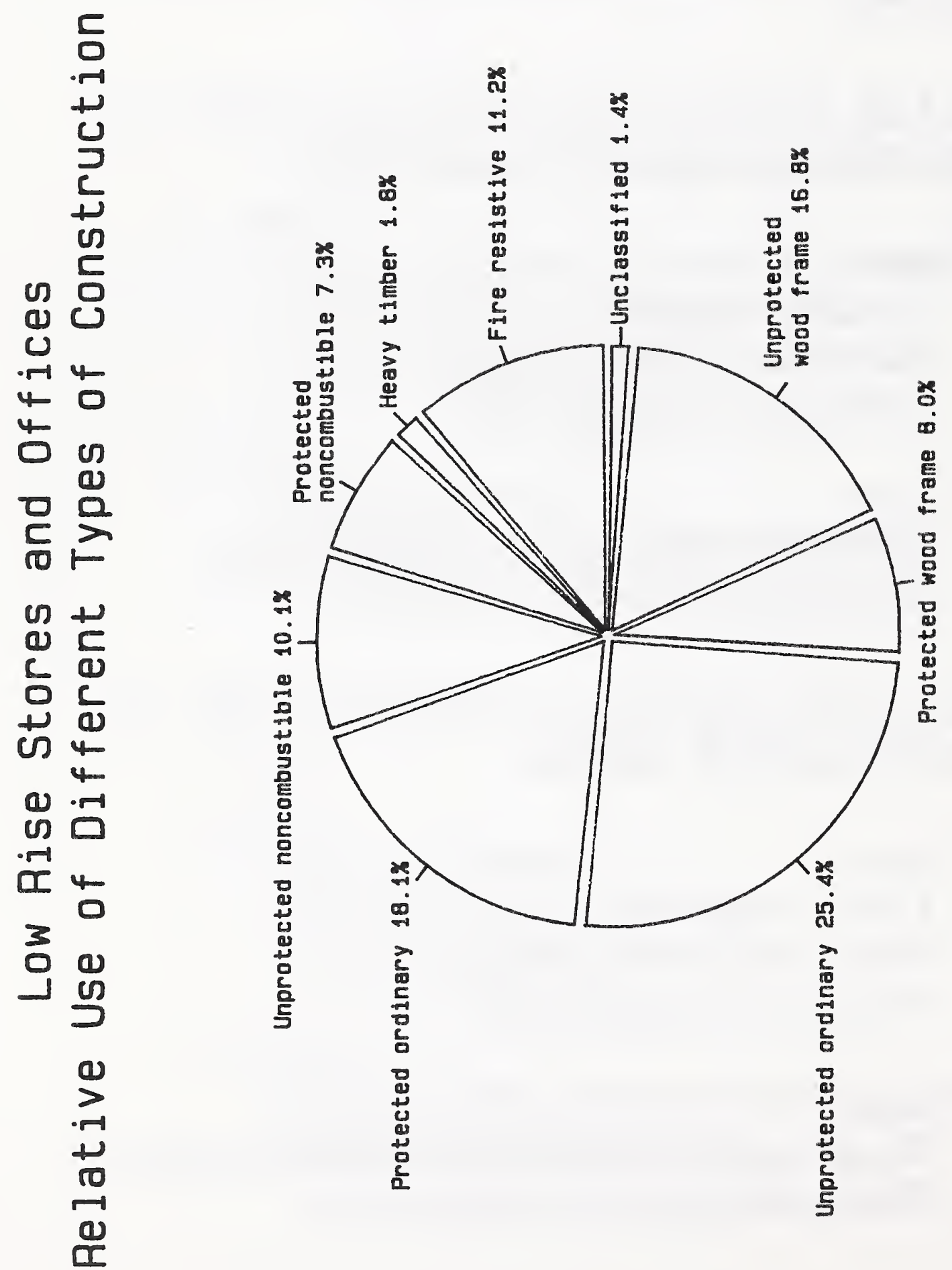

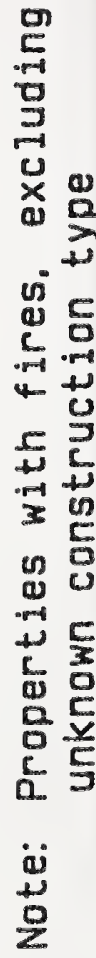




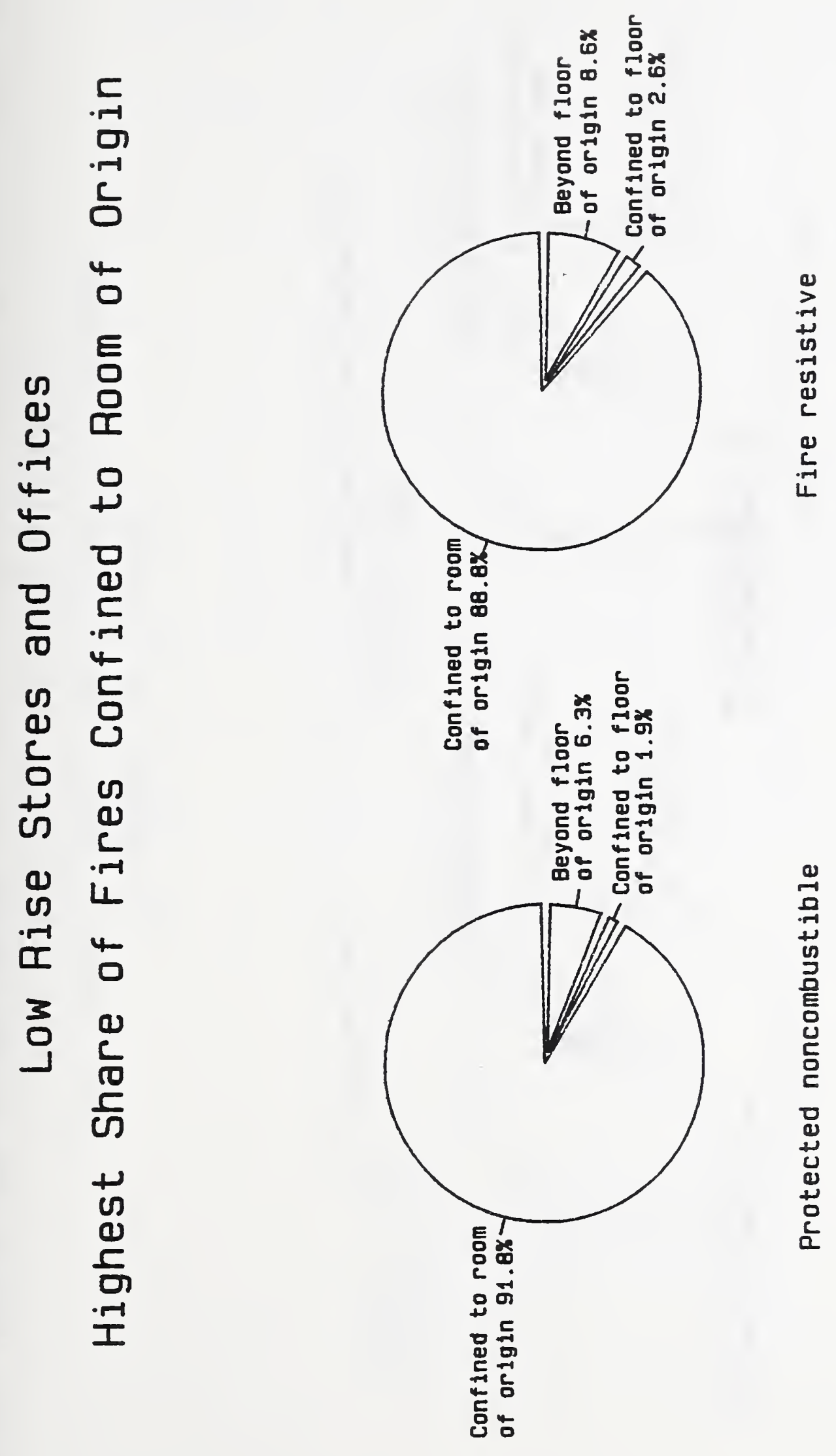

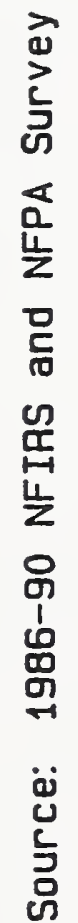




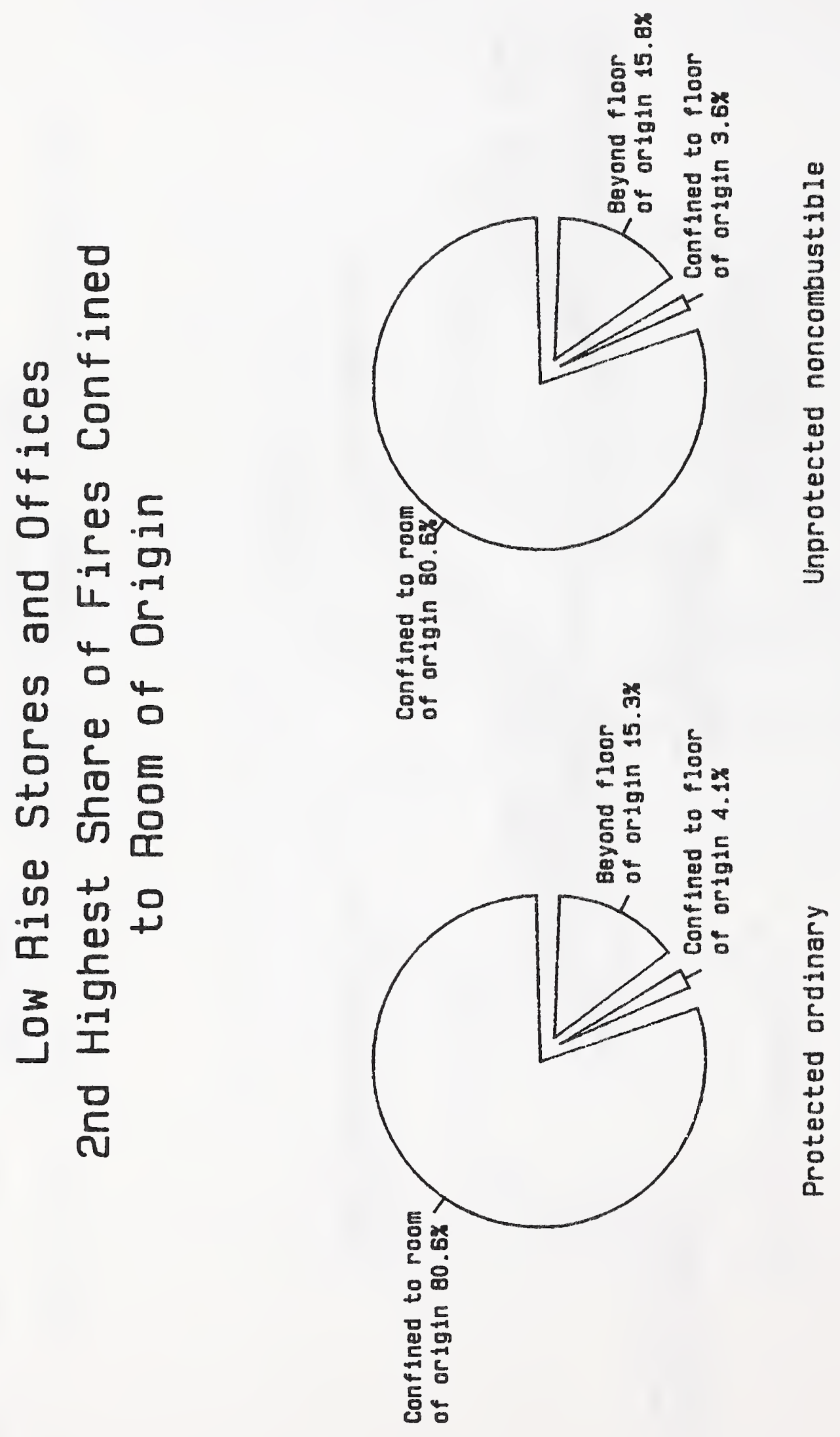




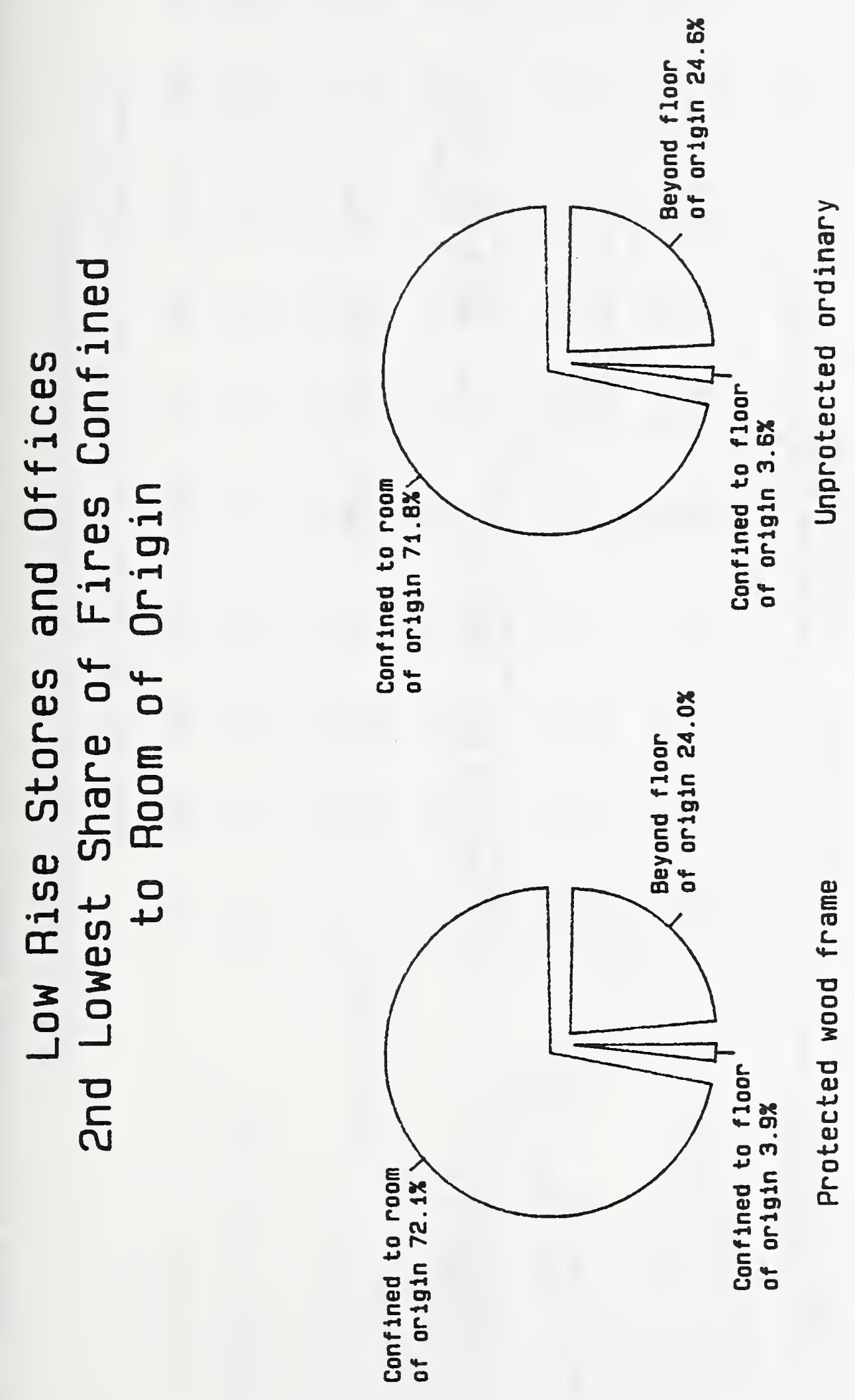



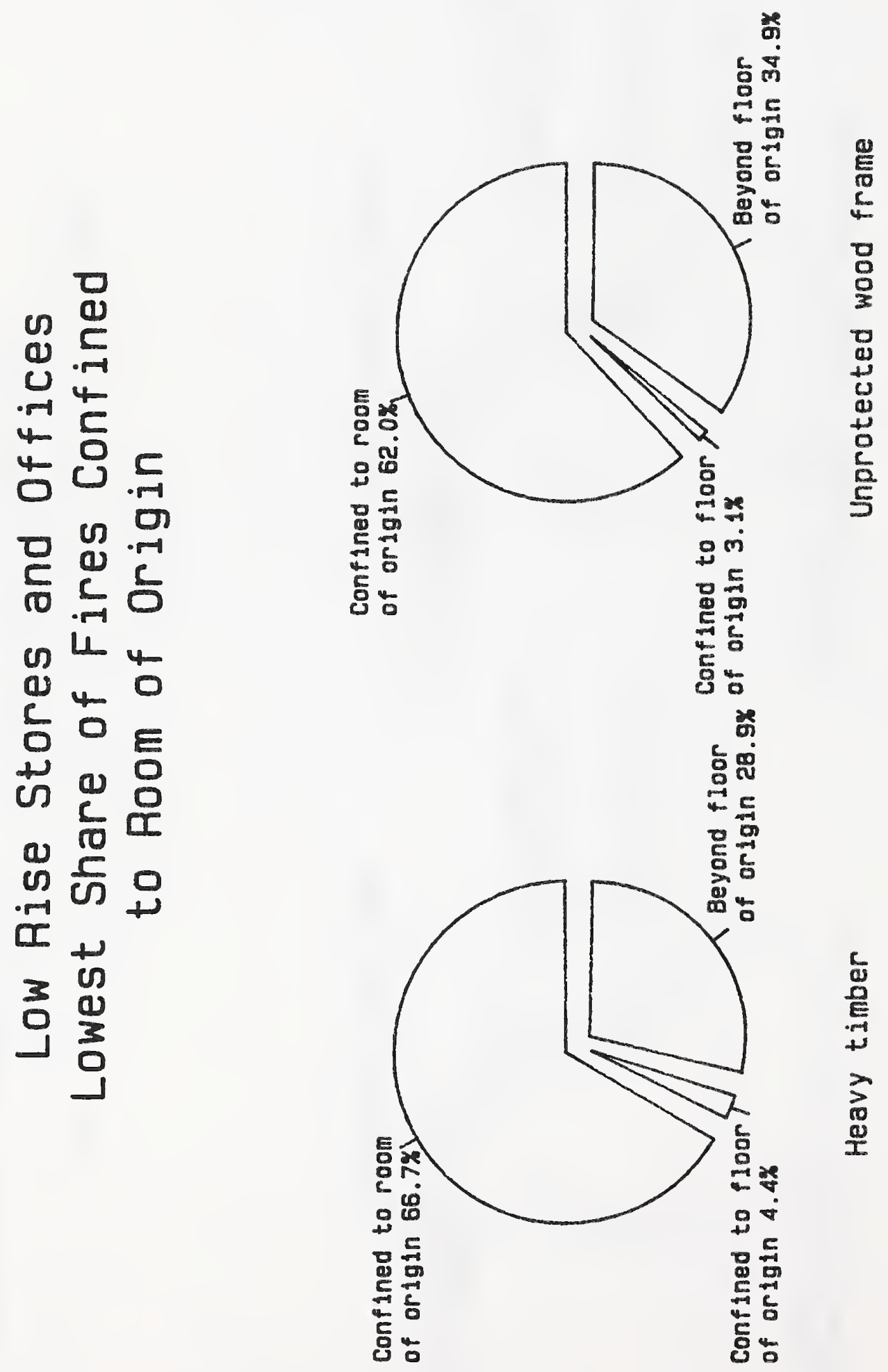


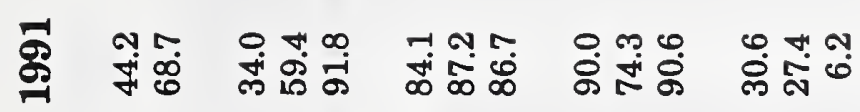

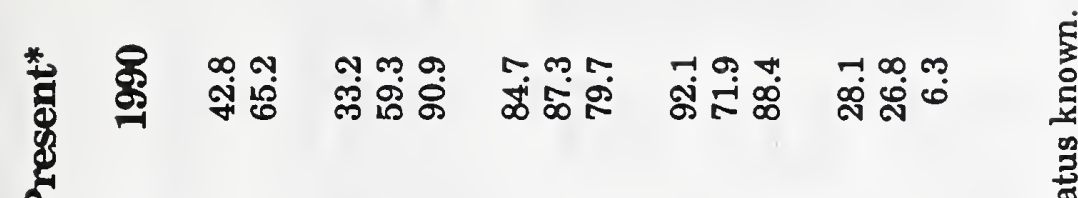

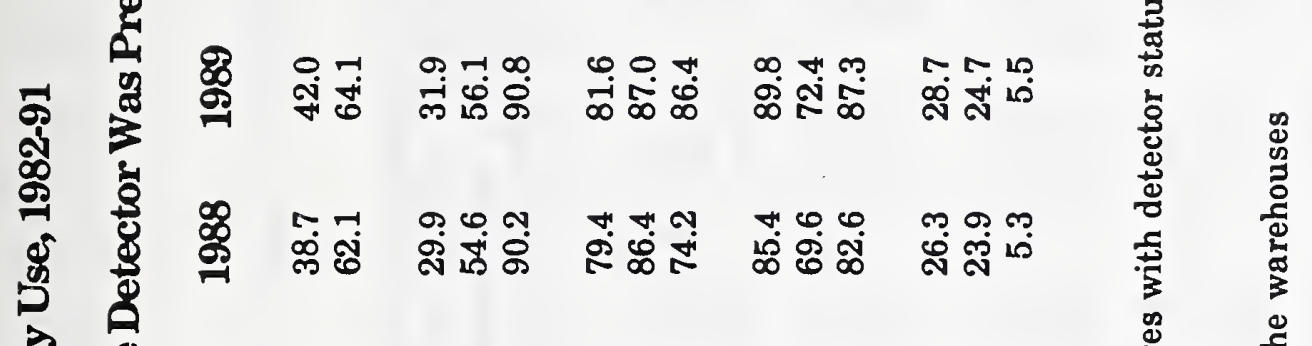

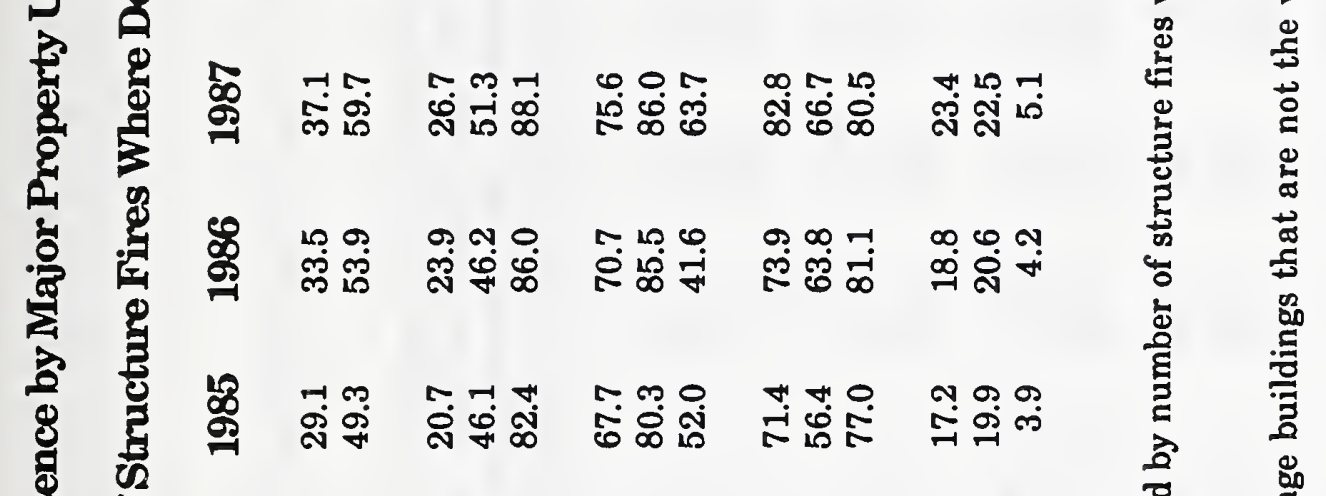

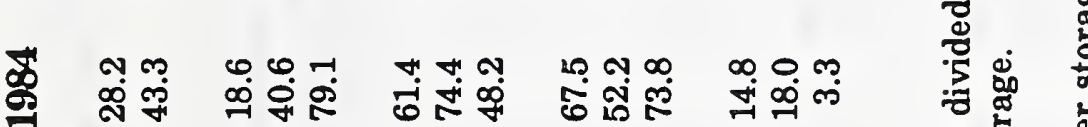

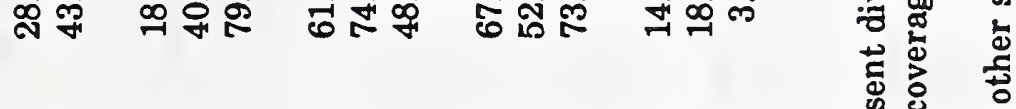

ஜ

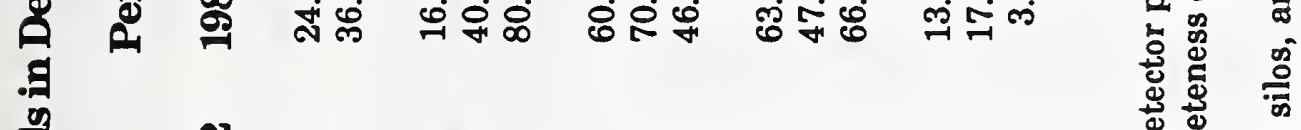

๙ 
6)

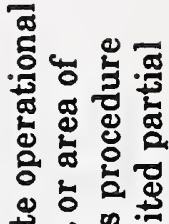

疍

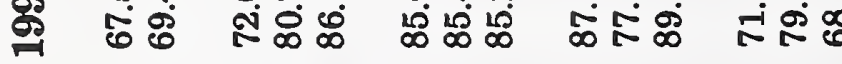

过范

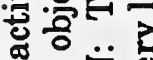

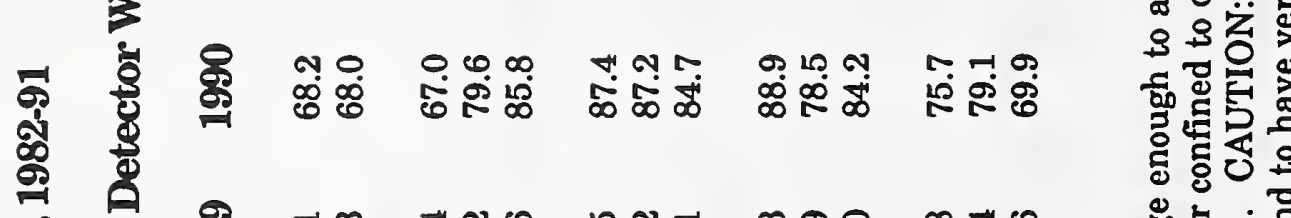

ஜ

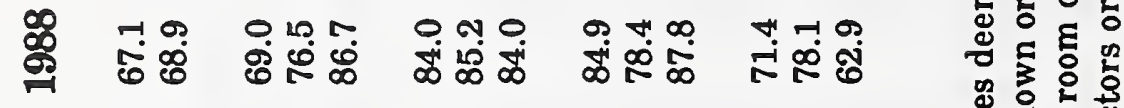

I 유

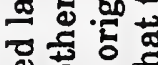

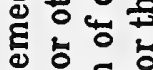

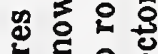

幽

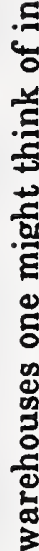

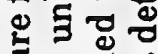

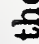

药

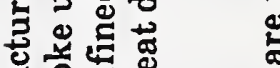

로용용

की

ह

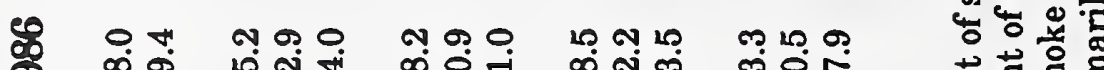

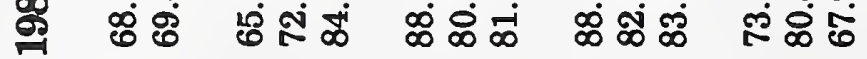

18 น

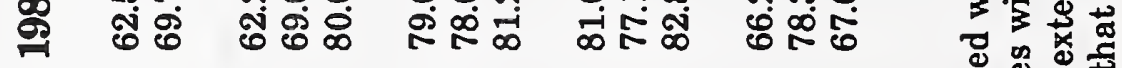

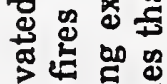

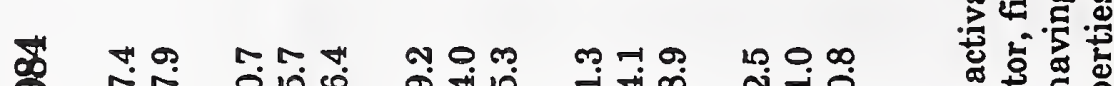

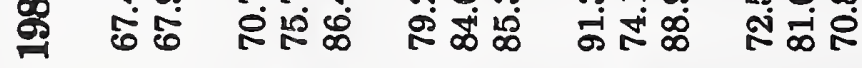

on

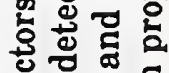

मู

क्न

웅

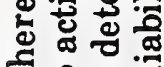

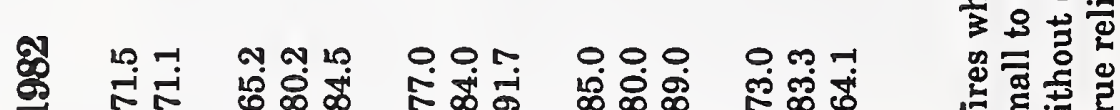

g 형

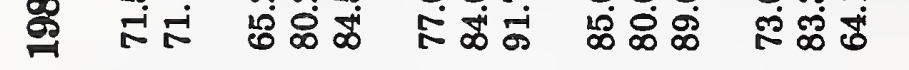

的零

론

귤욜융

苋

产

: 急

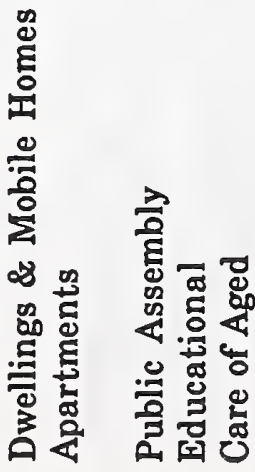

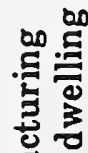

吉总.5 농

됴

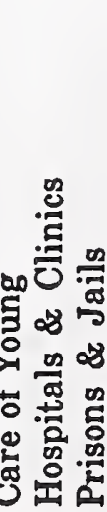

곯 $\frac{0}{9}$

कू

4\%

品整 学

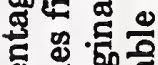

可产.

造 क

\% 웡

造要

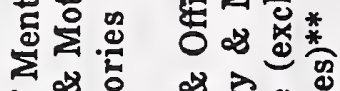

ब进

\& $\overrightarrow{5}$

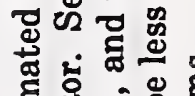

㟧

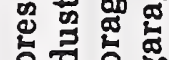

눈

옹 용

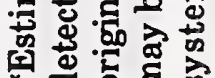

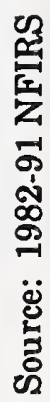

急

क्ष

.

용

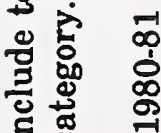

. ฮ

兽站 蛋

完要

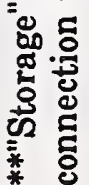

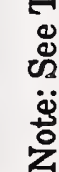


Table 2 Life-Saving Effectiveness of Home Smoke Detectors

Deaths per 100 Fires

\section{Year}

Detectors Present

No Detector Present
How Much Lower is the Death Rate With Detector Present?

$\begin{array}{lll}1980 & 0.54 & 1.00 \\ 1981 & 0.53 & 0.92 \\ 1982 & 0.43 & 0.90 \\ 1983 & 0.55 & 0.90 \\ 1984 & 0.43 & 0.84 \\ 1985 & 0.62 & 1.02 \\ 1986 & 0.55 & 1.07 \\ 1987 & 0.59 & 0.99 \\ 1988 & 0.66 & 1.16 \\ 1989 & 0.65 & 1.06 \\ 1990 & 0.61 & 1.14 \\ 1991 & 0.53 & 0.84\end{array}$

$46 \%$

$42 \%$

$52 \%$

$39 \%$

$49 \%$

$39 \%$

$49 \%$

$40 \%$

$43 \%$

$39 \%$

$46 \%$

$37 \%$

Last Ten Years

Averaged (1982-91)

0.57

0.97

$42 \%$

Source: 1980-91 NFIRS, NFPA Survey 
Table 1. Sprinkler Usage in Hotels and Motels, 1988

Percentage of Hotels With These Areas Sprinklered

Areas of Hotel

Guest rooms (all)

Corridors (some or all)

Public and service areas (some or all)
Large-Chain Hotels Independent Hotels All Hotels

49

41

45

42

33

38

48

49

49

Source: "Fire Protection in the Lodging Industry," Washington, DC: American Hotel and Motel Association, June 30, 1988, pages 6 and 18-19. The "all hotel" figure is provided only for guest rooms but provides a basis for calculating the figures for the other two areas. 


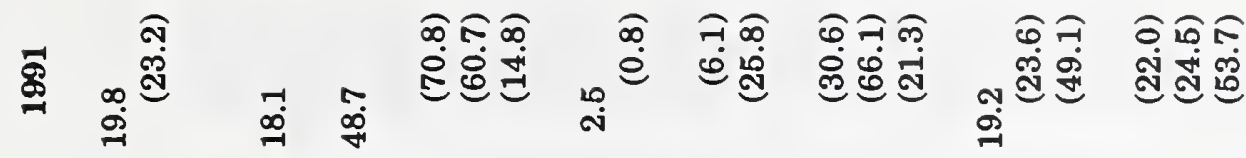

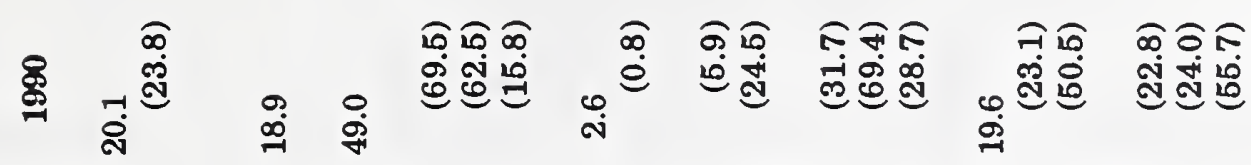
密

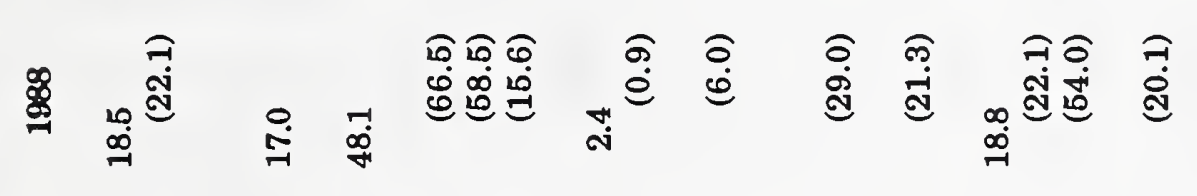

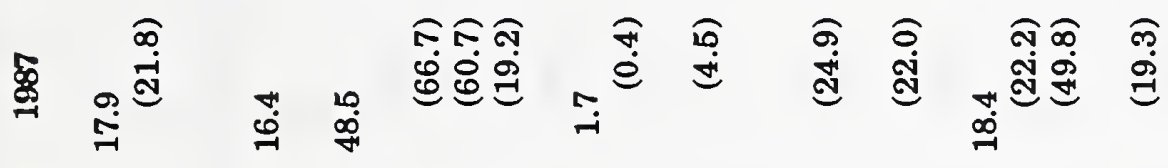

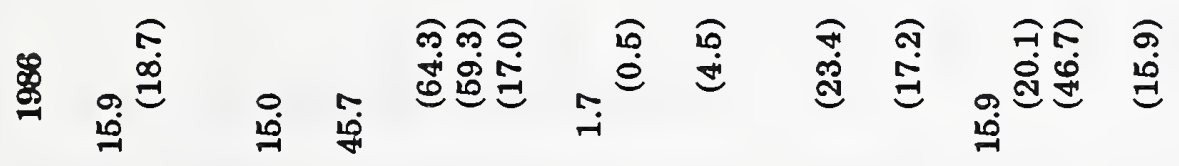

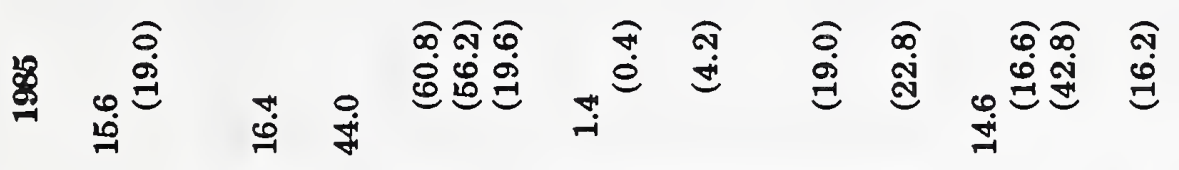

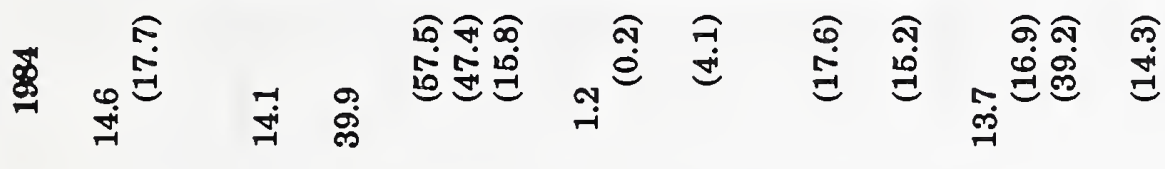

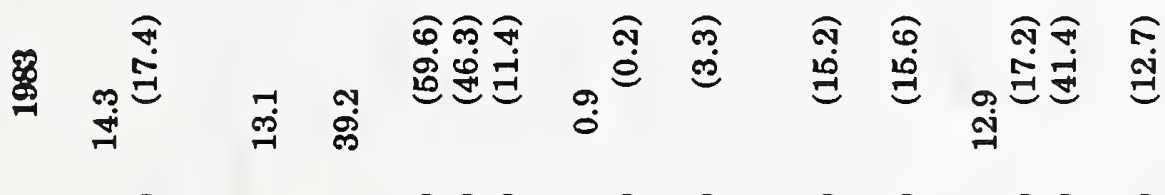

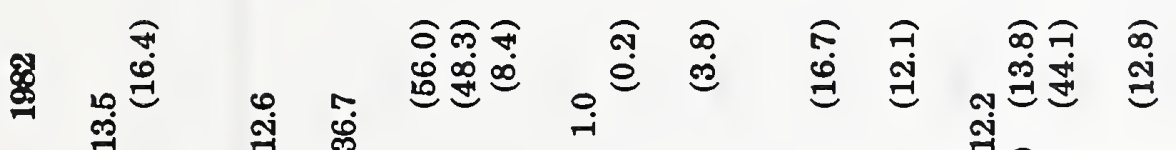

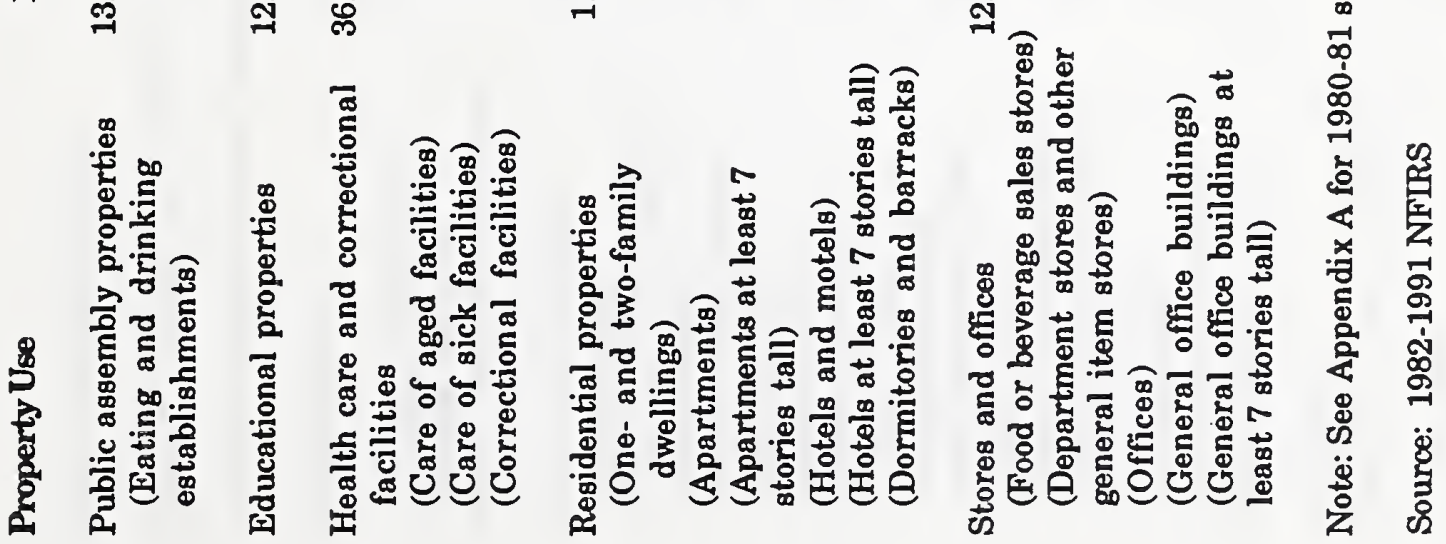




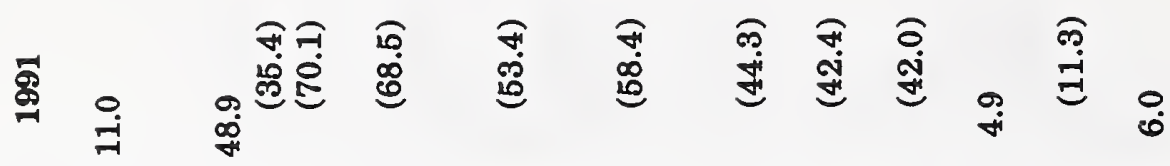

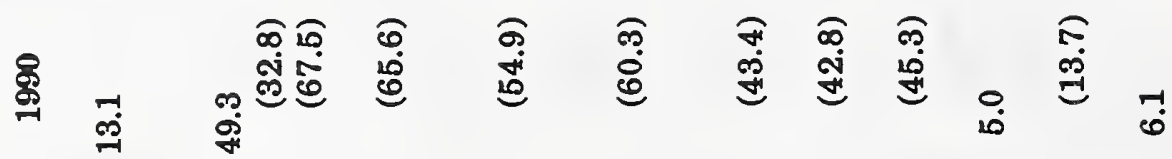

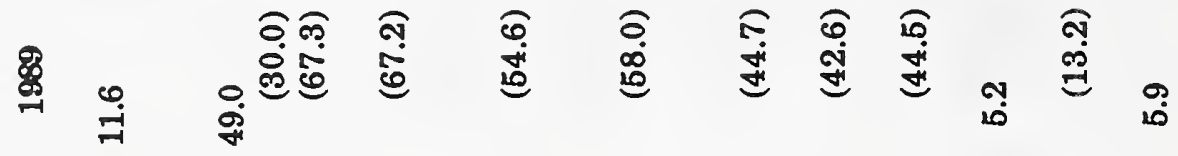

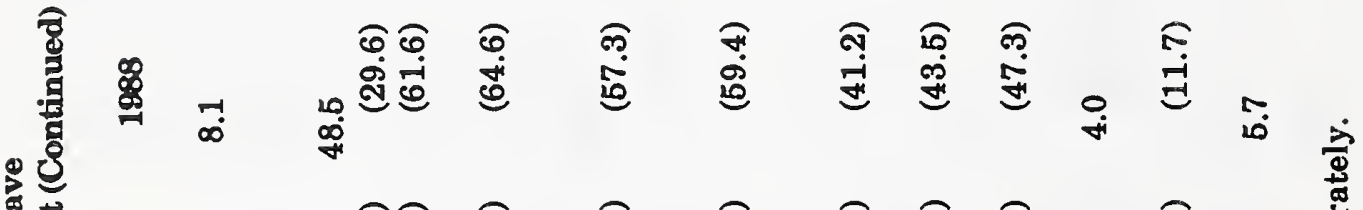

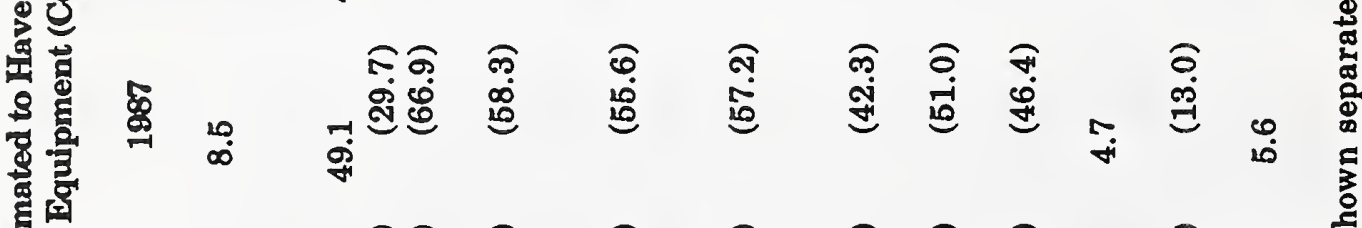

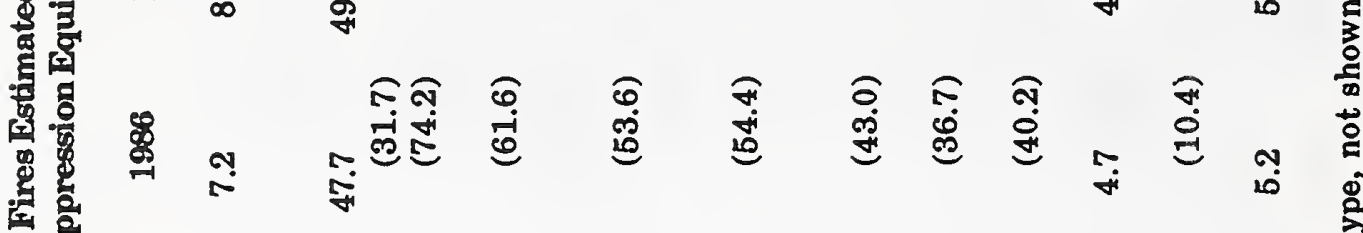

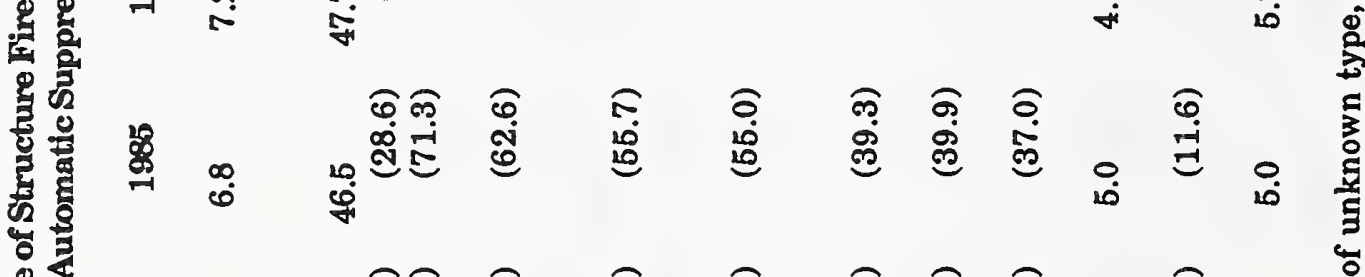

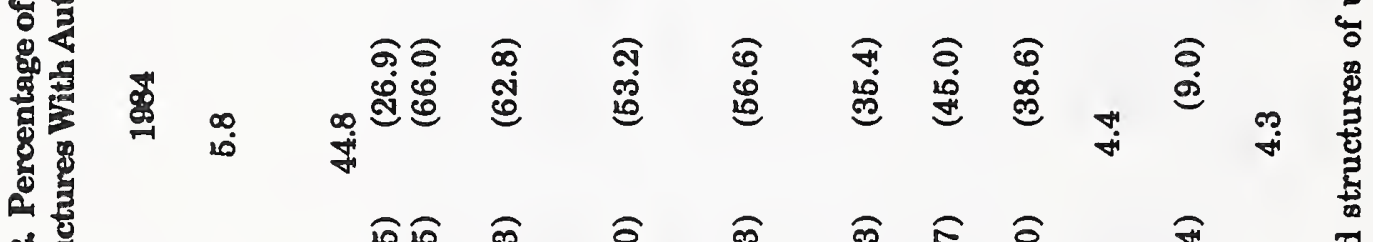

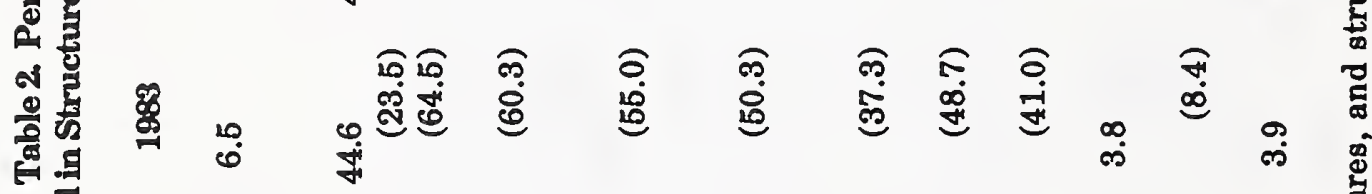

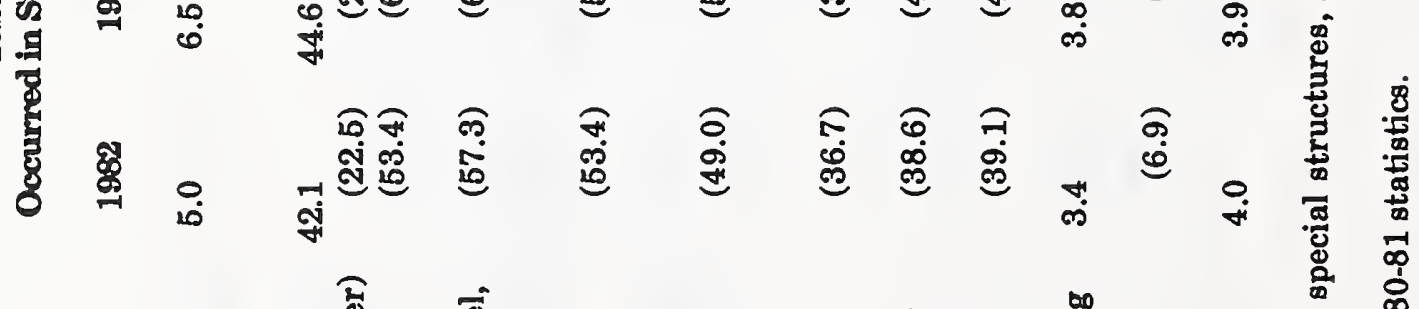

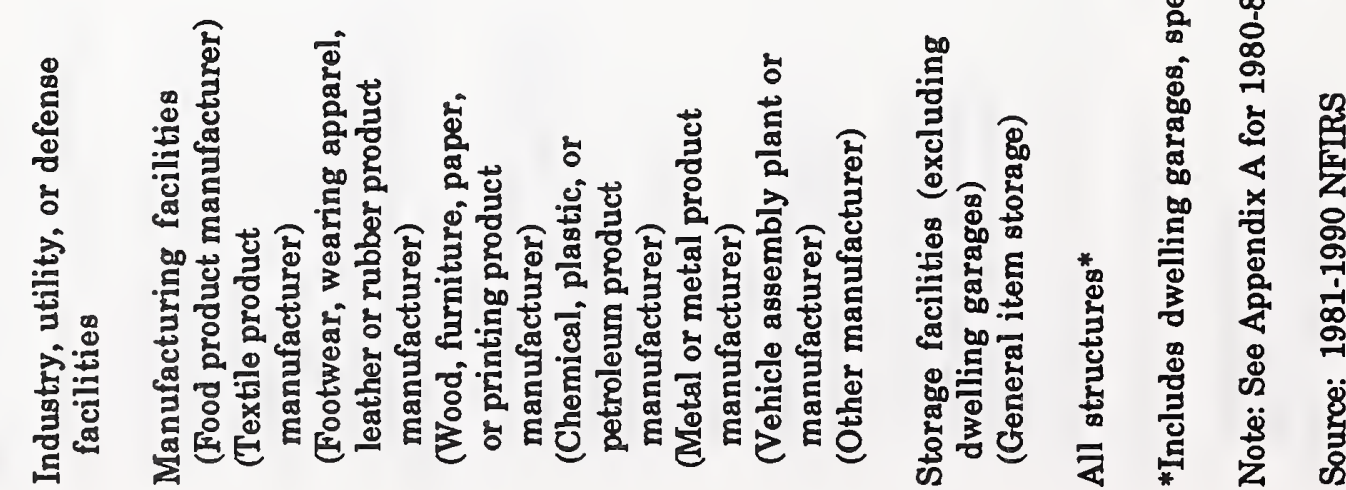


Table 3. Estimated Reduction in Average Civilian Deaths per Thousand Fires

Due to Automatic Suppression Equipment in Selected Property Classes Annual Average of 1982-1991 Structure Fires Reported to U.S. Fire Departments

Civilian Deaths per Thousand Fires

Property Use

Public assembly properties

Educational properties

Health care properties**

Hotels and motels

Stores and offices

Manufacturing properties
Without Automatic Suppression Equipment

1.3
Percent Reduction***

91

$0.4^{*}$

$0.3^{*}$

2.1

2.6

$1.1 \quad 0.4^{*} \quad 65$

$\begin{array}{lll}2.0 & 1.2 & 37\end{array}$

9

51

65

Source: 1982-1991 NFIRS and NFPA Survey

* Based on fewer than two deaths per year in the entire ten-year period. Results may not be significant.

** Refers to care-of-aged and care-of-sick facilities only.

*** Percent reductions calculated before death rates are rounded. 
Table 5. Estimated Reductions in Average Loss per Fire Due to

Automatic Suppression Equipment in Selected Property Classes

Annual Average of 1982-1991 Structure Fires Reported to U.S. Fire Departments

Average Direct Property Damage per Fire

\section{Property Use}

Public assembly properties

(Eating and drinking

establishments)

Educational properties

Health care and correctional

facilities

(Care-of-aged facilities)

(Care-of-sick facilities)

Residential properties*

(Apartments)

(Apartment buildings at least

7 stories tall)

(Hotels and motels)

(Hotels at least 7 stories tall)

(Dormitories and barracks)

Stores and offices

(Food and beverage sales)

(Department stores and other

general item stores)

(Offices)

(General office buildings)

(General office buildings at least

7 stories tall)

Manufacturing properties

(Food product manufacturers)

(Textile product manufacturers)

(Footwear, clothing, leather, or rubber product manufacturers)

(Wood, furniture, paper, or printing product manufacturers)

(Chemical, plastic, or petroleum product manufacturers)

(Metal or metal product

manufacturers)

(Vehicle assembly plants and

manufacturers)

(Other manufacturers)
Without Automatic

Suppression Equipment

$\$ 16,100$

$(\$ 13,400)$

$\$ 11,200$

$\$ 2,400$

$(\$ 2,500)$

$(\$ 2,300)$

$(\$ 6,500)$

$(\$ 2,300)$

$(\$ 10,200)$

(\$7,600)

$(\$ 5,500)$

$\$ 18,000$

$(\$ 15,100)$

$(\$ 24,800)$

$(\$ 16,400)$

$(\$ 18,500)$

$(\$ 28,000)$

$\$ 27,800$

$(\$ 32,600)$
$(\$ 12,300)$
$(\$ 28,100)$

$(\$ 24,400)$

$(\$ 47,800)$

$(\$ 23,300)$

$(\$ 46,900)$

$(\$ 21,000)$
With Automatic

Suppression Equipment

$\$ 6,200$

$(\$ 4,400)$

$\$ 3,300$

71

$\$ 800$

65

(62)

$\$ 10,500$

$(\$ 4,100)$

$(\$ 12,400)$

$(\$ 6,400)$

(61)

$(\$ 8,700)$

$\$ 12,900$

53

$(\$ 18,600)$

$(\$ 33,200)$

$(\$ 14,300)$

$(\$ 9,800)$

* The overall percentage of fires in residential properties with automatic suppression equipment reported as present is too small to put in this table, but results for selected sub-classes of residential properties are meaningful.

** Simple statistical analysis does not show favorable effects of sprinklers because losses are dominated by one or two large-loss fires, each involving valve shut-off, an initial explosion, or fire origin in unsprinklered concealed spaces. See discussion in text. 
Table 6. Leading Reasons When Sprinkler Performance Is Unsatisfactory

\section{Problem}

Water shut off

System not adequate for level of hazard in occupancy

Inadequate water supplies

Inadequate maintenance

Obstruction to water distribution

System designed for partial protection only

Faulty building construction

Antiquated system

Slow operation

Defective dry-pipe valve

Exposure fire

System frozen

Other or unknown

Total

Source: "Automatic Sprinkler Performance Tables, 1970 Edition," Fire Journal, July 1970, page 37. Based on 3,134 fires reported to NFPA during 1925 to 1969 for which sprinkler performance was deemed unsatisfactory. Of these, $75.0 \%$ were in industrial facilities, $12.0 \%$ were in storage facilities, $5.6 \%$ were in stores, and $7.4 \%$ were in all other properties.
Percentage of Cases

35.4

13.5

9.9

8.4

8.2

8.1

6.0

2.1

1.8

1.7

1.7

1.4

1.9

100.0 


\section{Problem Group}
A. Failure to maintain operational status of system

B. Failure to assure adequacy of system for complete coverage of current hazard

C. Defects affecting but not involving sprinkler system

D. Inadequate performance by sprinkler system itself

E. Other

Total

\author{
Percentage \\ of Cases
}

53.4

21.6

15.9

5.6

3.6
Problem

A1. Water shut off

A2. Inadequate maintenance

A3. Obstruction to water distribution

A4. System frozen

B1. System not adequate for level of hazard in occupancy

B2. System designed for partial protection only

C1. Inadequate water supply

C2. Faulty building construction

D1. Antiquated system

D2. Slow operation of sprinklers

D3. Defective dry-pipe valve

E1. Exposure fire

E2. Other or unknown
Percentage

of Cases

35.4

8.4

8.2

1.4

13.5

8.1

9.9

6.0

2.1

1.8

1.7

1.7

1.9

100.0

Source: "Automatic Sprinkler Performance Tables, 1970 Edition," Fire Journal, July 1970, page 37 . Based on 3,134 fires reported to NFPA during 1925 to 1969 for which sprinkler performance was deemed unsatisfactory. Of these, $75.0 \%$ were in industrial facilities, $12.0 \%$ were in storage facilities, $5.6 \%$ were in stores, and $7.4 \%$ were in all other properties. 


\title{
FIELD RELIABILITY OF FIRE DETECTION SYSTEMS
}

\author{
Presented by
}

\section{KENNETH W. LINDER Industrial Risk Insurers}




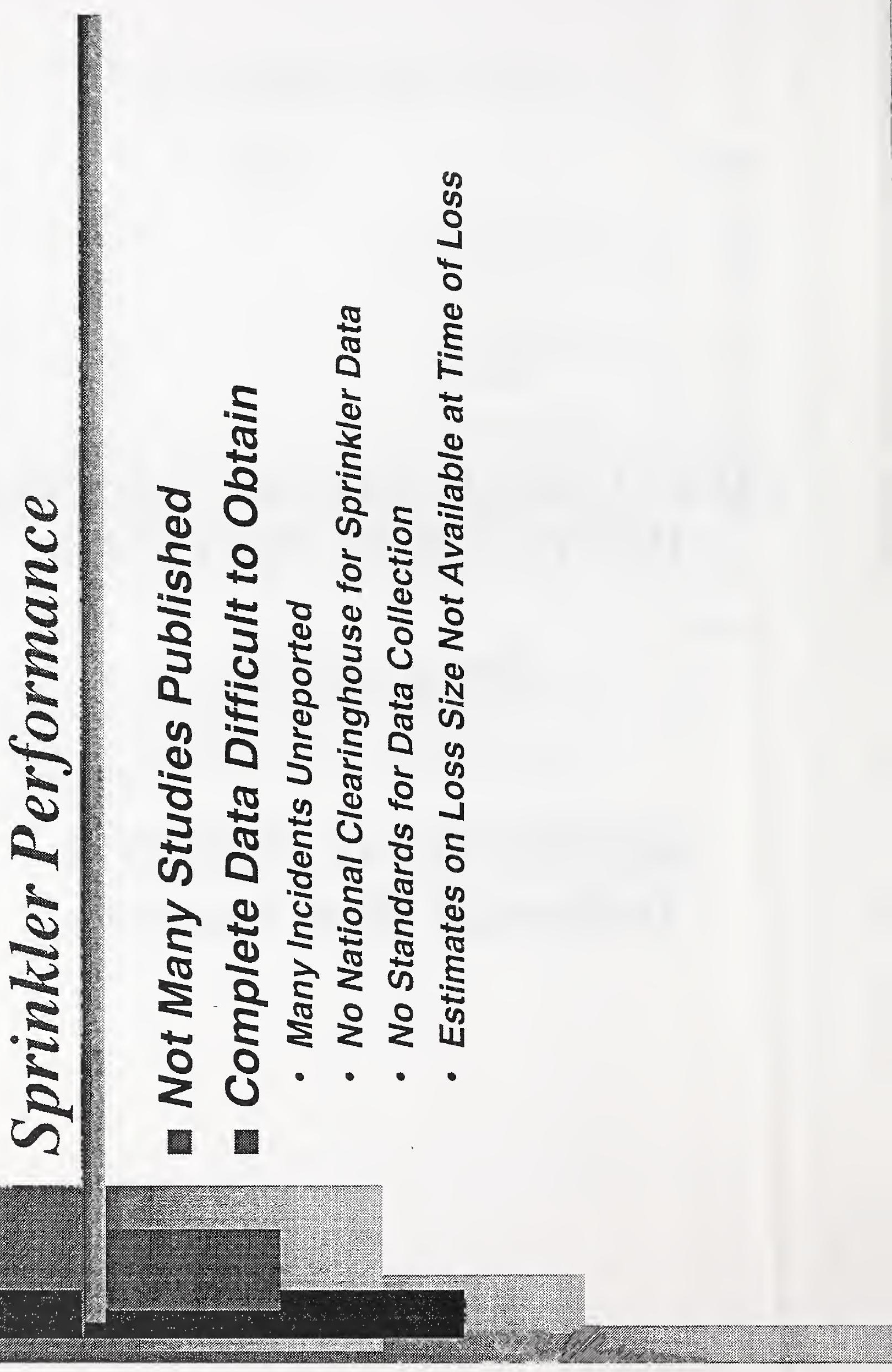




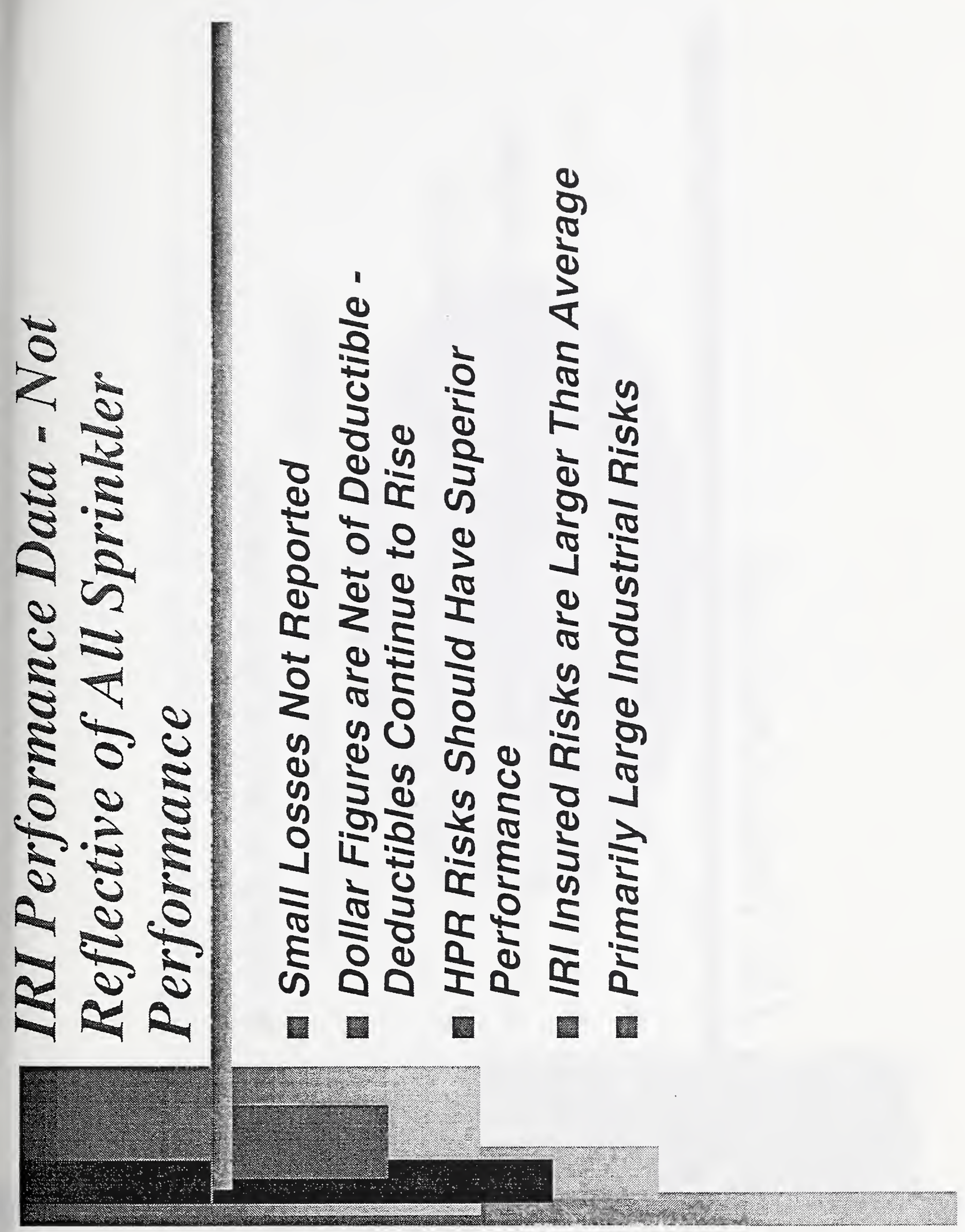




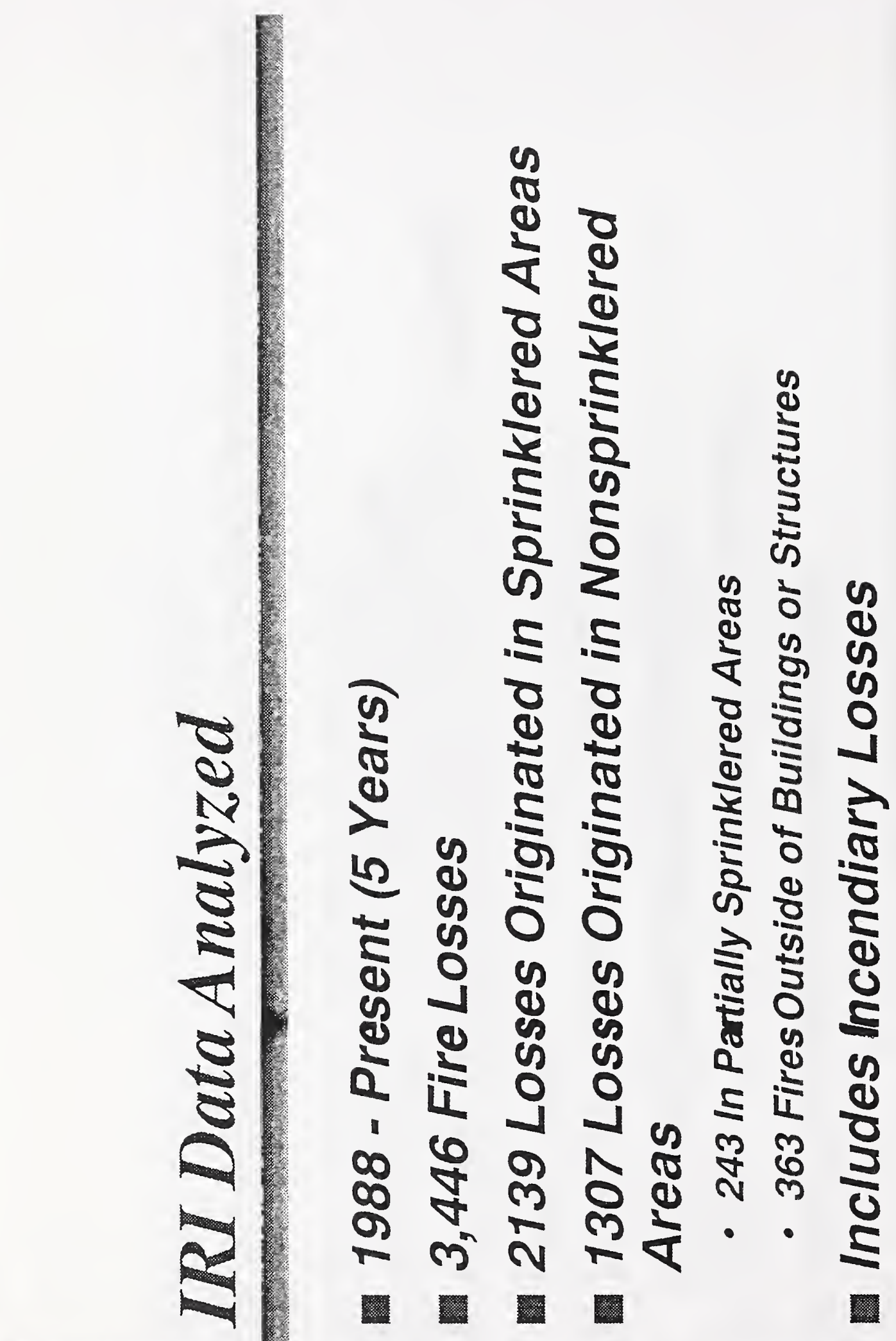




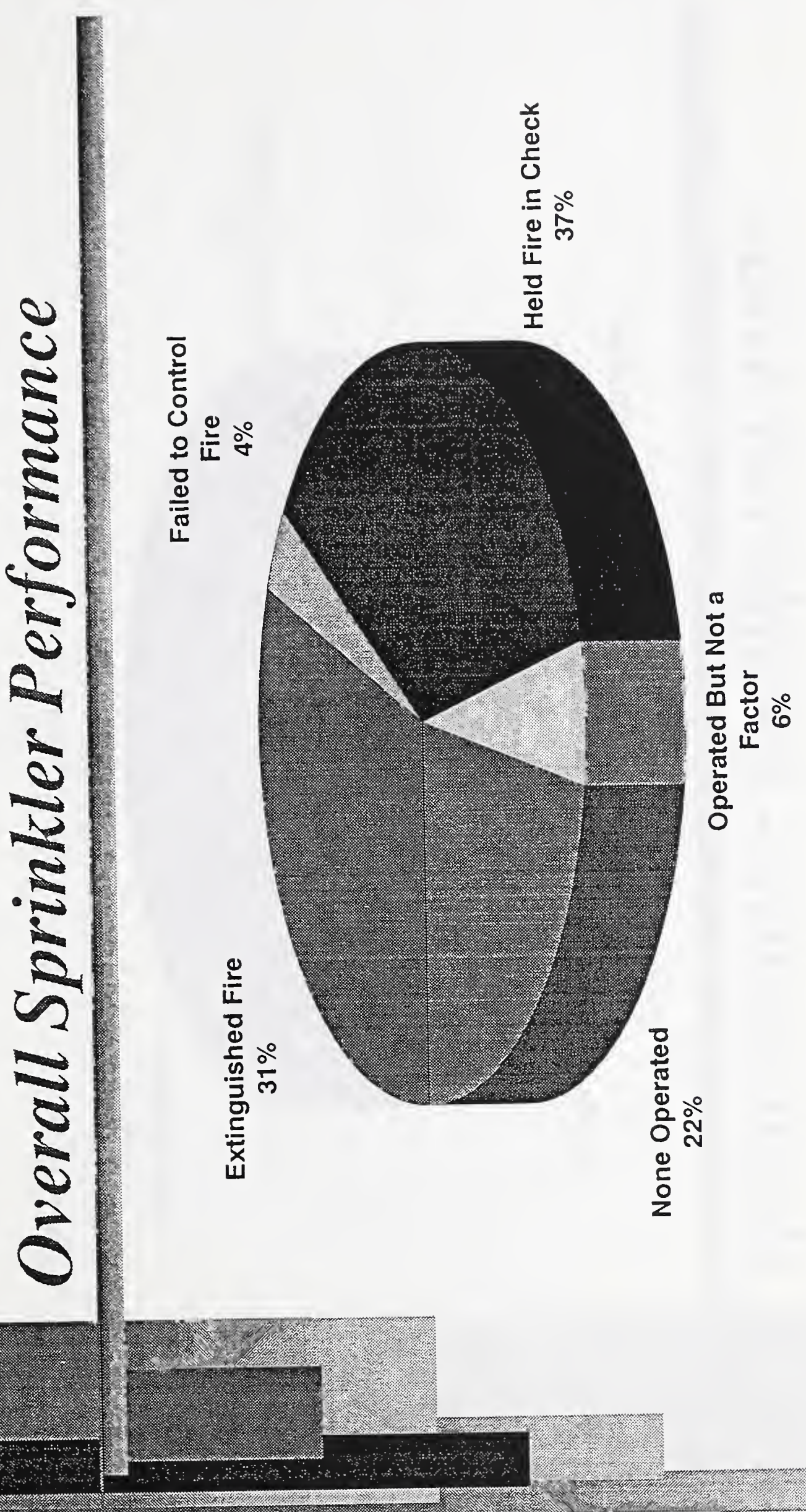




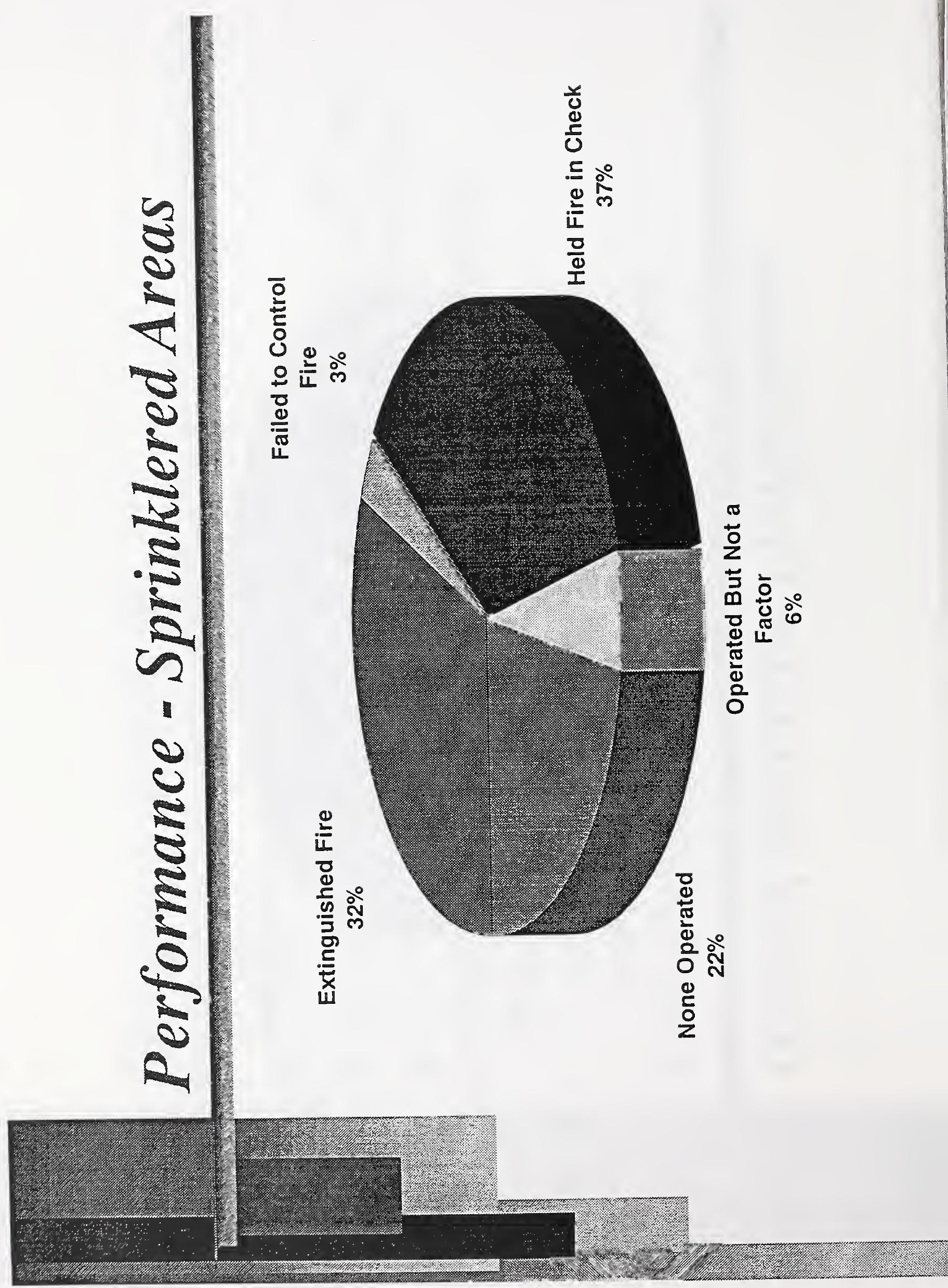



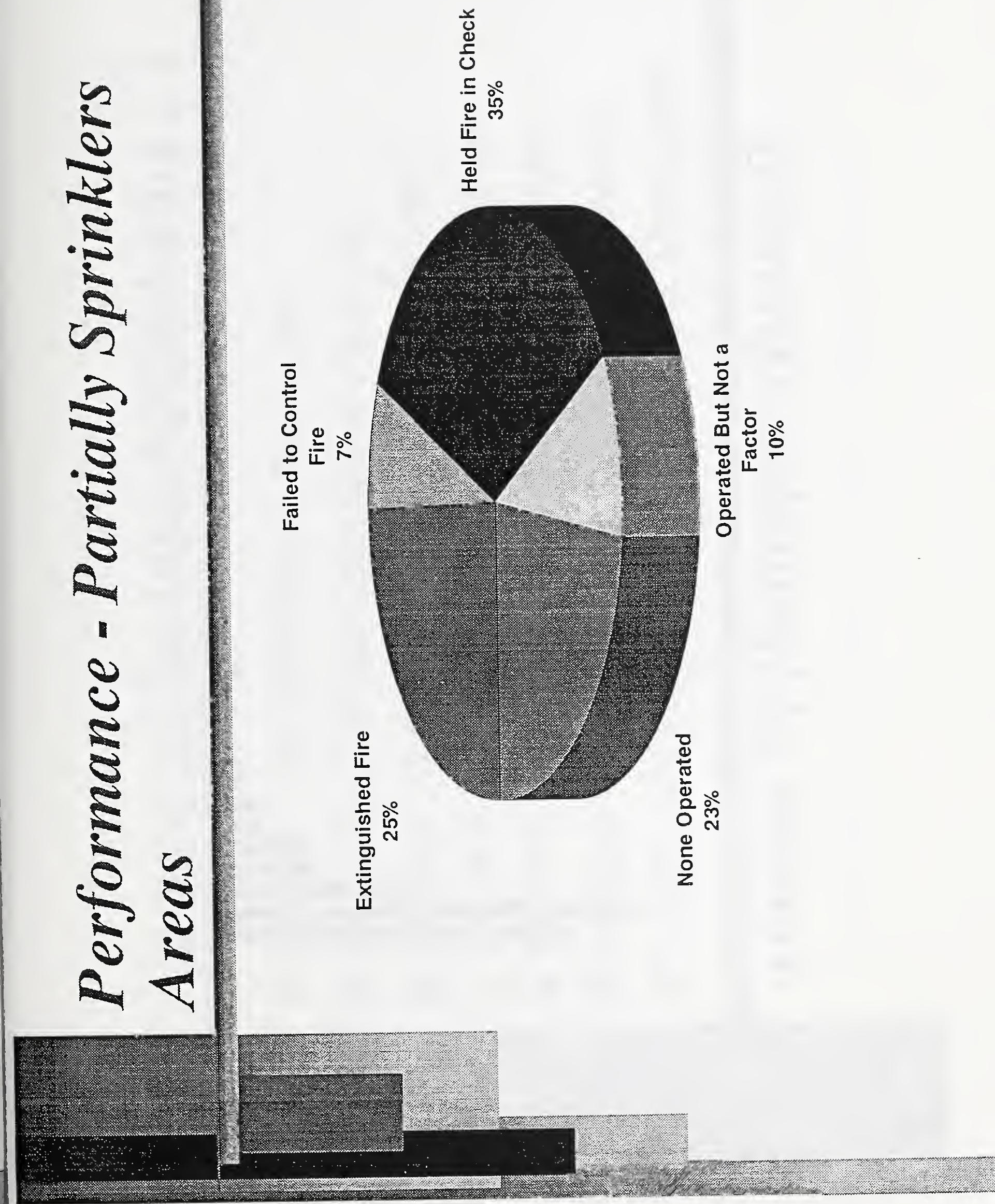


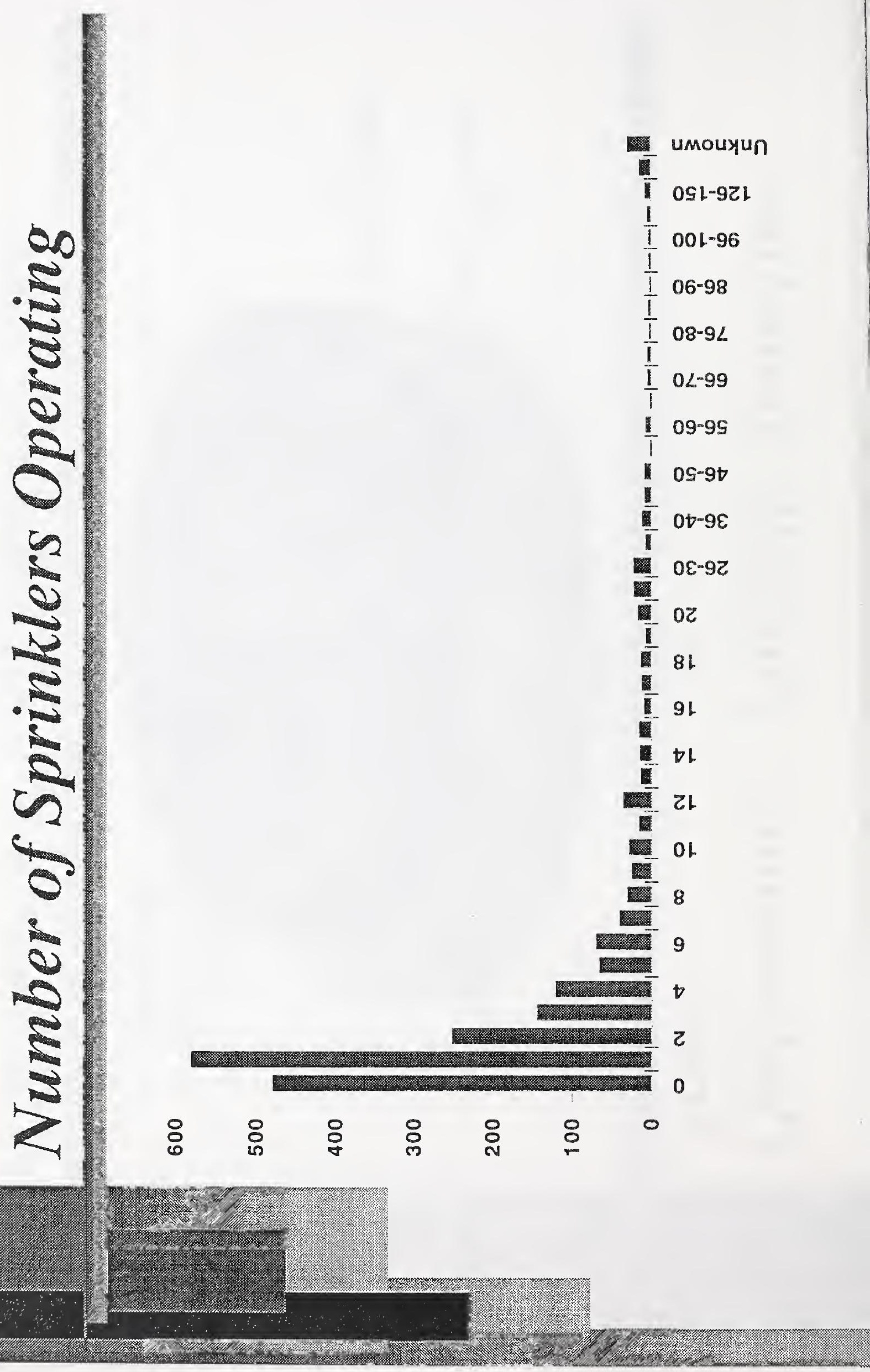




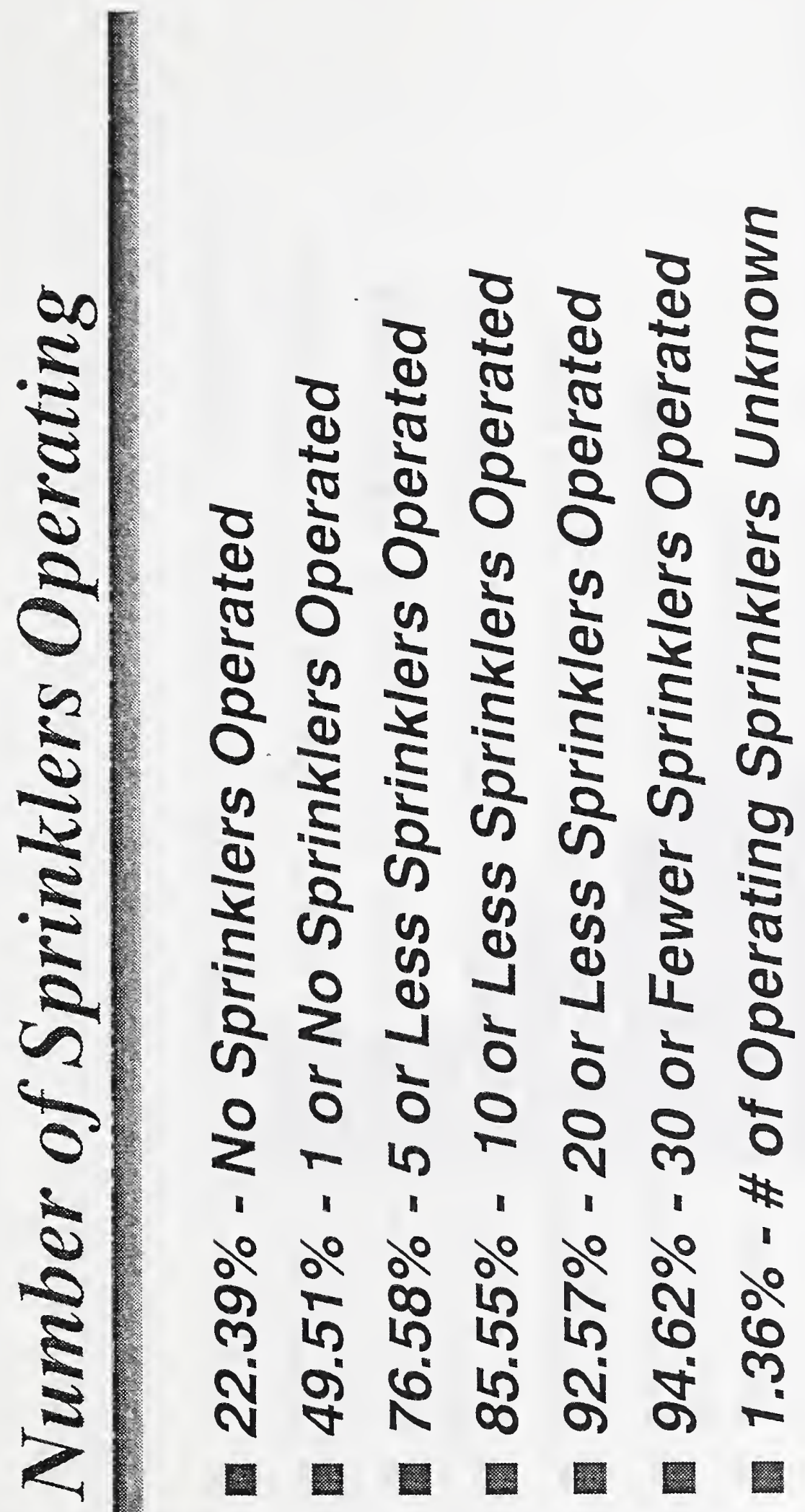



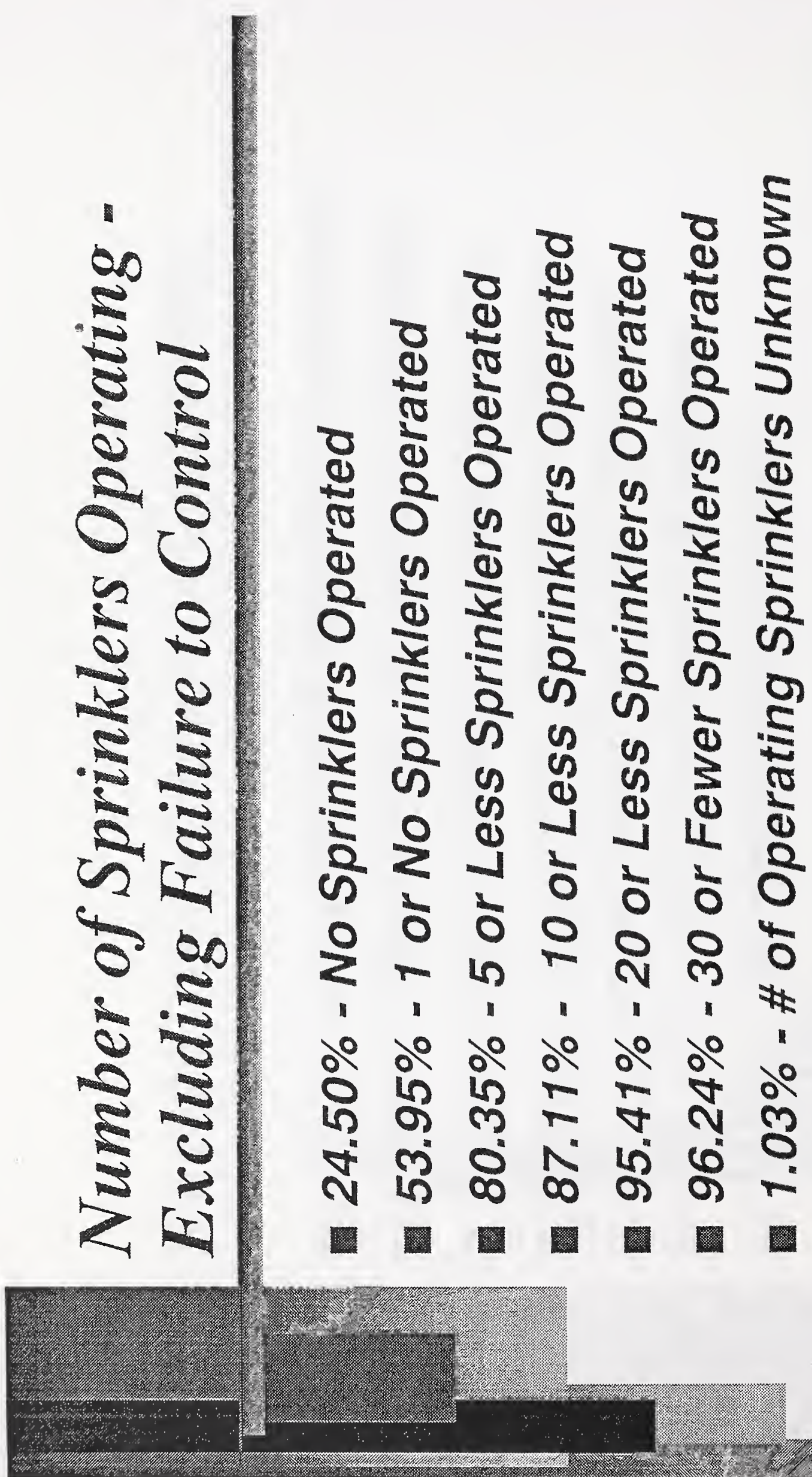


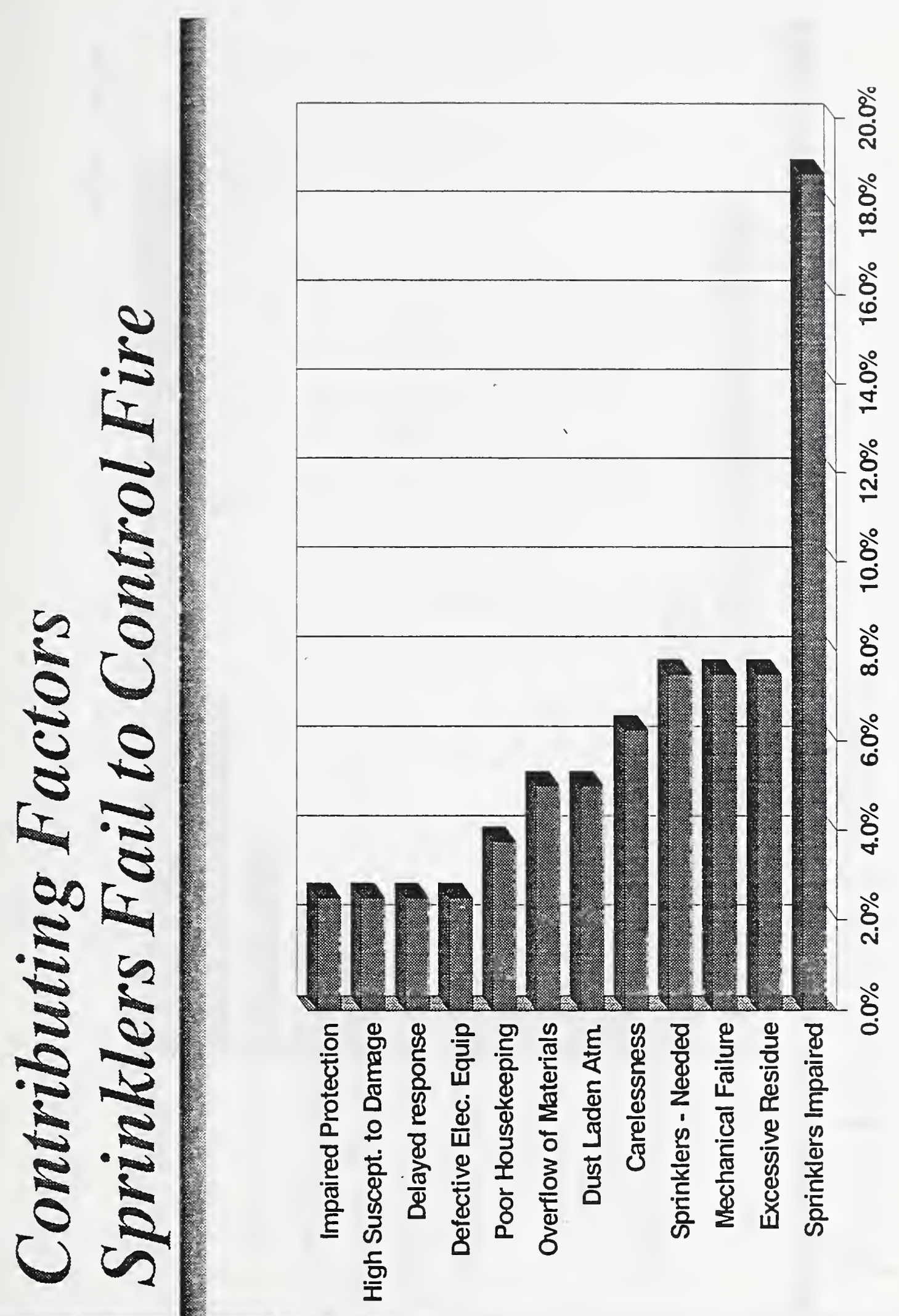




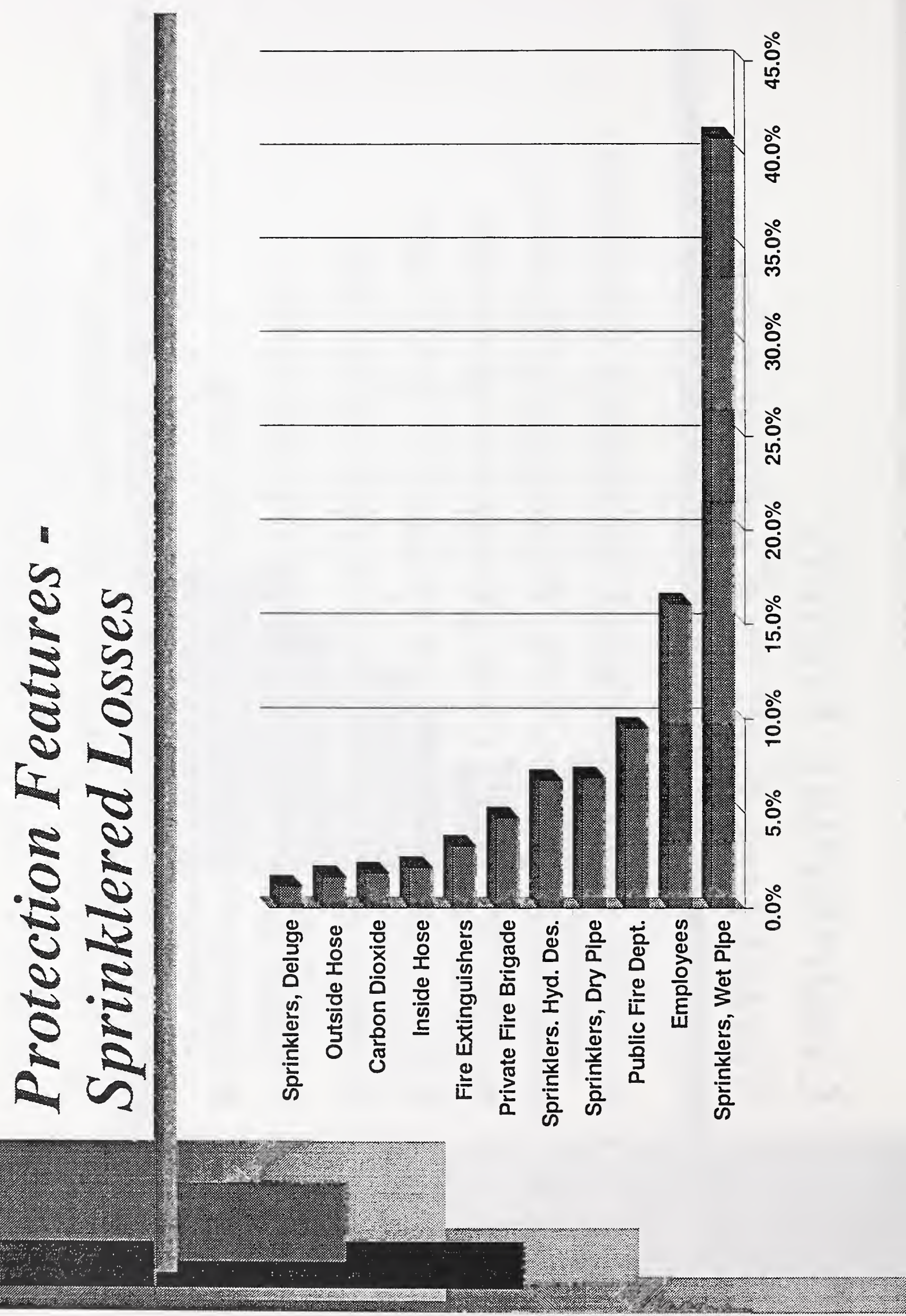




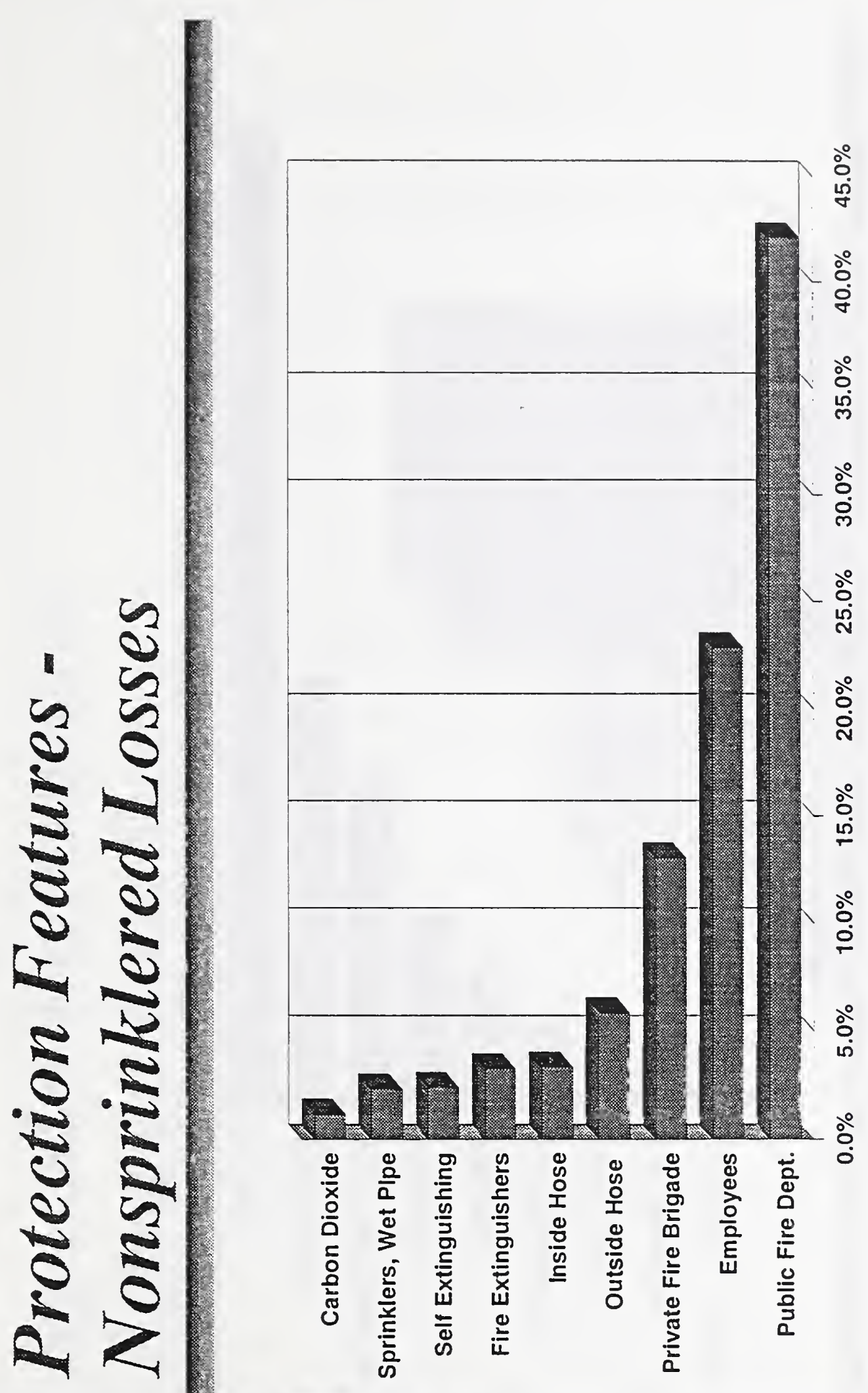



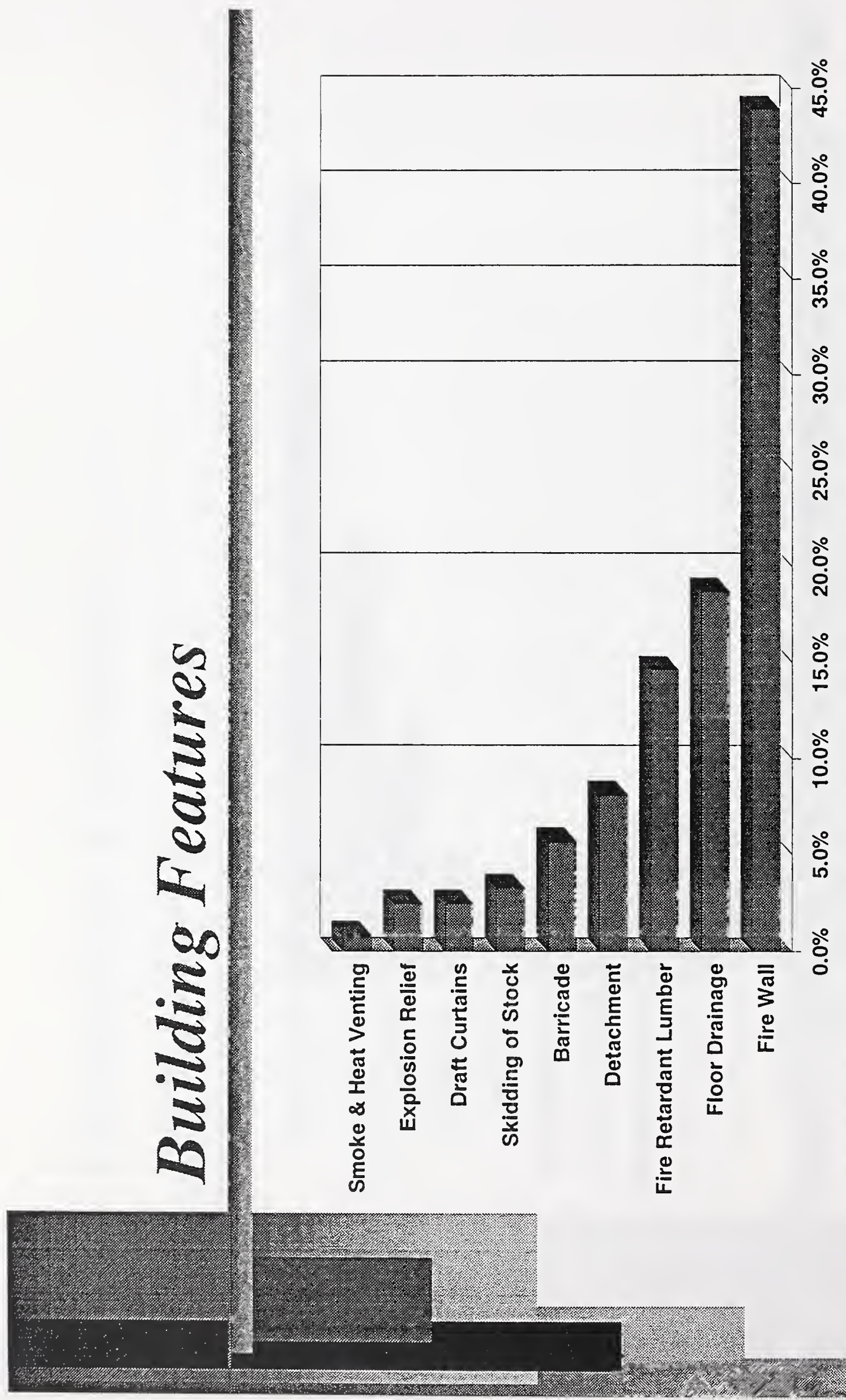


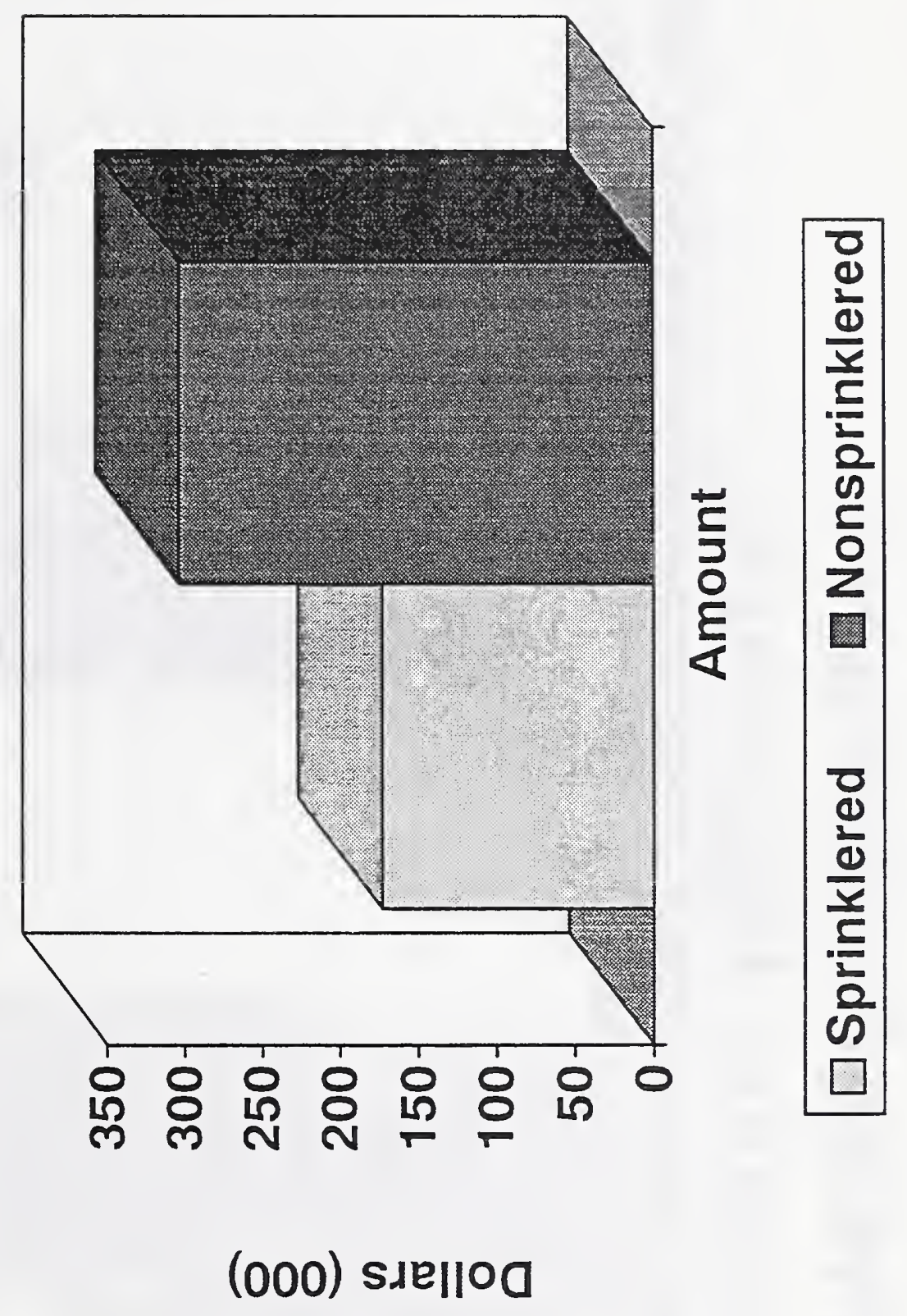




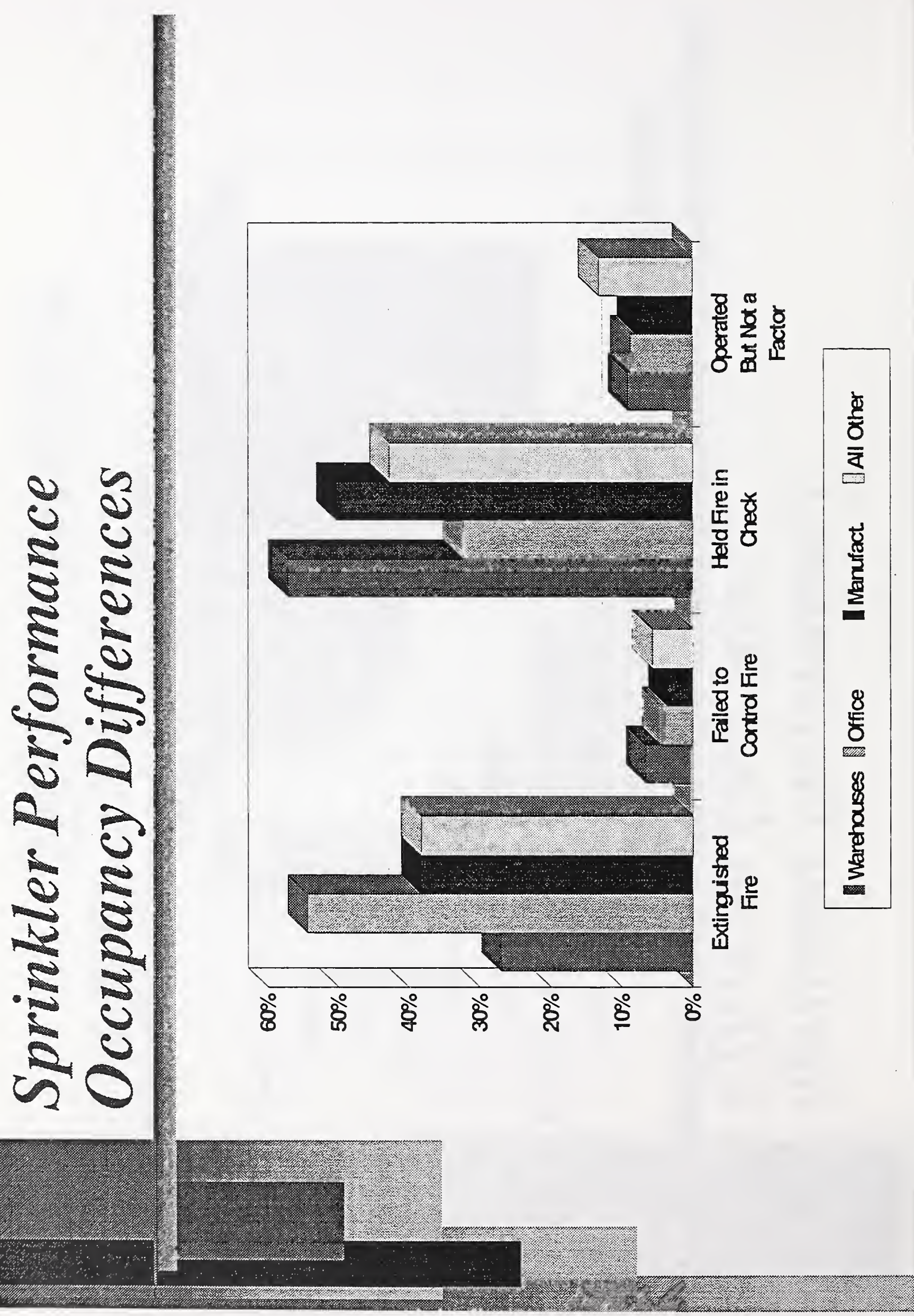




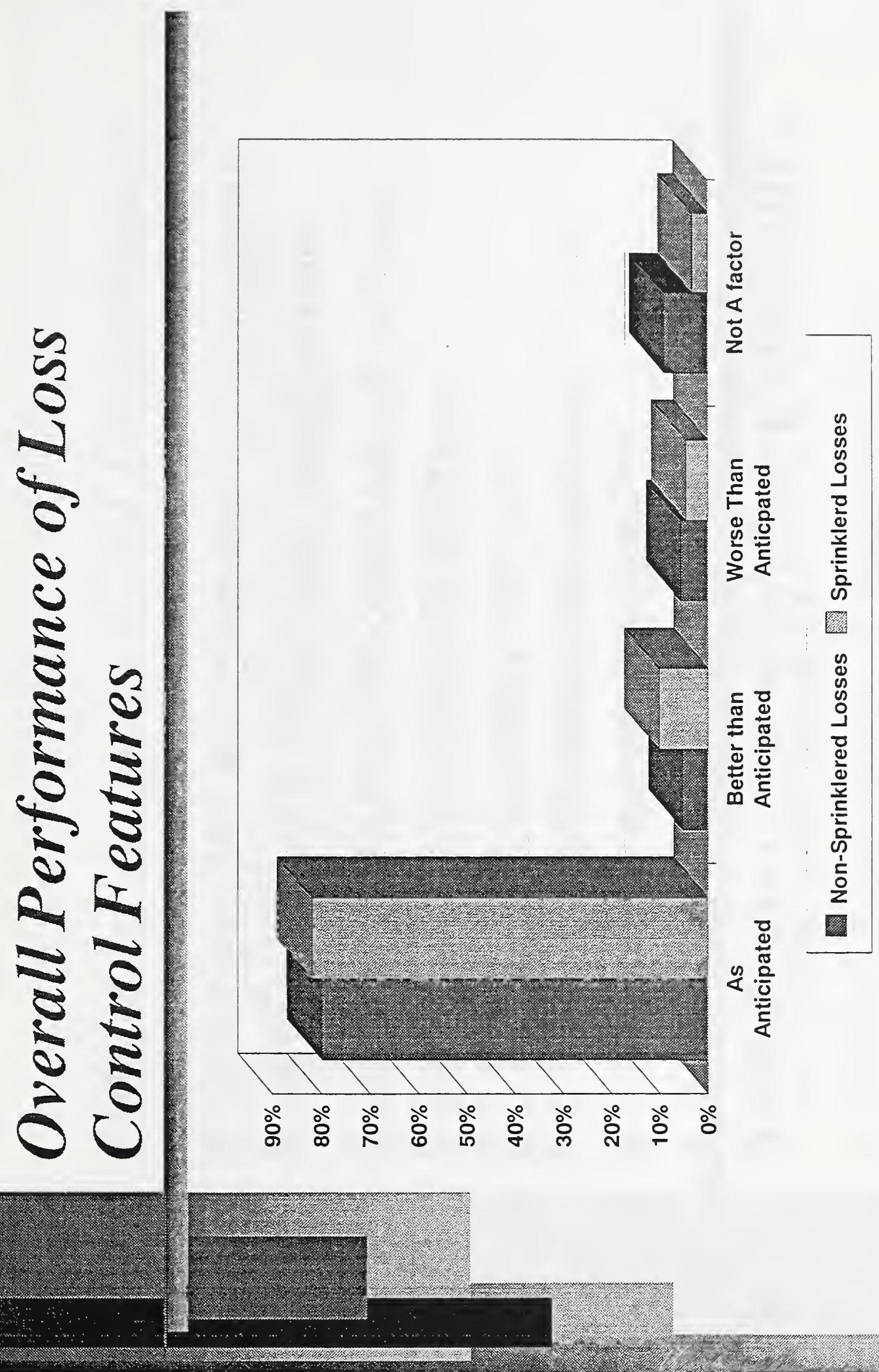




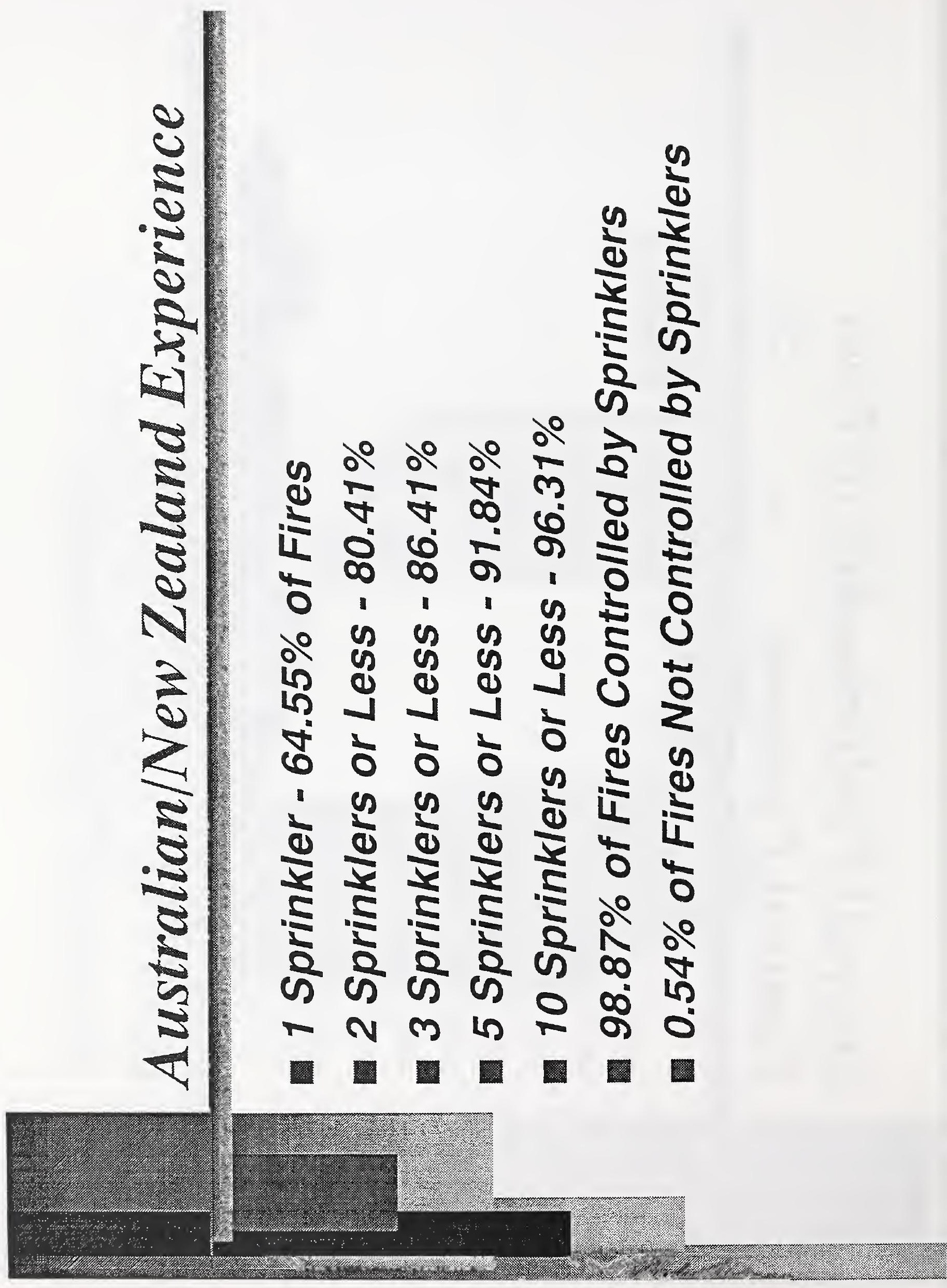




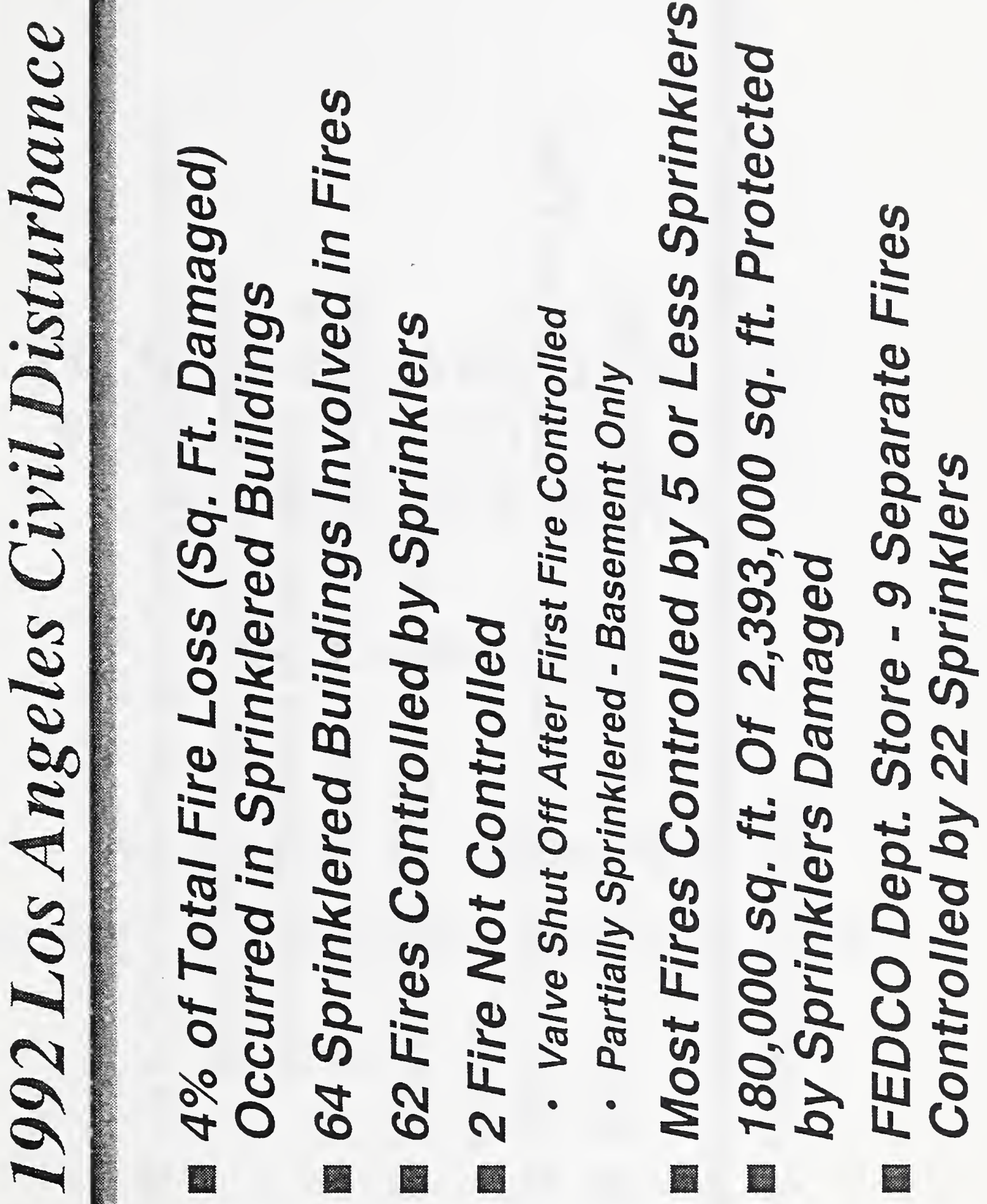



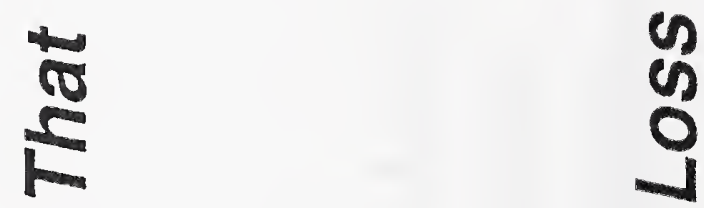

10

$\infty$

rom

0

क

$\sum_{0}^{0} \frac{1}{4}$

II

$>\hat{2}$

के

¿

है

$+5$

잉

U.

2

(1) 5

$\frac{5}{\pi}$

千

U

(s)

능

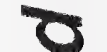

(1)

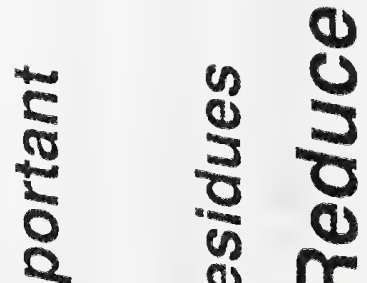

5

$\checkmark$

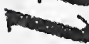

$\exists$

0 오

요

$E$

(1)

๓

उั $\frac{0}{\frac{1}{5}}$

व

की

a

ป

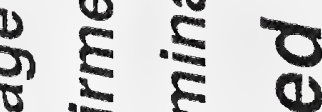

क

니 $0=$

U

ma

0

$\mho$

, 


\section{FIELD RELIABILITY OF FIRE DETECTION AND ALARM SYSTEMS}

\section{Presented by}

WAYNE D. MOORE

the Fire Protection Alliance, Inc. 
Field Reliability of Fire Detection and Alarm Systems Wayne D. Moore

the Fire Protection Alliance, Inc.

The most commonly accepted definition of reliability is given in the book "Reliability Engineering" (ARINC Research Corporation, 1964): "Reliability is the probability that a system will perform satisfactorily for at least a given period of time when used under stated conditions."

Does this definition relate well to fire alarm systems? First we must agree on what is considered satisfactory performance of a fire alarm system. The most often referenced reliability statistic when dealing with installed systems is the reliability of the equipment being used in the installation. In fire alarm systems, the equipment reliability is made up of the individual components reliability, ie. smoke detectors, heat detectors, manual stations, notification appliances, control panels, etc..

The prediction of reliability in electronic equipment necessarily represents the expected average reliability of a quantity of test equipment being tested. The reliability of the individual pieces of equipment will vary from the average, but the limits of that variation can be predicted mathematically. Generally reliability statistics are expressed in terms of Mean Time Between Failures (MTBF) over the expected life of the equipment. 
The measurement terms that are commonly used are:

Failure Rate---Number of failures over time, commonly expressed in Failures/Million Hours.

Mean Time Between Failure (MTBF) is the reciprocal of failure rate.

Probability of number of failures in time $T, R(T)=e-\lambda t$ Where, $\lambda$ is the mean failure rate, and $t$ is time.

Classical reliability behavior is represented by the bathtub-shaped and is a plot of failure rate as a function of time.(see Figure one)4. Classical reliability best describes equipment related failures. The bath tub curve shows three areas of equipment failure. The "early failure" stage is where poor components that escaped quality control inspection are found. As these are eliminated, the failure rate will decrease. In the case of fire alarm control equipment, the factory testing and field installation testing should be long enough to detect these early failures. The "constant failure" rate area of the curve is the operational life of the system. The "wear-out" stage of the curve defines the useful life of the system. The area of concern that I will be investigating is the area of simple distribution applicable to the constant failure rate stage of the curve in Figure one. The critical aspect of reliability is : What is the probability that the fire alarm system will be inoperative at the time a fire occurs? 
Automatic fire alarm systems are generally installed for early warning. the types of detectors used in these systems can be heat, smoke or flame detectors. Each of these detectors will provide differing (often significantly different) amounts of early warning. Therefore the type of detector must be matched to the protection goals of the owner or designer.

A general model for a fire alarm system is shown in Figure two (2). The time delay between ignition and growth is dependent on both the type and sensitivity of the detector used and many other variables that will be discussed later. There is an additional time delay after detector activation to alarm initiation, fire department notification, fire department arrival and extinguishment of the fire.

Therefore the value of the automatic fire alarm system is measured in terms of its ability to provide the early warning necessary to evacuate the occupants and reduce the time delay of fire department notification, arrival and ultimately extinguishment of the fire. With reference to our definition of reliability, the automatic fire alarm system must respond satisfactorily with regard to the protection goals (stated purposes) and perform all of its functions reliably. 
The major factors that affect the ability of the automatic fire alarm system to operate reliably are highlighted in Figure three,(3). Obviously from Figure three, the factors affecting fire alarm system reliability are complex, many having qualitative attributes, meaning that assigning numbers to an event from test or historical data is difficult at best. In addition, education of the "players" involved in the installation process lags considerably the technical advances of the fire alarm systems manufacturers, making these qualitative judgements even more difficult. Because of this and the fact that most of the complex variables involved with fire alarm system installations are not fully considered, most installations are not as reliable as one would hope for a life safety, early warning system. Thus far many of the "reliability" studies of fire alarm systems have focused on the false alarm issues. Certainly these issues are important to the effectiveness of installed fire alarm systems, but it can be shown that other factors affecting reliability combine to cause these systems to be false alarm prone or worse, ineffective in offering early warning. 
In their 1982 report of the assessment of fire alarm systems reliability (in the U K), Peacock and Watson stated: "Better control of factors affecting installations, environment, maintenance, overall layout and human intervention will undoubtedly improve AFDS [Automatic Fire Detection Systems reliability, but until further experience is gained factor quantification as contrasted with overall alarm analysis will be essentially obscure (3)." Here we are eleven years later still with very little quantification of these same reliability factors.

As part of an on-going study, the goal of this presentation is two-fold. I will present some preliminary Quality Assurance (Q/A) data regarding the electrical components used in fire alarm systems and devices, detection device $\mathrm{Q} / \mathrm{A}$ data and anecdotal data on equipment failures in the field. Secondly, the other factors affecting fire alarm system reliability will be reviewed with an eye to developing a better data base from which to evaluate the system performance reliability as we have defined it.

To date (6/06/93), one manufacturer has supplied reliability data on their components and products(6).- This manufacturer is primarily a device manufacturer so there is very little information at this time that can be assigned to control panels. (We may be able to access other non-fire alarm control panel reliability statistics and extrapolate that information to the fire alarm controls we are presently using (10).) 
Figure four (6) shows the reliability statistics, in terms of failures/million hours of operation, for a single manufacturers' heat and smoke detector.Figure 5 shows the failure rate, in terms of events per thousands detectors per annum(2), for devices commonly used in fire alarm systems.

Realizing that this is limited data, one can still see that with the exception of UV and IR detectors, device reliability is high. From my experience, these types of failure rates are typical for most of the devices on the market today. Most fire alarm control panels are constructed using a modular approach, which means there are a number of component assemblies used in each panel but not all assemblies are used in every panel. Reliability will also vary from manufacturer to manufacturer. This problem can be overcome with averaging I'm sure, but to date I have no quantitative data to evaluate. However, what statistics are available from the field indicate a relatively low overall failure rate of control panels. The most active part of the fire alarm system control is the power supply. This component appears to have the highest recorded failure rate for a control panel component. The overall equipment failure rate is shown in Figure six $(5,7,11)$. Again this data is from limited sources, but it does indicate that overall equipment reliability was poor in the late 1970's and early 1980's. 
There are a number of sources that have attempted to establish probabilistic numbers for installed systems. Figures 7 and 8 (2) indicate relatively low failure rates of installed fire alarm systems in specific occupancies, again in terms of events per thousands detectors per annum. Unfortunately this and other data regarding many of the other factors affecting the reliability of installed systems represent more opinions rather than quantifiable data.

Many of the surveys highlighted major deficiencies in data collection, such as the lack of adequate methods of reporting alarm incidents; the lack of detailed maintenance and service records; the absence of as-built drawings; the difficulty of manual efforts required in detailed data collection and a lack of systematic methods of recording the history of the installed systems.

Factory Mutual published information in 1987 gathered from their inspections of their approved central stations. In analyzing over 200,000 test reports, it was found that $70 \%$ of all failures were caused by the human element. Non-standard central station service has been shown to be $21 / 2$ times more likely to fail than standard service. It was also determined that non-approved central station service was nearly five times more likely to fail than standard service. Figure 9 (7) shows the overall results of the FM survey. 
One of the interesting elements of the survey that was not mentioned in the survey was that the equipment failure component of the aggregate failure rate was only $1.0 \%$

More recently, CIGNA Loss Control Services performed a survey of installed fire alarm systems in their insured properties (5). Of 1455 properties surveyed, $64 \%$ had alarms in service (see Figure 10), and $36 \%$ did not. They discovered a $2 \%$ failure rate (did not activate in a fire) and $2 \%$ of the systems were judged to suffer from poor workmanship.

One of the issues raised by the author, William Jenaway, is that " the systems are getting smarter than the people installing (and inspecting) them."

Many of the problems uncovered in the survey led to the conclusion that there were two overriding factors in the systems which failed: 1) the system was not installed properly, and 2) the " acceptance test " was either not performed or was not done properly. Once again, the human element seems to be the overriding factor in systems failure.

I was asked to review whether or not a reduction or total elimination of fire alarm systems use would be acceptable in terms of increased risk of loss. After this initial investigation, I believe that reducing or eliminating the use of fire alarm systems would result in an unacceptable risk of loss. 
We do need to understand our systems problem and that's mainly education. We also have to understand the limitations of fire alarm systems. No one would call a sprinkler system with three sprinkler heads a "complete coverage" sprinkler system. Why then do we have people labeling a fire alarm system with three smoke detectors, a "complete" smoke detector system?

We were also asked to define the state of knowledge of the field performance of fire alarm systems. That information is woefully lacking.

In 1960, the NFPA distributed over 5000 forms to the fire alarm industry to attempt to establish field performance experience levels as on file with sprinkler systems. By 1964, less than 100 had been returned and the project was abandoned.

obviously, we need more statistics on the observed reliability of installed fire alarm systems. The challenge to the fire alarm industry is to take the lead to both gather and publish this information. 
1. Reliability Engineering;1964,ARINC Corporation, Prentice Hall

2. Reliability Appraisal of Fire Detection Systems;

S.T.Peacock, Dr. A.R.R.Kamath, Dr. A.Z.Keller Postgraduate School of Studies in Industrial Technology

University of Bradford, UK

16th AICHE Loss Prevention Symposium, 1982

3. Reliability Assess of Automatic Fire Detection Systems S.T.Peacock, I.A.Watson; 6th Advances in Reliability Technology Symposium, Bradford, UK, April 1980

4. Reliability in Control and Indicating Equipment in Automatic Fire Detection Systems G.J.Sard, Mather \& Platt, London, England

5. The Impact of Fire Alarms on the Fire Service; William F. Jenaway, THE VOICE, ISFSI, December, 1990

6. Personal Communication, Kidde-Fenwal, 1993

7. Central Station Service: Standard Means Quality, RECORD, Jul/Aug. 1987

8. Reliability Assessment of Protective Systems, A.R. Eames, "Nuclear Engineering", March 1966 


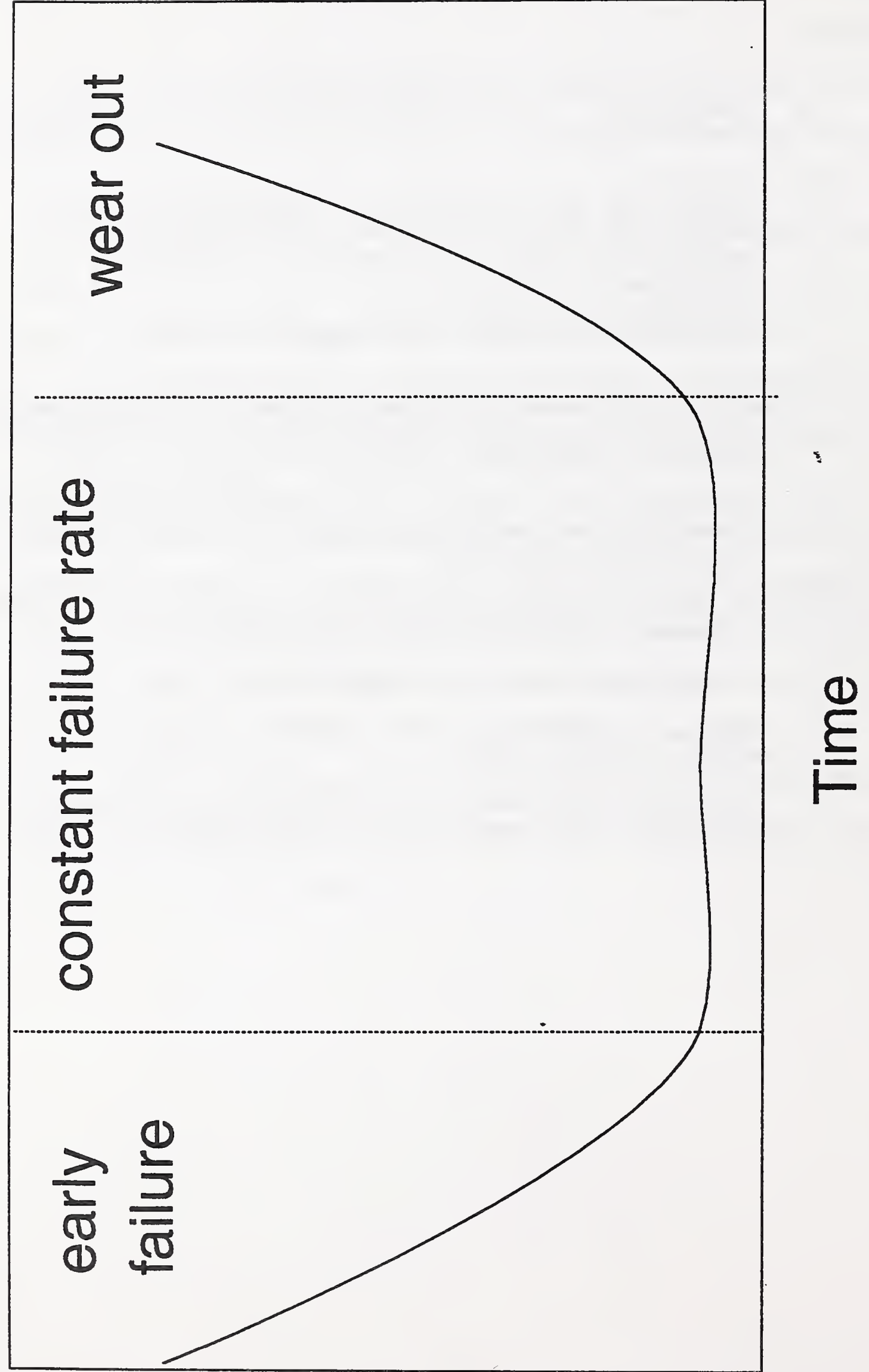

แ $\sigma-\supset レ \sigma \propto \sigma \leftarrow \sigma$ 


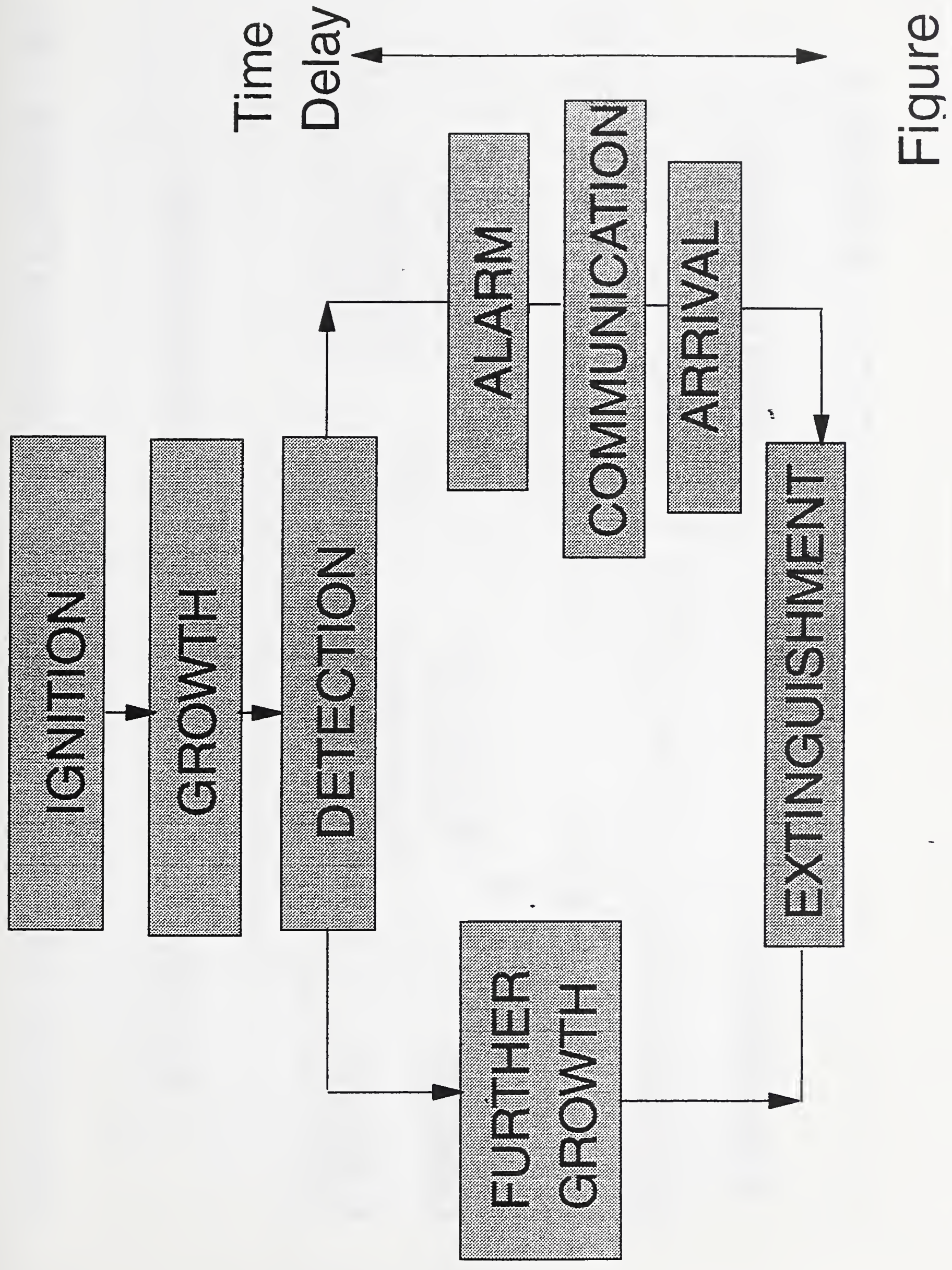



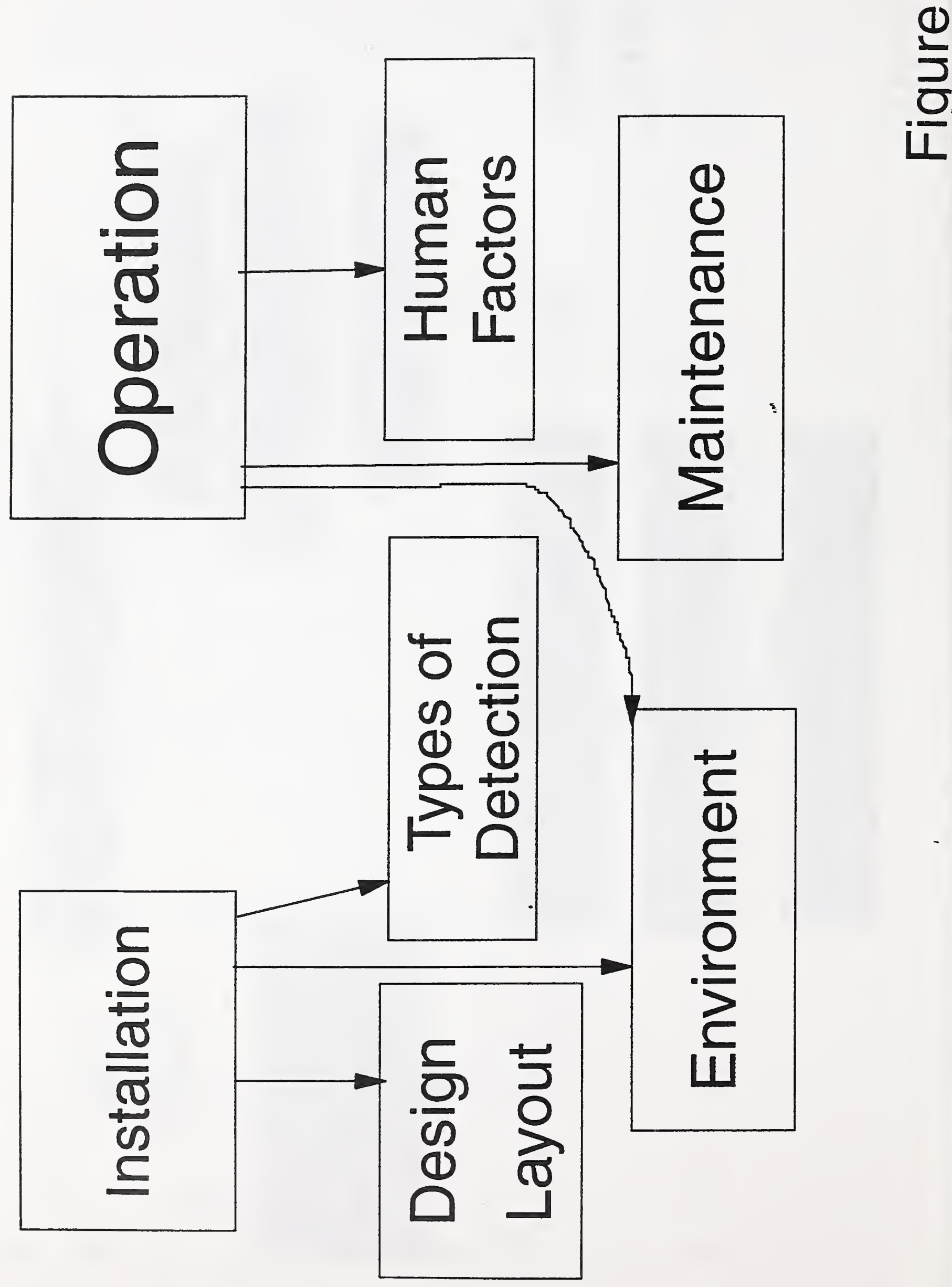

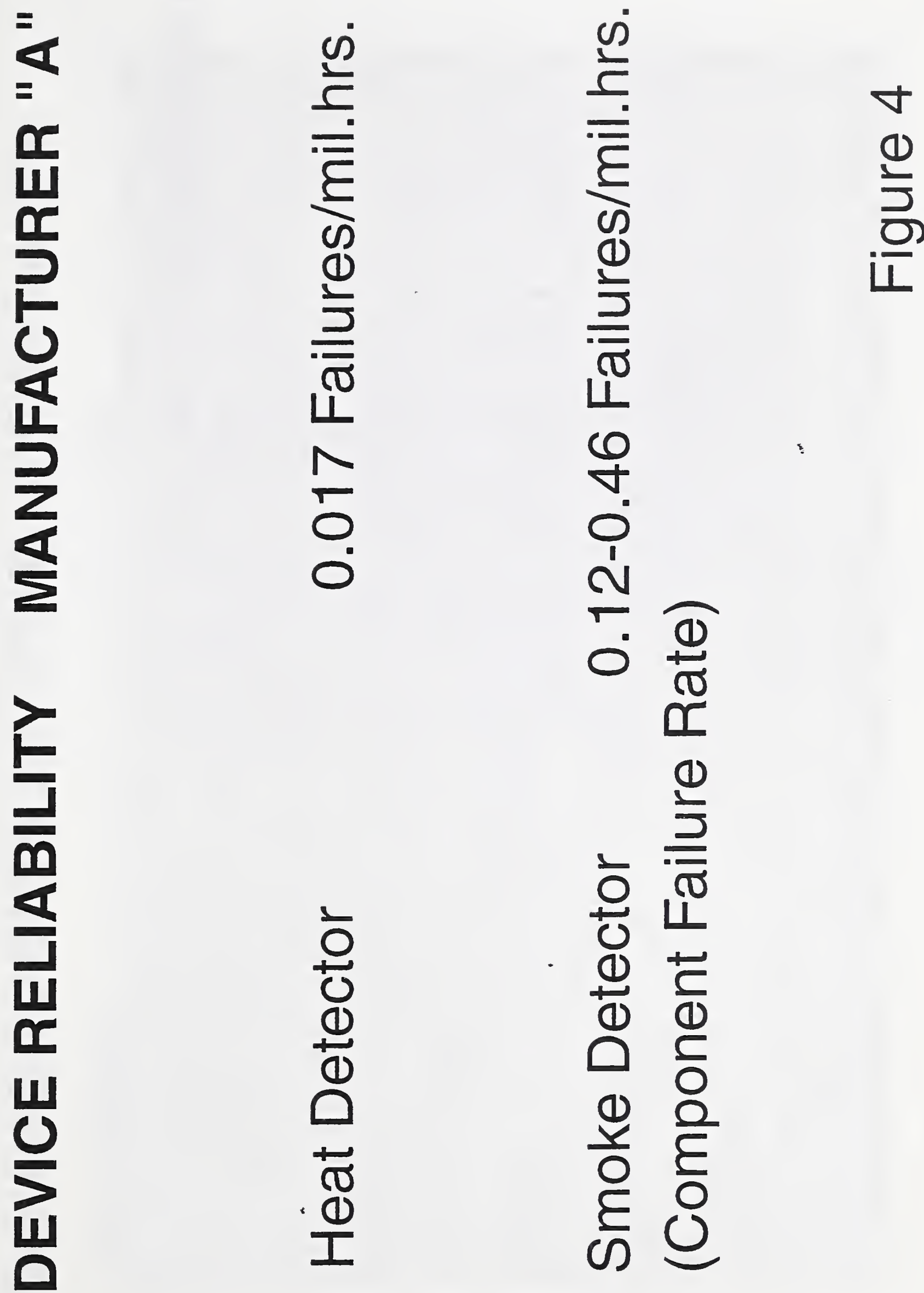

(1)

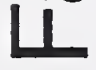

6

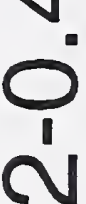

एक

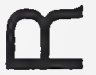

(1)

$\div \stackrel{\varrho}{=}$

○

$+4$

$\stackrel{0}{ \pm}$

(1)

ค $\frac{\varepsilon}{0}$

ํํㄹ ह

I

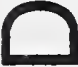

ज 


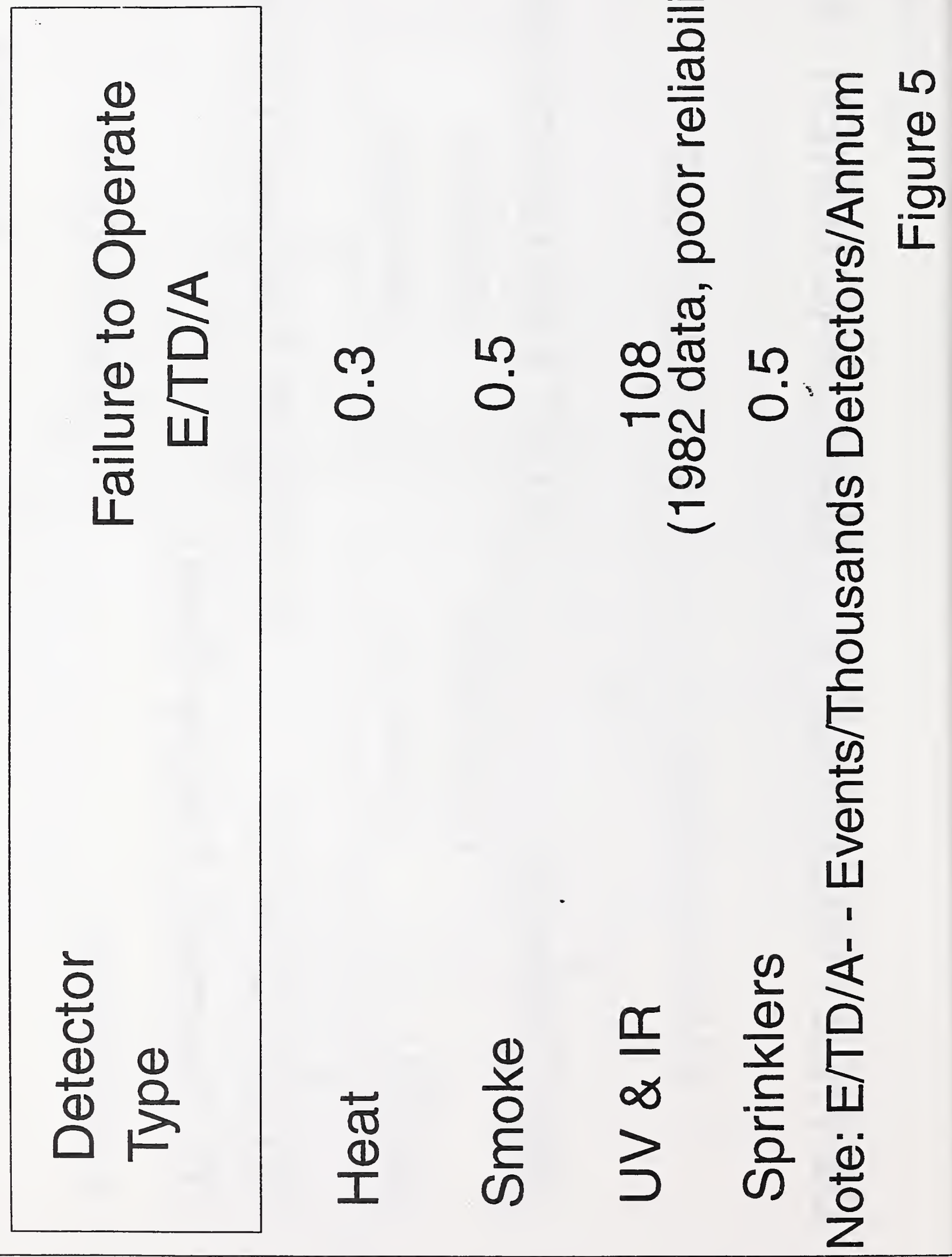




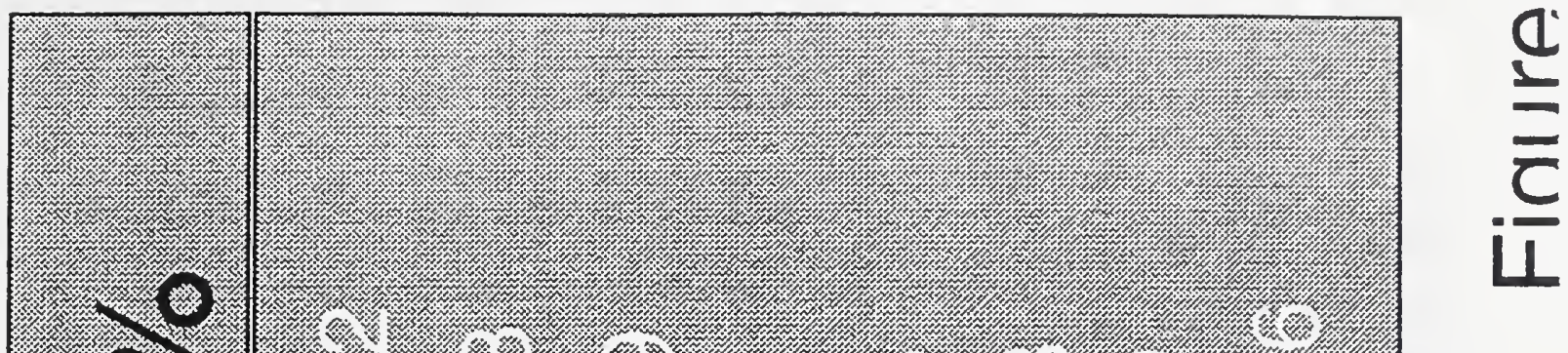

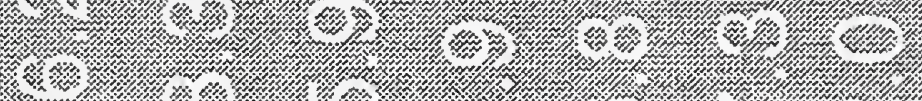

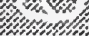

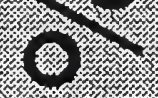

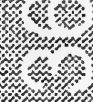

.1. . . 2.

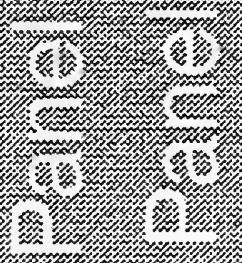

a
a 

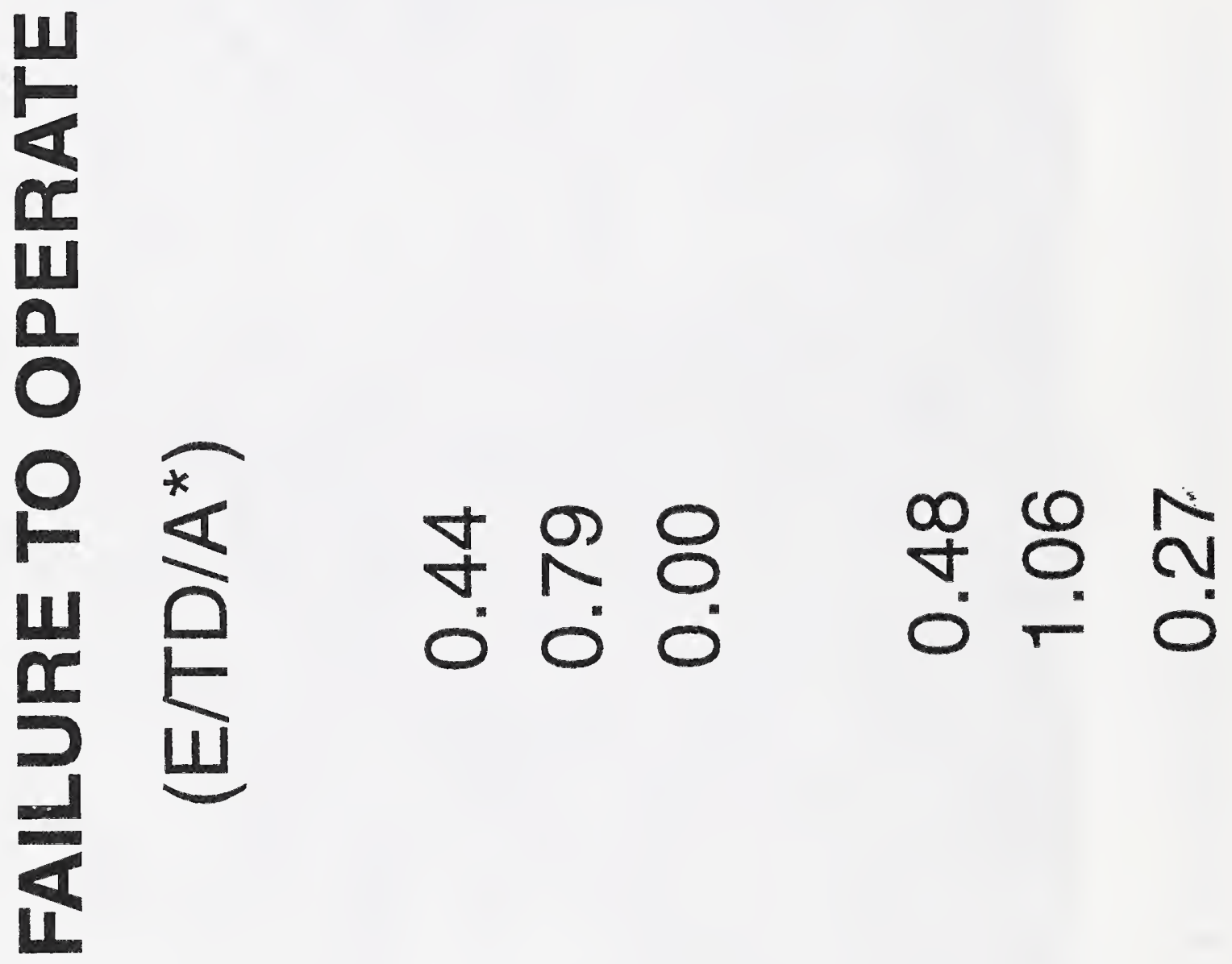

UI

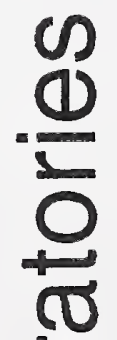

点

- N

$m$ 흔

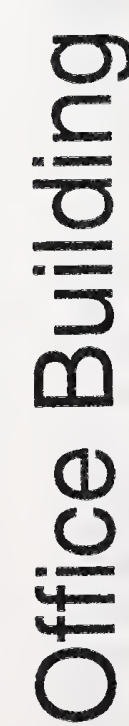




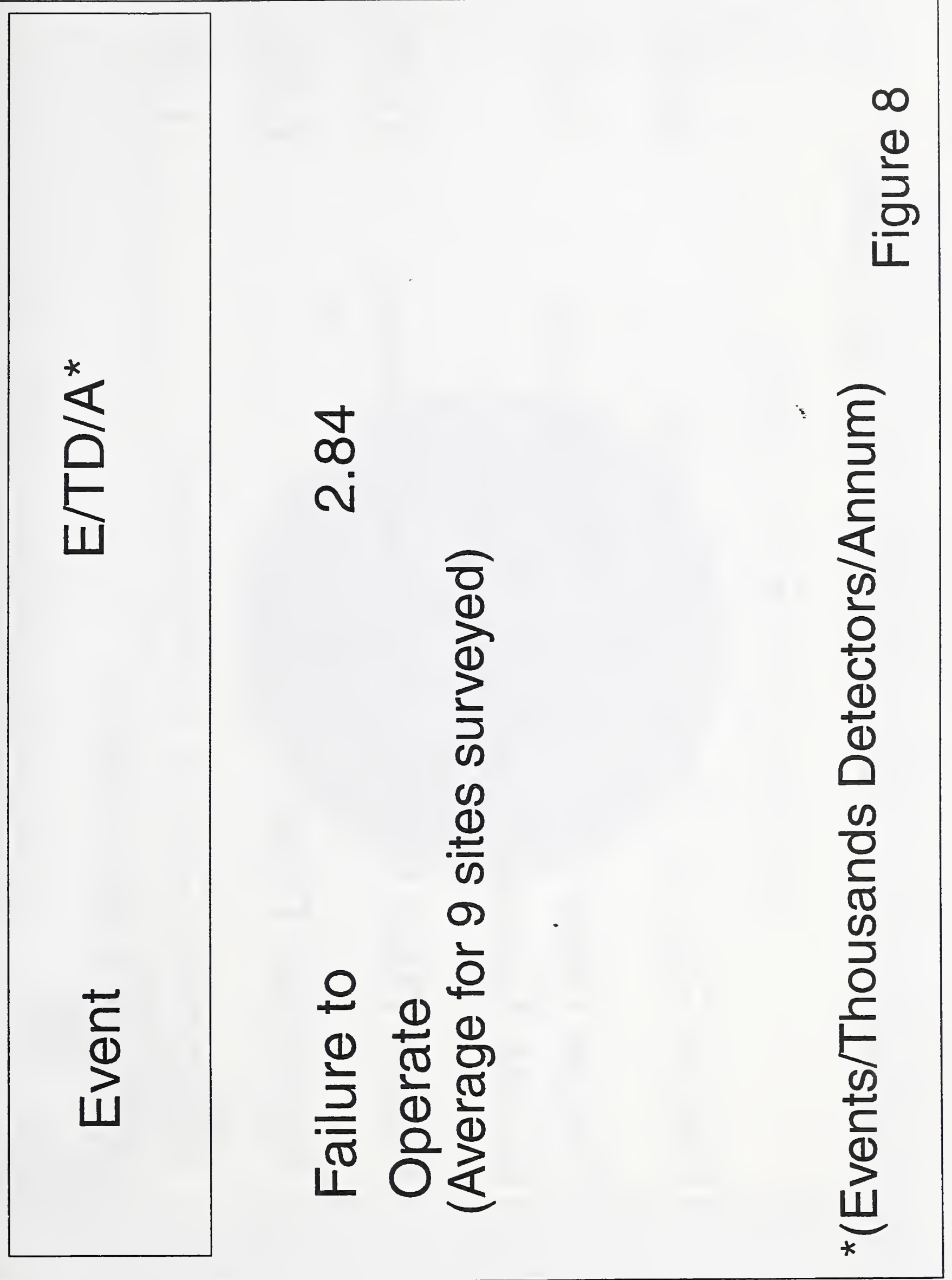


0
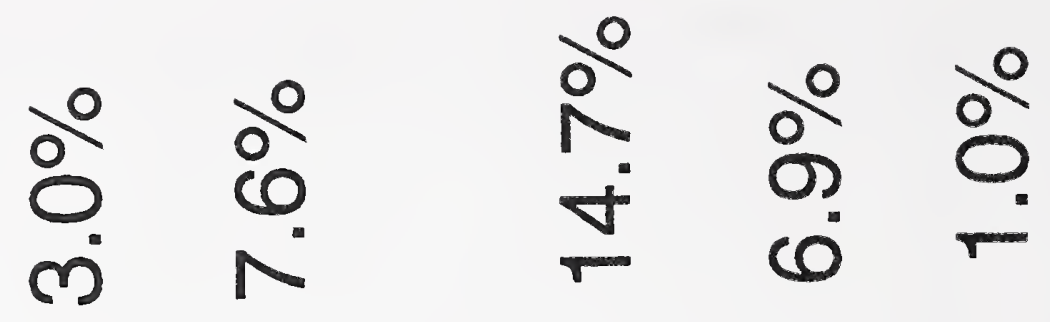

$\frac{0}{2}$

$\infty$

の

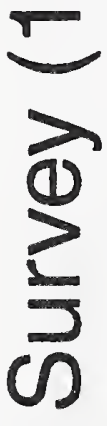

$\frac{7}{\frac{10}{0}}$

$\Phi$

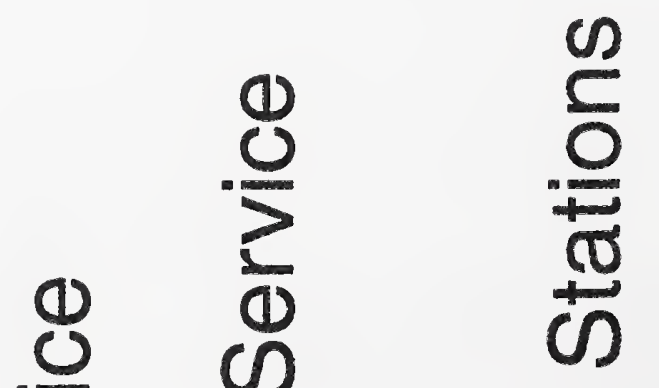

$\frac{0}{2}$

$\frac{c}{0}$

$\geq$

D

(5)

$\frac{0}{0}$

ब(1 음

क

몬

ธั

음

(ర)

$\pm$

ธั

c

느 ᄂ ํํ \

$\frac{1}{0}$

(1) $\pm \frac{1}{ \pm}$

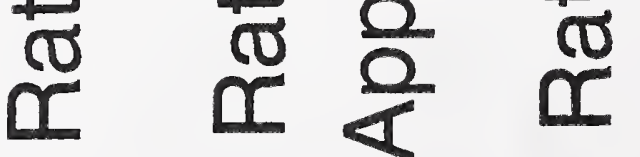

(1)

产

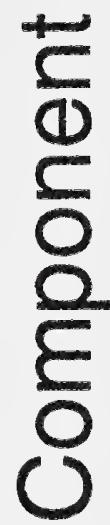

高

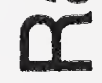

$\frac{ \pm}{ \pm}$

O

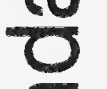

$\omega$

으

ช

(5)

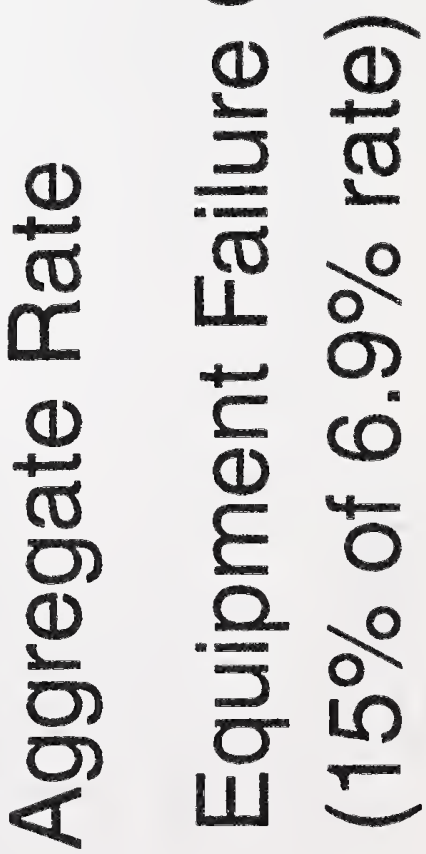

(1)

ษ

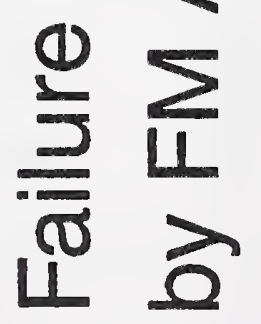




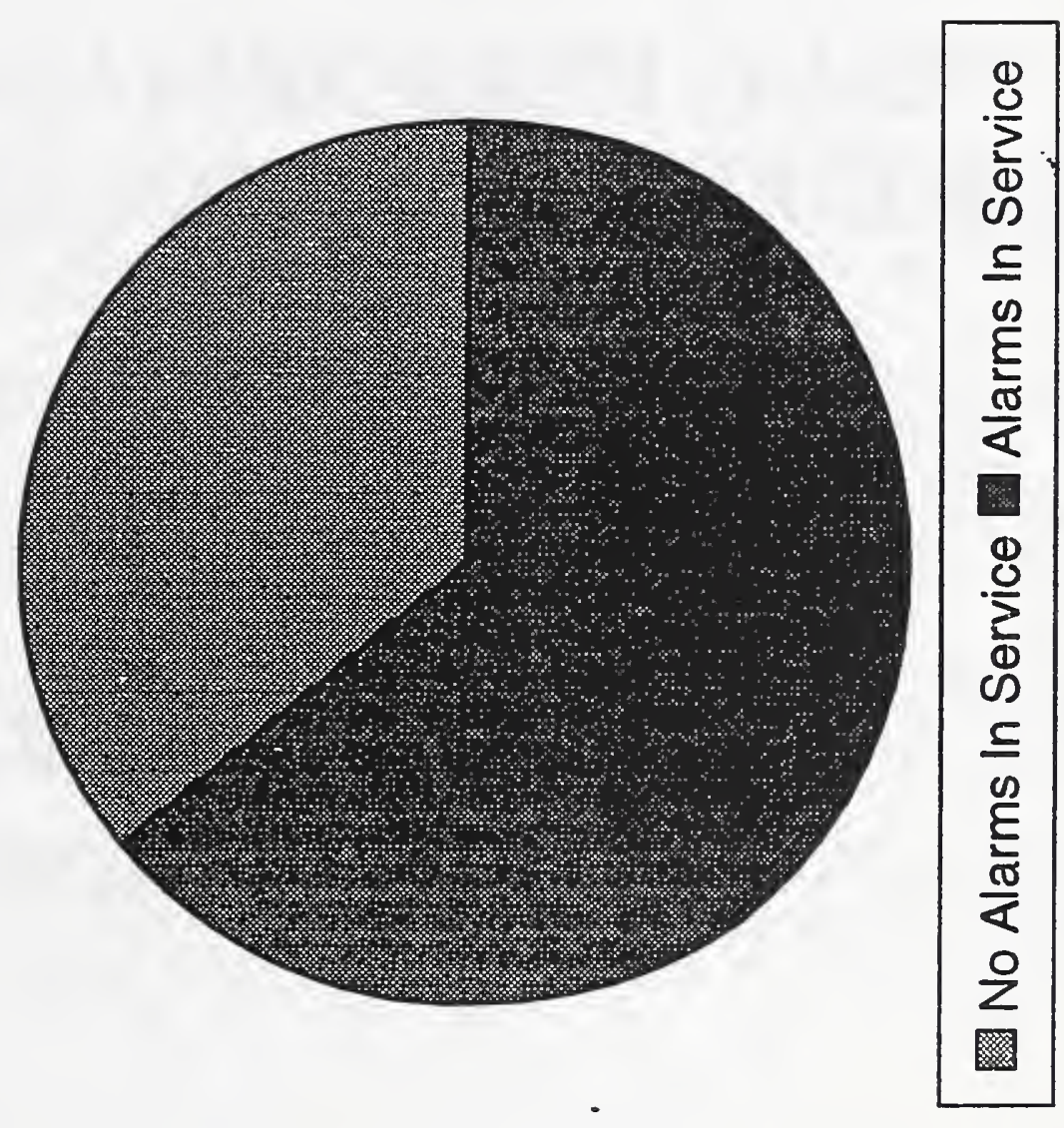




\title{
FIELD PERFORMANCE OF FIRE PROTECTION SYSTEMS
}

\section{Presented by}

\author{
SONNY SCARFF \\ Marriott Corporation
}




$\begin{array}{ll}\text { DATE: } & \text { July } 12,1993 \\ \text { TO: } & \text { Sonny Scarff } \\ \text { FROM: } & \text { Jerry Kirby } \\ \text { COPIES : } & \begin{array}{l}\text { Arnold Davenport } \\ \text { Jim Bell }\end{array}\end{array}$

SUBJECT: Twelve Month Report on Life Safety Inspections

Attached is a summary of the deficiencies found during the inspection and testing of life safety facilities in 275 courtyard, Fairfield Inn and Residence Inn hotels in the 12 month period between June 1992 through June 1993.

Please note that the figures in each category represent the numbers of hotels in which the deficiencies occurred--not the total number of defective units. For example, emergency lights were found defective in 98 hotels. Because some of these hotels had as many as 23 defective lights, the actual number of defective units is much higher than the totals represent.

In addition to identifying, and in many cases correcting the deficiences, we dedicated time to training the engineers in the maintenance and operation of the hotels' life safety systems.

It is our feeling that the program has been successful in not only recognizing and abating life safety hazards, but in educating hotel personnel in the importance of system maintenace and Emergency Organization training. Hopefully the hotels will be safer as a result of these efforts.

$\mathrm{JK} / \mathrm{jp}$

Attachment 
MARRIOTT INSPECTION \& TESTING

JUNB 1992 THRO JUNB 1993

\section{PROPERTIES}

171 Courtyards

72 Fairfield Inns

32 Residence Inns

275 Total Properties 


\section{BAFETY I88UES}

Defective Emergency Lights 98

Defective Exit Signs $\quad 77$

Electrical Rooms $\quad 60$

storage or

3 Ft. Clearance

Iinen Chutes

Not closing

Not latching

No links

Cooking Line - Grease Build-up 39

Storage Blocking Sprinklers $\quad 37$

Gasoline/Propane $\quad 39$

Equipment

storage

Doors Blocked Open or Kickdown stops 50

Keys for Locks 40

Not keyed alike or not available
Kitchen Hood Flow Switch

- Drop Gas Solenoid

- Drop Electric Shunt-Trip

Sprinkler Leaks, Corrosion 30

$\begin{array}{ll}\text { Fire Pumps } & 27\end{array}$

Tests due

Maintenance needed

Additional Sprinklers needed due to 27

renovations, decking

Fire Dept. Connection

Accessibility

Visibility

Missing Caps

\section{BPRINIIER BYBTEM8}

Floor/Zone Control Valve closed 5

* 1991 - Main Control Valve closed 1

Control Valves not tampered or 92

No Locks and Chains
ctive Tamper Switches

$\begin{array}{ll}\text { Defective Tamper Switches } & 64 \\ \text { Defective Flow Switches } & 62\end{array}$

(incl. Attic Dry Pressure Switch)

$\begin{array}{ll}\text { Placards Needed } & 55 \\ \text { No Inspector Test Valves } & 54\end{array}$

(Mainly Kitchen Hoods)

Dry system Compressors

Needed Draining, Adjustment

Potential Problems

* 1991 - One FACP found dead 
Smoke Detectors - Dirty

Smoke Detectors - Did not function

Duct Detectors - Did not function

8

Batteries

47

over 4 years

Corrosion or Low Charge

Fire Alarm Panel or Annunciator Zoned incorrectly

Manual Pull stations

Did not function

Corrosion

Fire Alarm Troubles

Grounds Trouble

Functional problems

Horn/Strobes

32

Duct Detectors

7

HVAC did not shut down

\section{OTHER}

Main Drains - Need re-routing

16

due to flooding

Valves not trimmed correctly 


\section{FAILURE MECHANISMS OF FIRE RELATED CONSTRUCTION}

Presented by

\section{RICHARD WALKE Underwriters Laboratories, Inc.}



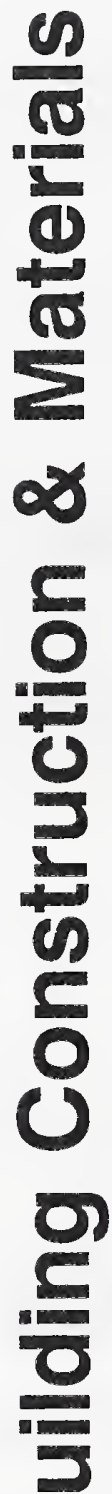

m

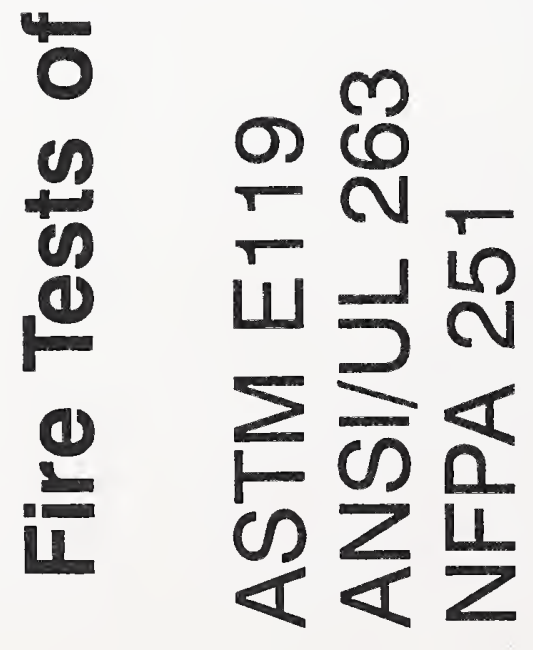


皇

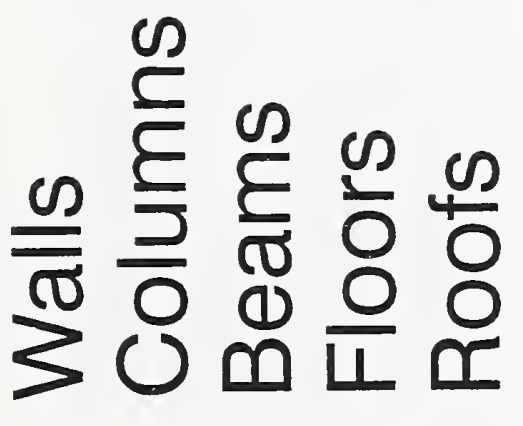

$$
\begin{aligned}
& \text { - }
\end{aligned}
$$


总

(1)

는

(1)

2

(a)

2

E

(1)

4

(a)

E

O

T

I

II] 


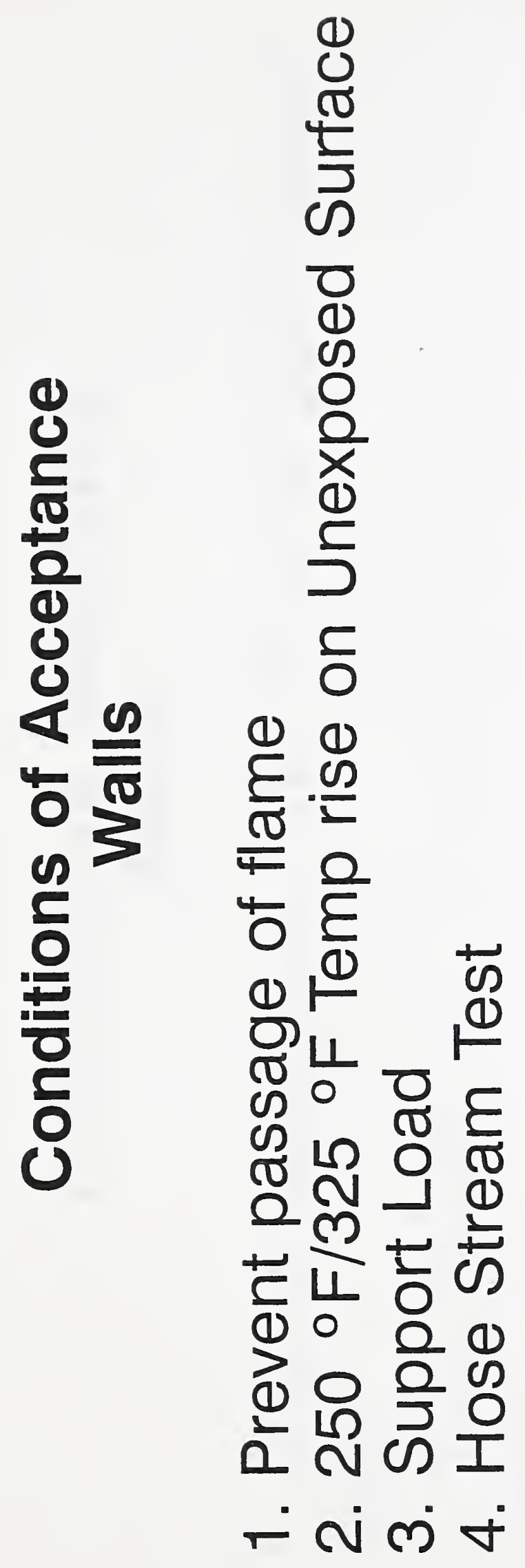




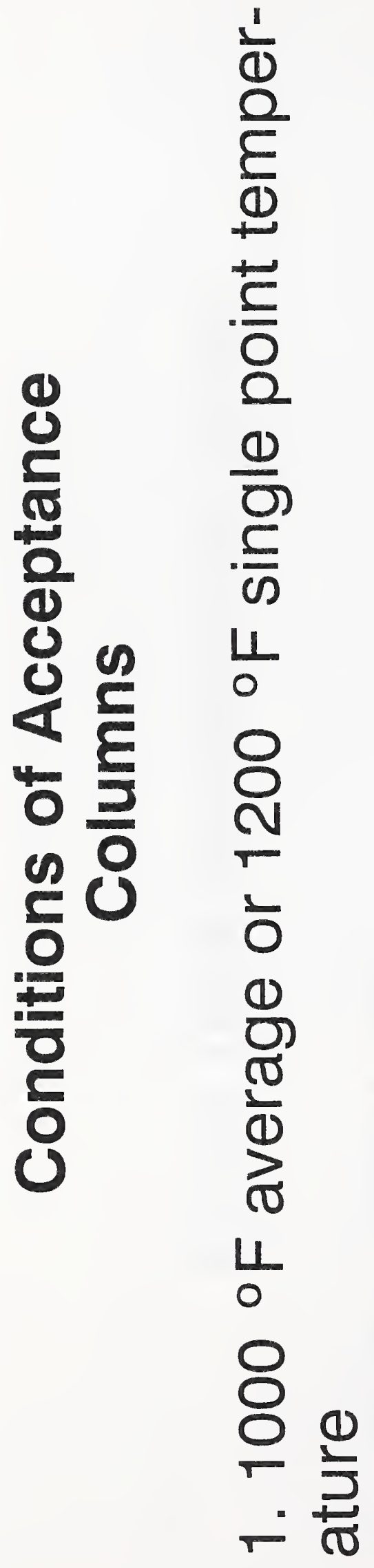




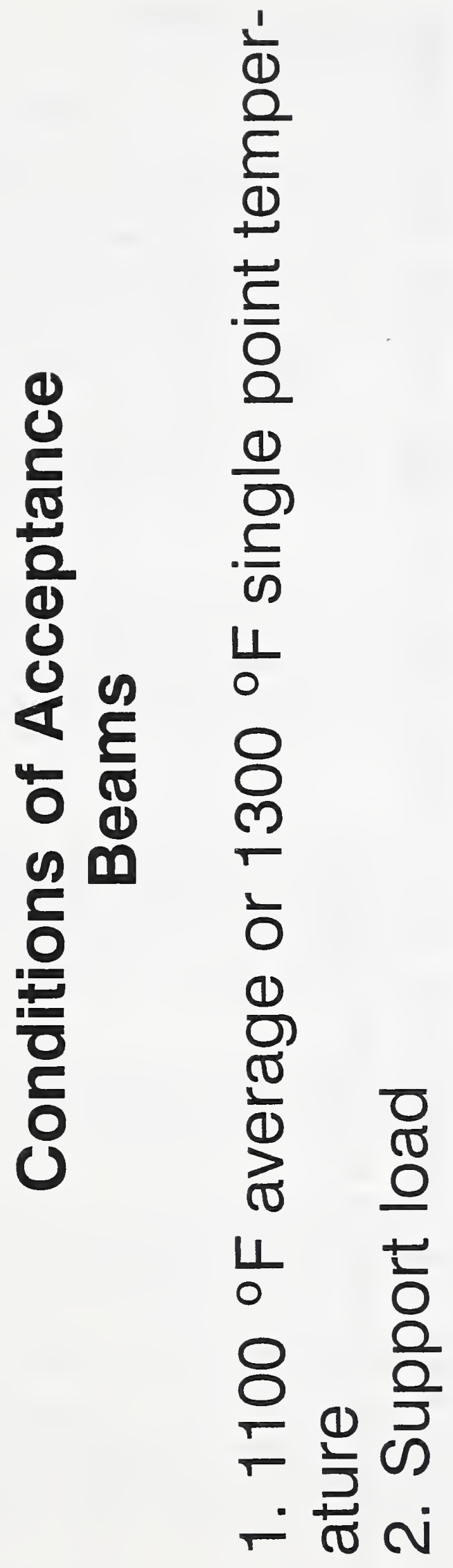



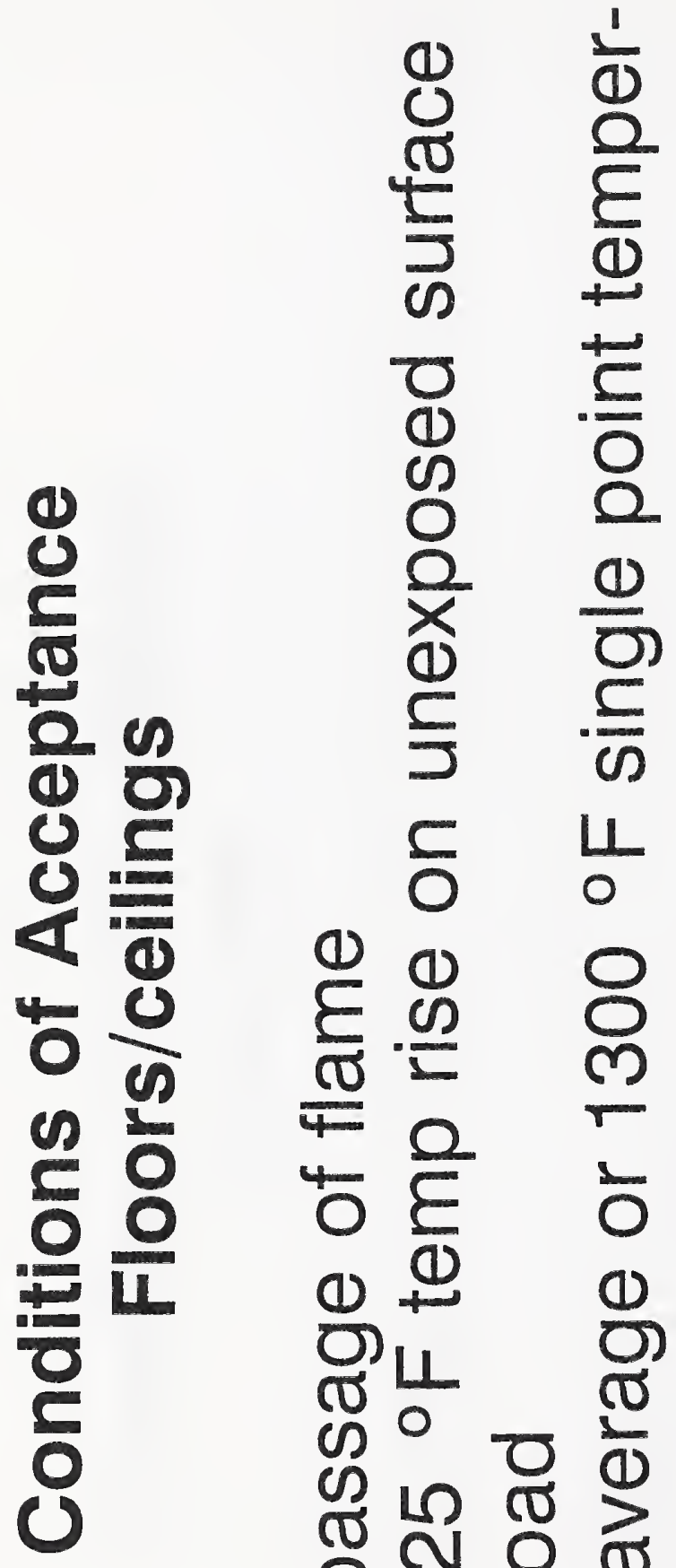

(1)

है ल

ॠ $\frac{1}{\mathrm{E}}$ के

0)

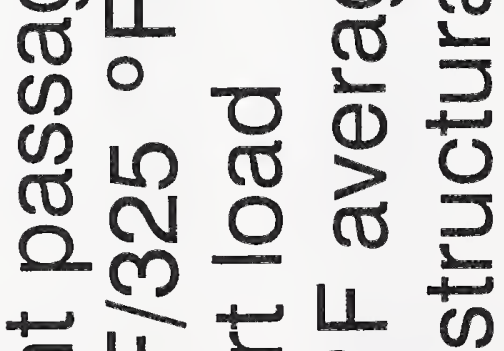

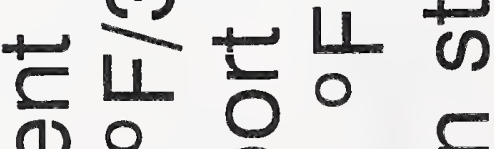

(1) 0 응

(1)응ㅇㅇ

는ำ

ณ $\backsim+\frac{5}{5}$

- Nं 


\section{Workshop on Balanced Design Concepts}

Breakout Session Notes

\section{Instructions to participants}

In the first half day we have discussed the goals and objectives of this proposed study and have heard from a distinguished group of speakers on what we know and do not know about the performance and reliability of fire detection, sprinklers, and compartmentation. The assignment to the breakout groups is to apply their own knowledge and experience as well as the information presented in the papers to develop recommendations on the best way to achieve the project objectives. The groups have wednesday afternoon and thursday to deliberate and produce a report which will be presented by the group facilitator on friday morning.

The group's report should explicitly address the specific topics presented below. The group reports, a list of workshop participants, and any other related materials will be compiled into a workshop report which will be mailed to each participant within a month.

\section{Constraints}

The time allotted to conduct the study is 30 months. Allowing the final 6 months for compiling, writing and reviewing the final report this means that the technical work must take no longer than 2 years. The maximum budget is $\$ 1 \mathrm{M}$, but is contingent on a $25 / 75$ ratio of funding from private sector sources to government funds. Thus, if the private sector funding is less than $\$ 250 \mathrm{k}$, the scope of the entire study is to be reduced proportionately.

\section{Task 1}

The first task is to quantify the performance and reliability of detection systems, suppression systems, and compartmentation, including the field assessment of performance. We also wish to utilize to the greatest extent possible, data on the observed reliability of these systems in actual use. This type of quantification requires a common metric against which the performance of these systems can be evaluated. We suggest that fire risk is the appropriate metric -- but if the group has a better idea, please suggest it.

To evaluate the contribution(s) of these systems to risk mitigation we must begin with an explicit set of objectives and then evaluate the relative contribution of each system to each. We suggest the following objectives as a strawman:

Safety of people:

(1) escape routes and safe egress time shall be adequate to allow people (including physically challenged) to reach a safe place without being overcome by effects of fire.

(2) Fire service personnel to have suitable routes to allow adequate time for rescue operations.

(3) Fire fighters not to be endangered while fighting fire.

Protection of property:

(1) Adjacent buildings or ownership units not to be threatened by the fire.

(2) The environment to be protected against adverse effects from fire.

(3) The economic impact to the property owner and to society to be limited. 
Continuation of business (mission):

(1) Damage to vital equipment and materials is limited or backups are available such that functions can continue without unacceptable interruption.

(2) Any major incident which might erode public confidence in the business is avoided.

The reliability of the system is the likelihood that the system can function to achieve the objectives considering any and all factors which might prevent it. Such factors as improper installation, maintenance, operation, field modification, component failure, etc. should be considered.

Specific questions which the group should address include:

Do needed data on field performance and reliability of these systems currently exist?

If so, who has it and how can we access it? (insurance inspections, corporate sources, government agencies)?

If not, can it be collected within the time constraints of the study and by whom?

What proprietary and liability issues must be addressed in order for the information to be made available?

To what extent can current predictive techniques (models) be applied to the quantification of system performance?

What role would models and calculations (e.g., Failure Modes and Effects Criticality Analysis) have in assessing system reliability?

As systems become increasingly less over designed, is the potential for failure increasing?

SUPPRESSION GROUP: How can we assess ...partial systems? ... the future reliability of municipal water supply systems? ... the potential for shielded fires or fuel loads not contemplated in the design?

DETECTION GROUP: How do we address ...software reliability issues? ...the response of the fire service to off-premises signals? ...the response of occupants to evacuate once notified (considering an increase in handicapped populations)?

COMPARTMENT ATION GROUP: How do we account for ...variations in "as built" from "as designed"? ... the impact of field modifications? ... the role of openings (e.g., chocked doors, doors held open during egress or not closed after evacuating)?

\section{Task 2}

The second task of the study is to determine the conditions under which one or more of the three systems can be reduced or eliminated without unacceptable risk of loss. Given that task 1 will result in a method to quantify the contribution of each system to controlling risk of failure to meet the objectives presented above:

How might we define unacceptable risk of loss? Is there a single definition?

Is it unacceptable to fail to meet even one of the objectives?

In fact, are these objectives "pass/fail"criteria at all?

Are there other objectives that need to be considered? ... generally or for special cases?

Are there other levels of these objectives that are more appropriate?

How can we be sure to account for all of the interactions of these systems?

What is the "acceptable performance level" and must we apply a safety factor?

Is it sufficient to assign a "relative contribution value" as in FSES? 


\section{Task 3}

The third task is to conduct a comparative analysis of compartmentation using fire resistive and noncombustible construction. We take this to mean that we are to compare the risk (performance times reliability) due to failure of compartmentation classed as fire resistive versus that classed as noncombustible. Since these terms are subject to some differing interpretation, we will define them as:

Fire resistive constructions utilize interior structural members and floors of noncombustible materials with fire resistance ratings of 2 or more hours.

Noncombustible constructions utilize interior structural members and floors of noncombustible materials with fire resistance ratings of 1 hour or less.

Questions for the COMPARTMENTATION GROUP:

Is anything more needed than will be done in task 1 to address this issue? For example, the likelihood and potential impact of unplanned penetrations might be considered higher for noncombustible constructions compared to fire resistive constructions. If it is necessary for task 1 to analyze the risk impact of construction at this level of detail, then it would appear that no additional studies would be needed to satisfy the needs of this comparative study. Can you prioritize the most critical considerations on which the comparative performance depend?

\section{Resources}

The legislation requires this study to be a partnership between the private sector and government in a $25 \%$ to $75 \%$ ratio with a cap of $\$ 1,000,000$ total. We feel that a credible job will require the full amount. Do the groups agree and, if not, what is the minimum funding level required to do a credible job?

What private sector sources are realistically available from whom we could raise $\$ 250,000$ (by the end of calendar 1993) to conduct this study?

Reprogramming $\$ 750,000$ of BFRL's budget for fire research will have a significant impact on our long term research goals and objectives. Which government agencies would be willing to assist in the funding of this study as a means of addressing their own needs for a rational basis on which to make tradeoff decisions? 


\section{A Preliminary Plan for Implementing the Study Mandated in PL 102-522}

\section{Background}

The Fire Administration Authorization Act of 1992 (PL 102-522) assigns the NIST Building and Fire Research Laboratory to conduct a study of the use, in combination, of fire detection systems, fire suppression systems, and compartmentation. The objectives of the study can be separated into three principal tasks. First, to quantify the performance and reliability of detection systems, suppression systems, and compartmentation including the field assessment of performance. Second, determination of the conditions under which reduction or elimination of one or more of these results in unacceptable risk of loss. Third, conduct a comparative analysis of compartmentation using fire resistive and noncombustible construction.

The study is to be conducted and a report thereon submitted to Congress within 30 months after enactment of the law. NIST is required to solicit non-Federal funds to support this effort in the amount of $25 \%$ of the cost, with the remaining $75 \%$ to be obtained from Federal sources and its own appropriated funds. The total cost of the study shall not exceed $\$ 1,000,000$ with the scope of work determined by the level of funding achieved. The study does not commence until receipt on all matching funds from non-Federal sources.

\section{Approach}

The time available for the study is insufficient to develop the needed predictive methods to address these issues solely by modeling. Thus, there needs to be a short term approach and a long term approach. For this study, it will be necessary to rely on field data for estimates of both performance and reliability; supplemented by predictive methods wherever possible.

For example, in the detection and suppression areas there have been several studies/surveys conducted over the past few years which have examined the operational readiness of systems in selected cities/occupancies. Insurance interests (e.g., FM, IRI, Cigna) inspect insured properties on an unannounced basis to determine the condition of the protective systems. HCFA does an annual survey of health care facilities receiving Medicare and Medicaid funds. If these data can be accessed they can form the basis for the needed information on reliability. These sources, along with calculations on prototypical buildings can be used to develop quantitative performance figures for typical installations of properly operating equipment.

Unfortunately, for compartmentation the only available performance measure is ASTM E119 and the standard time-temperature curve. The need is to understand the performance of compartment barriers to arbitrary fires. Without calculational techniques the only hope is to gather incident data on the conditions of failure of rated constructions. These data may or may not be available, and they may not be sufficiently reliable. Insurance industry data will be more reliable than NFIRS type data.

The other crucial activities for compartment barriers relate to the documentation of failure mechanisms in the E119 test as a method of scoping the needs of predictive models. These should be easy to obtain from industry and testing organizations. A second is to document the ways in which the systems are compromised in the field -- penetrations, modifications, construction techniques, maintenance, etc. These factors form the basis for the reliability assessment of the construction systems. 


\section{Study Options}

Since the scope and extent of the study is contingent on the level of funding achieved, a series of options have been identified for the three principal tasks consistent with three levels of funding $(\$ 0.3 \mathrm{M}, \$ 0.5 \mathrm{M}$, and the full $\$ 1 \mathrm{k})$. These are summarized in the attached chart.

\section{$\$ 0.3 M$ funding level}

At the lowest funding level the scope of the study would be limited to utilization of existing data and code requirements to address the technical issues. In the 1980's, NIST pioneered a code equivalency system known as the Fire Safety Evaluation System (FSES). This is a method of estimating the impact of fire safety features on the ability of the system to meet the objectives of the prescriptive codes. It utilized panels of experts (Delphi groups) to establish point scores for construction, detection, suppression, and other arrangements representing their value on the same relative scale. FSES's are particular to specific occupancies, and systems were developed (and are recognized by the codes) for Health Care, Board and Care, Business, and Residential (overnight accommodations) occupancies.

At this level of effort these safety parameter values will be employed to represent the performance and (implied) reliability of detection, suppression, and compartmentation (task one). The FSES framework along with current requirements in the model codes will be used to establish the specific conditions under which the performance levels of one or more can be reduced in the presence of others, or where one or more can be eliminated (task two). The performance of fire resistive (FR) and non-combustible (NC), bearing and non-bearing assemblies when tested under ASTM E119 will be documented and related to the minimum performance level mandated in current codes (task three).

\section{Limitations}

The results of the study if conducted at the lowest level of funding would represent a compilation of current knowledge and practices. While it would help to quantify the relative contributions of each of the three technologies to the overall fire safety of the building, it would not quantify their impact on life safety and property protection, and would have a limited impact on the identification of new trade-off options.

\section{$\$ 0.5 M$ funding level}

At a mid level of funding the resources would be available to collect and utilize new sources of data. The industry and insurance data on operational readiness of detection and suppression systems would be analyzed and data from NFIRS and other fire incident data bases would be collected to expand our understanding of the actual performance and reliability of these systems in the field (task one). Data would be collected so that fire hazard analyses could be conducted for a limited number of key fire scenarios in prototype buildings to clearly demonstrate the impacts of reductions in performance or elimination of the various technologies on life safety and property losses (task two). The same incident data bases would be probed to collect data on performance of FR and NC constructions under actual fire conditions in real buildings. Failure rates and failure modes would be documented and related to construction type and estimates of construction quality (task three). 


\section{Limitations}

While at this level of funding the study will add new data on relative performance and reliability, the analysis will be limited to example cases. Key fire hazards related to trading off of one technology or another will be demonstrated but the risk impacts to life and property losses will not be specifically quantified.

\section{$\$ 1 M$ funding level}

If the full funding can be obtained it would be possible to incorporate all of the available data and utilize existing predictive capabilities to thoroughly quantify the performance and reliability of the three target technologies. In recent years the standards (i.e., NFPA 72E and 13) have incorporated procedures for performance prediction and, in the case of detectors, for design of systems on the basis of detecting critical rates of heat release. Once these levels of performance are quantified, risk assessment techniques can be used to relate reliability modified performance levels to the risks to life and property (task one).

Risk methods will also be utilized to quantify the conditions (along with uncertainties based on sensitivity analyses) for a range of trade-off options. Again, these analyses will quantify these impacts on the basis of life safety and property protection (task two). Finally, these risk methods will be used to quantify the impact of field conditions including the propensity of FR and NC constructions to compromise and field modification on performance and reliability and thus on the risks to life safety and property protection (task three). 


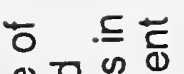

엉 은 은

응

톧ㄷㅇㅇㅇㅠ

잉

ธष्ठ

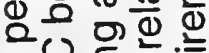

든든응

Ф

डั ธิ

응뜬든

E

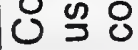
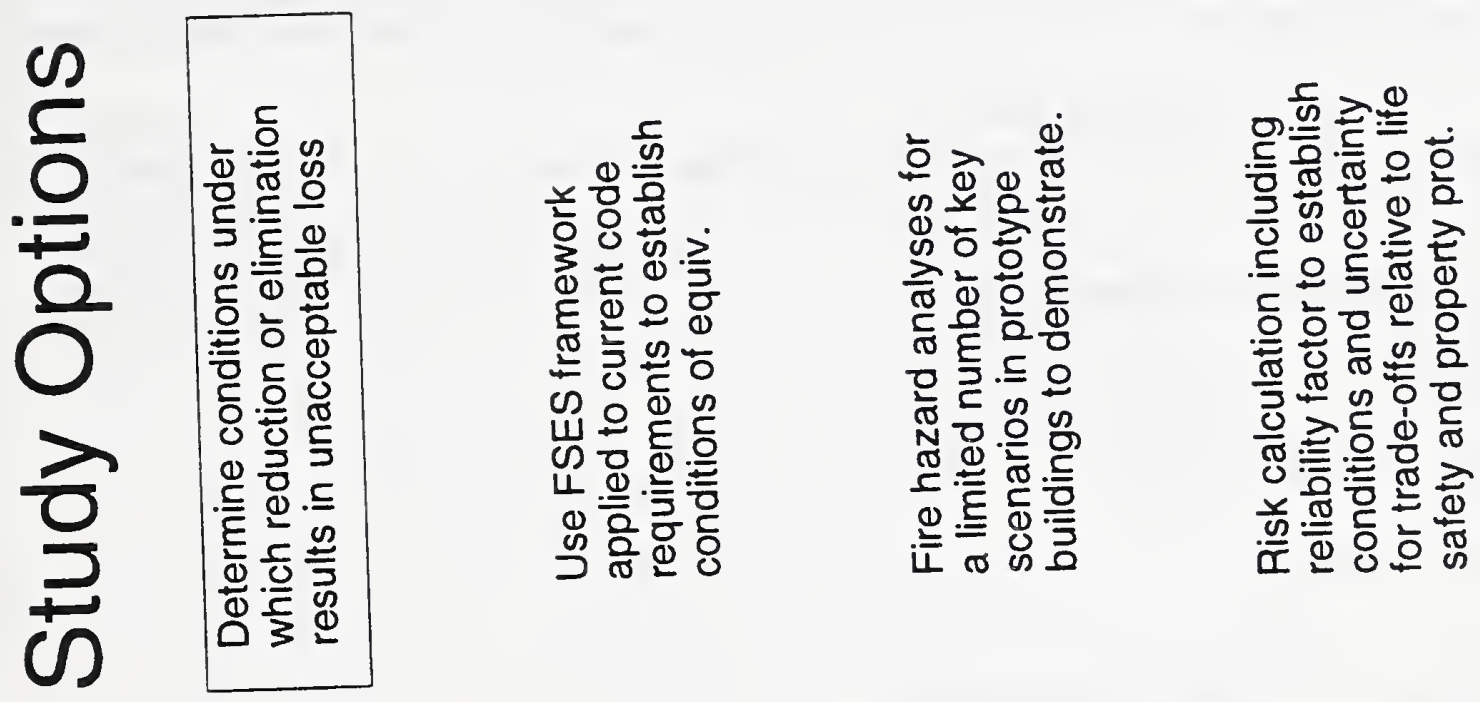

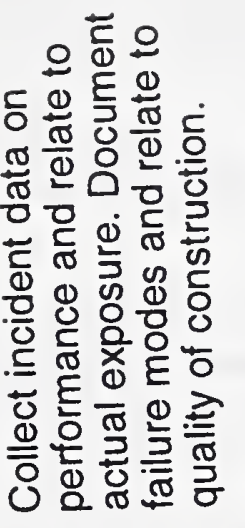

음 $\frac{\pi}{\frac{1}{2}} \stackrel{\frac{0}{0}}{\frac{0}{0}}$

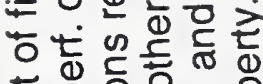

응으응 응

응을 은 틍

들⿺ㄴ

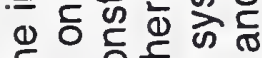

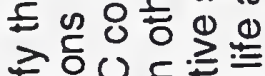

원웡웡

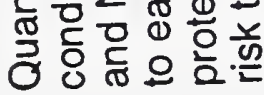

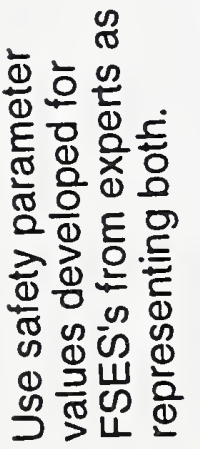

WE'O\$

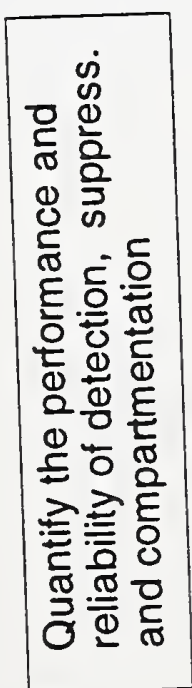

E

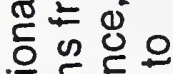

ซ

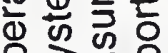

응 สิ. 응

등믄

ช ต ส

守导 至之

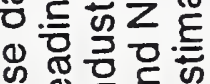

乌 ญ.도

WG'O\$

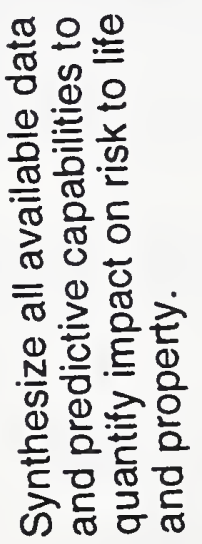

WI\$ 


\section{Detection Breakout}

1. Risk is the appropriate framework by which the three systems can be compared. The risk objectives presented are appropriate and complete.

(danger to fire fighters minimized but inherent)

2. Data exist

Hard to collect - demonstrate direct benefit to persons who have it. Reassure them that it won't be used against them.

Applicability of historical data?

Are the data complete? Can we identify roles of each system? Subjective? What is the rule of compartmentation when the others are present and operating? Not generally addressed.

Detection and compartmentation are crucial where suppression only controls!

Audits

Design the database for the future. Detection makes compartmentation more reliable by controlling openings and helps limit water damage. Sprinklers act where detectors only warn and they reduce the potential for any compartmentation failure but don't stop all smoke which may still damage sensitive property.

3. Models can quantify benefits against needs by occupancy. Assume operability and devalue for reliability.

4. Unacceptable risk of loss hard to pin down.

Reasonable

Occupancy related

\section{$\underline{\text { Construction }}$}

Study logical - next step.

Framework

Decision tree 3D matrix of design altern.

Separation by occupancy

Fire size, type, location

Limit number of combinations

Fire Department response/activity

Risk Metric Program

Objectives good - reasonable measures.

Construction reliability - degrees of impairment field performance vs lab performance.

\section{*Effect on Ventilation}

Record successes.

Cascading failures?

Time of failure

Method of failure (thru impairment) 
Trees - FMECA models applicable.

If you can do FSES, you can do more.

Safety factors reflect uncertainty and can be applied globally.

Private sector resources could include data and special studies.

Study will not answer all questions.

\section{Suppression}

Databases - not enough data on failures.

Small incidents not reported.

New database not possible in 30 months but should be done for longer term.

Credible job requires full amount. Several may provide in-kind assistance.

$$
\text { RA }
$$

Producers:

- Methodology

- Compilation of data \& data sources

- Some practical application

- Further needs
Framework/Measures

Occupancy

Field Information

Existing building surveys

Data resources

Simulate Performance

Compare with data

Summary/Recommendations 
Attendees - Compartmentation Breakout

John L. Gross

NIST

Don Bathurst

GSA

Gene C. Abbate

NYS Concrete Masonry Assoc.

Robert H. White

Les Richardson

Kathleen Almand

USDA, Forest Service, Forest Products Lab.

Forintek Canada Corp.

Steve Skalko

AISI

Gamal Ahmed

PCA

Mark B. Hogan

PCA

John A. Heslip

John Mueller

Richard N. Walke

James Quintiere

Karl Houser

Kenneth Bland

Gene B. Endthoff

John R. Hall, Jr.

Nat'l. Concrete Masonry Assoc.

Nat'l. Concrete Masonry Assoc.

New York State Office of Fire Prevention \& Control

Underwriters Laboratories, Inc.

University of Maryland

Gypsum Association

American Forest \& Paper Assoc.

National Fire Sprinkler Assoc.

NFPA

Alex B. Wenzel

Southwest Research Institute 
(Notes from Don Bathurst)

Introduction

Free Form Discussion

Settled into Channels/Paths

Convergence

Outcome

\section{Discussion}

Needed organization structure for discussion

Recommended framework for study

Framework

Capture impairments

Consider fire size, type, location

Consider occupancies

$$
\begin{aligned}
& \text { - } \quad \text { Uses } 2 \text { or } 3 \text { occupants } \\
& \text { - } \quad 3 \text { or } 4 \text { areas of origin }
\end{aligned}
$$

Time elements

Compartment geometry

\section{Data and Sources}

Describe time built environment

Describe how components react to fire

\section{Summary of Discussion}

Reliability of construction characterized different than detection/sprinklers.

Field reliability (field performance vs test perf)

Construction vs maintenance $\&$ orig. construction vs modification

Construction materials and geometry affect ventilation

Materials can affect fire growth and security

Fire security can be characterized by extending beyond area, room, floor, building

Change fire incident data collection - ongoing effort. Need to record successes

Structural model 
Compartmentation Breakout - June 30, 1993

Don Bathurst, GSA, Breakout Session Leader

Issues - Open forum

- $\quad$ Field performance

- Principle concern - lacking probability-based calculation framework (John Hall) how to chain together, existing modeling model

- Overall goal - develop tools to apply risk analysis - recommend NIST begin by developing framework - set aside 3-6 months (John Hall).

- Ways to measure reliability not same for compartmentation as for other systems (sprin$\mathrm{kler} /$ detection)

- Field reliability (field performance vs test perf.) and field fire vs std. fire test

- Construction vs maintenance \& orig. constr. vs modification

- Ventilation issue can't be separated from compartmentation

- Quality of inspection

- What needs to be accomplished \& who is going to use the results?

- Consider "catastrophic fire" as spreading beyond the room of origin

- $\quad$ Break point at several points: 1) beyond room of origin; 2) beyond floor of origin; 3) beyond building

July 1 - Compartmentation Breakout Session

Framework

Factors:

Fire size, occupancy, fire type, fire location

Design factors (alternatives) - openings, compartment geometries, sprinkler?

Other issues: time for intervention, egress, fire growth, volume of room, etc.

Lock to international databases to fill in gaps in ours. 
Attendees:

Don Bathurst

Gene Abate

Robert White

Les Richardson

Kathleen Almand

Steve Skalko

Mark Hogan

Gamel Ahmed

John Heslip

John Mueller

Richard Walke

Karl Howser

Gene Endthoff

John Gross

John Hall

Ken Bland

Jim Quintiere

Alex Wenzel
GSA

NYS Concrete Masonry Assn.

USDA

Forintek Canada Corp.

AISI

PCA

NCMA

PCA

NCMA

NY State Office of Fire Prevention \& Control

Underwriters Laboratories, Inc.

Gypsum Assn.

National Fire Sprinkler Assn.

NIST

NFPA

American Forest \& Paper Assn.

University of Maryland

Southwest Research Institute

Overall recommendations - give thoughts to the following:

thoughts on data sources - reliability (NF.PA, IRI, FM)

field inspections (GSA, Develop, Fire Serv Survey)

framework

break points: suppression \& detection room of origin compartmentation (intermediate floor of origin)

all three - building

Views on catastrophic parameter

candidate models - Canada, Fitzgerald (Australia), NIST

Funding sources (NCSC, NAHB, BOAM)

Look at $\mathrm{DB}$ questions in handout.

"As built" versus "as designed"

- depend on appropriate inspections

- specify higher fire ratings for key compartmentation elements

- intermediate walls

- occupancy separations

- some tenant separations

Field modification and role of openings

- lab tests on "field modified" assemblies

- fire modeling 
Notes by Richard Walke

1. Review whatever data may be available regarding success or failure of compartmentation (NERAC, fire services, etc.).

2. If data is not available, set up a matrix of worst case situations (i.e., doors open, holes in wall, etc.) and use modeling, confirmed by fire tests to determine performance. A subpart of this task is to determine 1) what models are available; and 2) which provides the answer closest to the fire test data.

3. Financing from private sector will almost have to come in the form of donated time and service.

4. Impact of field modification is unknown. We almost have to assume compartmentation doesn't exist or that holes do exist. "As built" variations would be accounted for by a safety factor in most cases.

\section{Notes by Robert White}

Task 1 - Quantify the performance and reliability of detection, suppression, and compartmentation.

A. Quantify the contribution of compartmentation to controlling risk of failure to meet the objectives of safety of people, protection of property and continuation of business.

1. Quantify the fires in which compartmentation plays a role.

2. Quantify the potential losses.

3. Quantify the necessary compartmentation to limit losses.

B. Identify likely failures of compartmentation.

1. Failures of rated assembly (ULC publication on extension of data).

2. Failures not related to rated assemblies.

3. Failures as function of type of construction (fire resistive vs noncombustible).

C. Survey of existing buildings for defective rated compartmentation.

Task 2 - Determine conditions under which reduction or elimination results in unacceptable loss.

A. Losses as function of compartmentation.

B. Translate needed compartmentation to E119 ratings.

C. Can improved detection/suppression reduce need for compartmentation based on equivalent losses?

D. Monte Carlo stimulations.

Task 3 - Comparative analysis of compartmentation using fire resistive and noncombustive construction.

A. How much losses are eliminated by increasing rating to 2 hours?

B. Is field performance of two different? 
Notes by John Mueller

\section{Compartmentation - General Comments}

Task 1 - Performance and Reliability

Real world performance of fire rated construction needs to be assessed and quantified through experiment, review of case histories, and inspection of conditions in the field. This performance must be assessed based on definite exposure to fire, not on probable risk to exposure. Performance should be assessed against a range of fire severity to determine at which point compartmentation factors become critical.

Task 2 - Conditions for Reduction or Elimination

Determining conditions for reduction of detection, suppression, or compartmentation will require a clear understanding of the interrelationship among the three systems. Study must be based on fire conditions severe enough to test the interrelationship (e.g., a fire beyond the room of origin). Performance goals should be to assure that occupants outside the compartment of origin can definitely be evacuated and that occupants within the compartment have a high probability of being evacuated safely.

The need for redundancy precludes the elimination of one or more systems.

Task 3 - Comparative Analysis

The analysis could be done as part of Tasks 1 and 2 using each type of construction since both are used in buildings now. 
Notes by Mark Hogan

Compartmentation Task Group

Task 1

- Solicit records of fire safety inspections by state and local fire officials, corporate and governmental agencies on observed violations (i.e., required corrections) of fire barriers surrounding compartments including openings, penetrations, etc., to document the probability of performance.

- Based on the records, identify revisions to fire barrier provisions to improve performance (annual inspections, posting, automatic door closures, renovation plan review).

- $\quad$ Review fire records and document performance of fire barriers in preventing the spread of fire.

- Review fire records and classify the role of all three balanced design components in controlling (or failure to control) the fire. 
Notes by John Hall

Suggested Framework for Analysis

- Identify for each group - detection, suppression, and construction/compartmentation - $\underline{a}$ manageable number (5-10) of alternative levels/statuses of protection. These alternatives should reflect both varieties in design according to code (e.g., fire resistive vs ordinary construction) and types of degrees of impairments in design (e.g., pokethroughs and holes totalling $\mathrm{x}$ square inches per wall, doors blocked open, ceiling tiles missing). The analysis probably cannot address all combinations of all alternatives and will need to account for fires.

- Analysis framework will consist of estimation of (a) probabilities of combinations of alternatives and (b) consequences for fire severity of combinations of alternatives.

"Performance" of detection, suppression and compartmentation will consist of severity given no impairment in the system being studied but allowing probabilistic variation of other systems and features.

"Reliability" will consist of the probability of impairment, for each system or feature.

Impact of "reduction or elimination" of a system or feature will be measured as the change in performance from (1) a case where the system or feature is present and has its current fieldestimated reliability patterns, to (2) a case where the feature or system is missing entirely or has a lower reliability or has a lower-performance design. Such impact will, therefore, be a function of the design and reliabilities of all systems and features.

- $\quad$ Estimates of probabilities will be drawn from representative national fire data, special fire data, and special property surveys, in that order of preference. Estimates of severity will be drawn from these data sources plus laboratory tests and models. Expert panels are likely to be necessary to provide some estimates not covered by other data sources.

- The framework will be developed and demonstrated on 3-4 specific occupancy groups, chosen to represent diverse situations in terms of life and property exposure. Within each occupancy, it is suggested that 3-5 different types of rooms or areas be used for modeling.

- It is suggested that the principal measure of severity be fire spread beyond the room of origin and that separate analysis be considered for fire spread beyond the floor of origin and fire spread to a second structure. It is expected that these three criteria will show dependence upon different aspects of compartmentation/construction and successively greater dependence upon compartmentation/construction vs sprinklers and detectors.

Note that this approach will not capture overall fire risk (including losses of life and property in smaller fires, which is a significant share of the total) and will not allow easy cost/benefit calculation. However, it will facilitate interface between lab tests and fire incident data, it will address the majority of loss of life and property, and it will place particular emphasis on the "harm due to a stranger" portion of risk which is of primary concern to the public and is the principal target of codes and standards.

A major outcome - but not the only outcome or the principal outcome - of the analysis should be a prioritized research agenda of needed statistical data, lab data, and modeling components to improve the framework. 
- The framework should address variations in sizes, locations, and types of initial fires through appropriate probabilistic combinations of design (or reference) fires.

- In the event of less than full funding, cut back the demonstration and development of the framework to fewer occupancies, fewer rooms and areas, more use of existing data, and fewer system alternatives. Do not use a less fundamentally based overall framework, such as FSES, as this will not provide a suitable basis for valid application or further work.

Sources for models, calculation tools, modules, etc.

- HAZARD I/FRAMEworks

- FPETOOL/FIRE SIMULATOR/ASET

- Australia/Canada Fire Cost/Loss Modeling Package

- Japan's comprehensive code-equivalency models

- Ling and Williamson network model of barrier breach

Note: The overall framework proposed is a simple fire risk analysis tree structure. The models listed above will be useful primarily as aids in estimating fire severity for the various alternatives. Many/most of these combinations will involve fire phenomena going beyond most existing models and fire tests. Special attention needs to be paid to those calculation methods used to address fire development beyond the first compartment.

\section{Sources for Data}

- NFPA - NFIRS-based national estimates, FIDO

- FM \& IRI databases

- $\quad$ CIGNA property surveys

- GSA, other Federal agency property surveys

- Lab tests (often proprietary) on performance of impaired systems as features, e.g., done to support major fire investigations.

- $\quad$ Trade associations (hotel, office managers, health care) databases on fire protection systems and features in use and impairments

\section{Answers to Dick's Questions (Hall)}

As systems become increasingly less over-designed, is the potential for failure increasing? Yes, probably so, but by how much? A large issue for analysis is the extent to which historical databases reflect current conditions. If not, can we compensate by projecting changes in probabilities of use and/or impairments?

How might we define "unacceptable risk of loss?" This term suggests an emphasis on prevention of large fires rather than reduction of overall fire loss. The eight objectives in the strawman also are stated in a way suggesting a qualitative approach (acceptable vs unacceptable fire size or consequences, rather than more vs less fire loss). Within this context, "unacceptable risk of loss" can be defined (a) as an unacceptable fire size (e.g., beyond room of origin); (b) as an unacceptable fire size relative to time (e.g., beyond room of origin in 15 minutes); (c) as a string of unacceptable physical characteristics of fire (e.g., smoke spread into any egress path).

What is the "acceptable performance level" and must we apply a safety factor? Ideally, the analysis framework should allow a safety factor to be applied to the entire system, with large or small safety factors applied to particular parts at the discretion of the designer. 
Is it sufficient to assign a "relative contribution value" as in FSES? No. Such an approach is too heuristic. It is not even clear whether the functional form of the interactions is correct, let alone the magnitudes, parameters, weights.

Resources. Many private sector groups and Federal agencies may be willing to donate in-kind resources for special data collection, lab tests, and design in detail of the overall analysis framework. This seems a more realistic and workable way of assembling a $\$ 250 \mathrm{~K}$ private contribution to satisfy the legislation. Moreover, given the sensitivity of the subject, there are advantages in thinking in terms of a multiorganizational research team to provide both a consensus and a technical basis for the analytical approach. 


\section{Data Needed and Sources}

Availability
A. Available - in correct form
B. Available - not in correct form -
C. May or may not be available - some idea of source
D. Not available - can be collected (survey, test, etc.)
E. Not available - cannot be obtained reasonably SWAG

\section{"What's out there?"}

Usage and status of systems \& features

Distribution of construction types

(by company $\&$ region)

Status Information

- doors propped open

- poke-throughs, penetrations, sealing

- location of openings

- degree of compartmentation (room dimensions-vol)

- workmanship

- modifications, deviations from design

- pressurization (smoke control)

"How well does it perform?"

1. How often does a fire go through impairments

2. For fires that go through barriers, how often is

2. For fires that go through barriers, how often is
this due to impairment vs larger than design fire?

3. Time to failure \& physical property data (may vary with temperature), type of failure.

4. Common causes of multiple failures (failures causing failures).

Models to fill in gaps in data:

FPE/TOOL

HAZARD I (FAST)

\section{Source}

Trade Assoc.

AHA,BOMA,AHMA,NAHB

MHI

Government Agencies

GSA,DoE,DoD,HUD,DoT,FEMA,HHS

Insurance Co's: CIGNA,FM,IRI

Fire Groups: USFA,NFPA

Research Groups: NIST

Fire Safety Inspectors

\section{Source}

$\begin{array}{lllllllllllll}\text { L } & a & b & o & r & a & t & 0 & r & i & e & s & \text { : }\end{array}$ NIST,SwRI,UL,FM,NRCC,Int'l.

Fire Groups: USFA,NFPA

Trade Associations

Manufacturers 
Summary Session

Detection

Risk analysis - agree

New Zealand - property protection not in realm of code

Data on reliability - hard to obtain

Role of models \& predictive methods - quantify the benefits

Acceptable risk of loss - don't know what it is - occupancy dependent

\section{Compartmentation}

Dependence on time - fire growth, response, suppression/containment. Also (my note) time variation of reliability estimates.

1. Data called a "ubata out ten" - estimate what is being built may or may not be the same as existing inventory.

2. Collection of actual data may not extrapolate to the entire country: i.e., practices differ by part of country data collection - big effort.

50 years, many materials - combinations, systems, occupancies.

\section{Suppression}

Task 1

Incident data to determine "how did it perform" report failures (barrier failed) - don't know why - was fire more severe than design fire? Don't know if barrier played a significant role (worked) and didn't fail.

Where do we go from here?

1. We will do something - based on funding.

2. Get started now!

3. Set short deadlines.

4. Start Oct. 1 - 90 days to pull together resources - lay out plan.

5. Jack Snell's "Strawman"

I. Fire/Measures 
Safety

Property

Mission

Measures

II. Occupancies

1 or 2 occupancies

Health Care

Hotel

Business/Office
III. Field Study

A. Exit-Building

Spec. age distribution

What they have

Condition/level of impairment
IV. Simulator Performance

Fires?

\section{B. Available data sets}

V. Compare with Data

VI. Summary/Recommendations

Products:

- Methodology

- Compilation of data and data sources

- $\quad$ Some practical (limited) application of methodology

- Further needs/action

- New combo of data/statistics and fire physics 
Miscellaneous Notes - Probably not of much use

4. Reliability probability

Performance as design

5. System effects

\section{Data Sources}

1. National file incident data

a. Pros

Representative

Good end-means

Large sample

b. Cons

Lack of detail

Questions on coding accuracy

2. Special fire incident

Pros

Greater detail

More accurate

Good end - measures

Cons

Less representative

Make-up of built environment

Modification to construction materials

Models

Fault and Event Tees applicable

Expert judgments

Sensitivity Analyses/Testing

FSES - Relative contribution - to make it work, can do more

Safety Factor on the whole calculation - to become part of the overall approach.

Data sources should be approachable for data and "in-kind" support - data collection.

Trade Associations for \$ - BOMA,IFMA, Insurance, Hotel/Motel Assoc./large owners (Marriott). GSA, VA,HUD,NIST, CoE,Navy,NCR/FCC,PHS

Special property surveys

Construction 
Stores and offices, low-rise

Field Performance of Compartmentation

Reliability - The likelihood that the partition will function as intended.

Constr. variations

Penetrations

Field modifications

Unprotected openings

Conditions exceed design

\section{NRC Canada}

- $\quad$ Predicting the performance of variations or tested assemblies

- Non-standard exposures

- Impact of historic materials and techniques

Models and validation experiments

Survey data needed to address:

Unplanned penetrations

Field modifications

Unprotected openings

Richard Walke - Underwriters Laboratories

Failure mechanisms in various assemblies.

Testing ANSI/UL 263

ASTM E119 Hourly rating 1-4 hrs.

NFPA 251

Walls, columns, floors/roofs, beams

Failure mo

Load bearing masonry - temp. on exposed side.

Non-load bearing gypsum wall - limiting avg temp or nos stream

Load bearing - struct. collapse near end of test (near limiting temp)

Column - avg. limiting temp of $1000^{\circ}$

Loaded steel beams - avg. temp of steel

Roof/ceilings - fail of struct. steel

Restrained cover floor - fail of steel deck

Load bearing time - collapse

P.S. concrete - unrestrained

partially restrained

totally restrained

temp.

struct. fail.

Reliability of test sample vs "real life" construction 
Notes from 30 June 1993

Risk is the agreed metric for measureing performance.

Objectives:

Design for fire

Design for egress

Performance Codes

Evaluators need to be competent. The Japanese model has a pnel of experts. Theis panel consists of locla individuals, univeristy professors \& officials from the ministry of building science.

In my opinion, the conversations revolved around three main issues: scope, acceptable level of risk and reliabilty.

\section{HISTORICAL RELIABILITY DATA}

Reliability was talked about in two ways, what reliability we now have, and what reliability future installed systems will have. The reliability we now have is based upon the historical track record of systems installed over the last 20 years. Problems with this data include: no record on the successes, no identification as to what type of system (heat, smoke), no correlation with presence of compartmentation and/or suppression, and poor correlaion between systems installed 20 years ago and and systems being installed now (end align supervisors versus addressable devices). The good thing about the present data is that the number of fire deaths in single family dwellings has dropped dramatically since the early 1970 's with the introduction of the single station smoke detector.

\section{FUTURE ACQUISITION OF RELIABILITY DATA}

To get data on the successes which detectors help produce is a difficult task. The successes necessarily imply that the fires never got too big. This in turn suggests that many go unreported. To obtain this data, individuals will have to work in contact with local alarm receiving companies or fire departments and visit each distinct occurence of alarm activation. Some sources of reasonable data exist. They are Illinois, Oregon, FM (good luck), insurance companies and regional HCFA offices. Most of these people will need to be convinced that the data is not incriminating.

It would be nice to break the acquired data into subgroups: occupancy, occupancy age, occupancy sex, time of day, type of structure, holiday, workday, weekday, weather conditions, season, etc...

It would be nice to determine system interactions: do fire alarm systems activate before sprinklers, do fire alarm systems reduce water damage, what role did detectors have in mission objectives.

how do we determinine if the fault is software or hardware driven.

This data is intrinsically hard to gather. Requires interviews (probably in-depth and random) because the detection system can not supply all the pertinent information( what system activated, what station activated, how was the system maintained and installed and designed, what is the system success rate. Places to go for data include Marriot, insurance companies, fire departments, universities). It also 
requires that the small fire events be investigated which may require cooperative work with local alarm and fire supp ssion companies.

Once a process is set in motion for obtaining the reliability data, the detection industry is interested in maintaining this information retreival system.

\section{RELIABILITY}

Redundancy is needed. Large life-loss fires typically occur when more than one system fails. Without redundant systems, the probability of one system protection failure could very well increase.

In predicting reliability, start out with the design assumption of $100 \%$ effeciency and subtract points (for maintenence, equipment installation practice, company personnel profeciency) from this basis.

Reliability is primarily a people issue. People are the most unreliable components of any system and within a system. Good maintenence, installation and inspection practices are necessary.

\section{RISK}

how to measure: locals, university types, building ministry submit report to a code body per Japan ala Article 38

Management needs to define the minimum acceptable level of loss.

Should people noninvolved in the immediate fire event be protected from the effects of fire.

Need to identify a baseline performance level. This could be the current code practice.

Who will bear the responsibility of failure-- $>$ this will help determine the acceptable performance level

The minimum acceptable risk level should be dependent upon: people protection and (property protection/mission continuity).

Systems (detection, compartmentation, suppression) should be complimentary and overlap in function such that a system going to failure is compensated for before its impending loss.

Items which could enter a numerical risk assessment system include people competence, system identification, construction details, maintenence schedule...

How do we address the A.D.A. and this population? (vibrational pagers, visual alarms...)

We don't have, nor does the world have, a definition for the term unacceptable level of risk. If the risk pertains to individual business and not individual or social life safety, the market place (insurer and client) should decide the level of risk which pertains to their business mission.

If life safety of either an individual (other than those individuals immediately involved in the initial fire) or society is involved, then the codes should prescribe a minimum level of safety equivalency. One such equivalent level of safety in commercial/industrial/residential occupancies is sprinkler protection. The 


\section{Conclusions and Next Steps}

The workshop participants concluded that the potential benefits of the information which should derive from this study warrant the expenditure of the funds needed to collect and analyze it. In fact, several of the industries present stated that the databases which would evolve would be of major benefit to them and that they would intend to keep them going beyond the completion of the study.

There was general agreement that a credible job will require the full $\$ 1 \mathrm{M}$ funding level. Due to the economic situation in several of the industries, they may have to provide in-kind assistance such as Research Associates who can work at NIST, full-time on the study.

The products of the study would include:

- A defined methodology for integrating the expected performance and reliability of systems and assessing their contribution to a set of fire-risk based goals.

- A compilation of data and data sources needed to make such assessments.

- Some practical examples of this methodology as applied to prototype occupancies.

- Discussion of further needs to incorporate what is learned into the codes as a means of understanding trade-offs.

Next Steps:

- Establish a technical steering committee from contributing organizations.

- Establish a finance committee to assist in securing the financial resources.

- Select a prototype occupancy (hotel, office, health care?)

- Organize the collection of field information from organizations and special surveys.

- Simulate system performance and interactions.

- Compare with field data.

- Develop summary of findings and recommendations. 


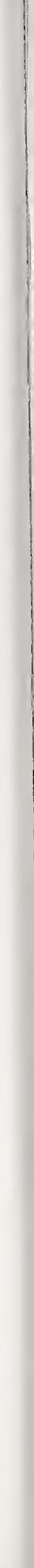



